\title{
A COGNITIVE APPROACH TO ANALYZING DEMONSTRATIVES IN TUNISIAN ARABIC
}

\author{
A DISSERTATION \\ SUBMITTED TO THE FACULTY OF THE GRADUATE SCHOOL \\ OF THE UNIVERSITY OF MINNESOTA
}

BY

AMEL KHALFAOUI

IN PARTIAL FULFILLMENT OF THE REQUIREMENTS

FOR THE DEGREE OF DOCTOR OF PHILOSOPHY

ADVISER

JEANETTE GUNDEL

November 2009 
(C) Amel Khalfaoui 2009 


\section{Acknowledgements}

Many people have contributed to this dissertation in so many ways. To all these people, I would like to express my genuine thanks and my gratitude. First, I would like to express my deep gratitude to my adviser Jeanette Gundel for sharing her expertise and her time to help complete this work. Her insightful suggestions and comments on different drafts of this dissertation challenged my thinking, helped me to have a better understanding of how to use theoretical tools to explain my findings, and encouraged me to keep pushing the boundaries of my work. I also like to thank members of my dissertation committee for the valuable feedback and suggestions at various stages of my research: Bruce Downing, with whom I share a passion for translation and interpreting and who has offered advice and support in other aspects of life and scholarship beyond this dissertation, Nancy Stenson for her valuable suggestions for future research, and Randy Fletcher who inspired me to use research methodology in this dissertation.

Without the support of my friends, it could have been a much harder path. An important person to whom I am deeply grateful is my friend Linda Hamilton Turner. Linda's friendship, love, and support have made the process seem much easier than it actually was. Thank you Linda for, as you like to say, "being part of this project" and for being that special person in our life. It has been a great honor to know Linda Humnick, a friend and a fellow researcher, who has been a great source of inspiration for me in my academic and personal life. Thank you Linda for your friendship and for your formatting tips that saved me a lot of time. I am also thankful to my fellow graduate students, with whom I spent many hours in the TA office at Nolte Center, for the interesting conversations and the laughs.

This is a great opportunity to express my thanks to Barbara London of the Institute of Linguistics, ESL, and Slavic Languages and Gabriel Schmigel of International Student Services whose understanding and incredible support in different aspects have made my life as an international student much easier and smoother than it could have been. I am also very grateful to all the native speakers of Tunisian Arabic who took the time to fill in the questionnaires used in this dissertation.

I am extremely grateful to members of my family: my parents who have always believed in me, and who offered nothing but prayers, support, and encouragement. I like to thank my siblings for their encouragement and their help in collecting data for this dissertation. I am very grateful to my husband Nabil for using his extraordinary skill in telling folk stories to provide me with valuable data for my corpus study. I also would like to thank Nabil for his friendship and for helping with family life to allow me to have time to study.

Finally, I would like to thank the loves of my life: my two children Sarah and Adam who, even after I have finished school, they will say "mama is at school". Their unconditional love and their presence in my life have been a great source of inspiration for me. 


\section{Dedication}

To my family and friends 


\begin{abstract}
Demonstratives have traditionally been analyzed as 'pointing words' whose primary function is to indicate relative spatial or temporal distance of a referent from speech participants. Recent research argues that the meaning of demonstratives is not limited to spatial distance and has given alternative accounts for the use of demonstratives that focus on other cognitive and pragmatic meanings (e.g., Gundel, Hedberg and Zacharski 1993, Enfield 2003, Botley and McEnery 2001, OH 2001). This dissertation contributes to research that looks at alternative meanings for demonstratives, focusing on Tunisian Arabic (TA). The goal of the dissertation is two-fold. First, working within the Givenness Hierarchy framework (Gundel et al.), it aims to show how TA demonstratives are used to indicate cognitive status, the assumed memory and attention status of a referent in the mind of the addressee. A combined methodology of questionnaires and corpus analysis is used to test hypotheses formed in a previous study (Khalfaoui: 2004) about proposed correlations between cognitive status and single demonstrative forms in TA and extend the analysis to phrases with double demonstratives. The second goal of this dissertation is to show how other factors can further restrict the choice among certain demonstrative forms that encode the same cognitive status. Specifically, it is shown that when there is more than one activated referent, communicators choose the demonstrative haða as a determiner, but not as a pronoun, although both the determiner and the pronoun encode the same cognitive status. I argue that Relevance Theory (Sperber and Wilson 1986/1995) provides a cognitive explanation for why communicators avoid the demonstrative pronoun in such case. This dissertation also discusses the advantages and limitations of the questionnaire and the corpus analysis as research tools.
\end{abstract}




\section{Table of Contents}

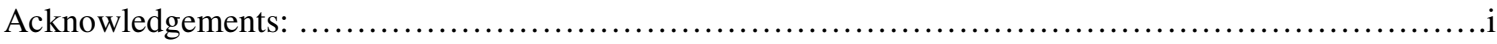

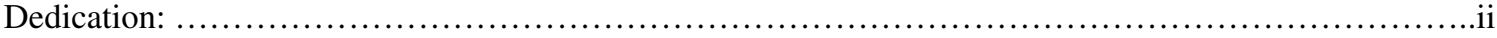

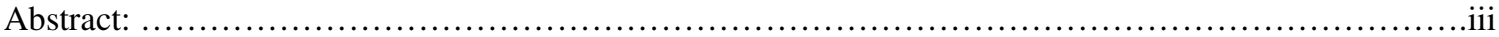

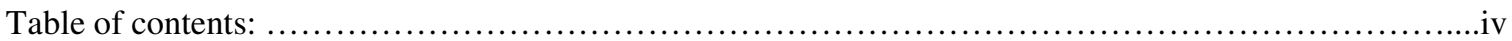

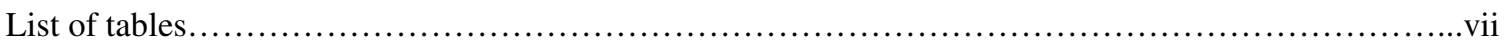

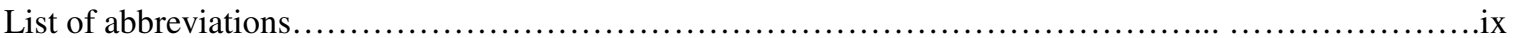

Chapter 1: $\quad$ Introduction, literature review, \& overview............................................................... 1

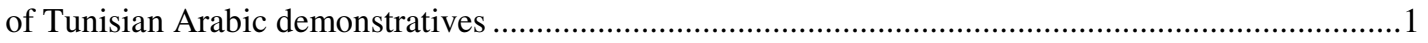

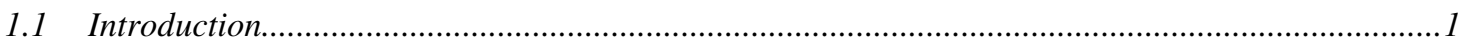

1.2 Demonstratives: Types, definition, syntax, morphology, and uses................................................

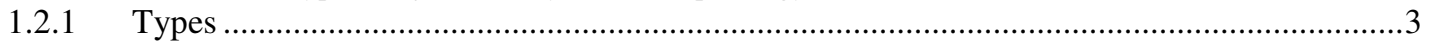

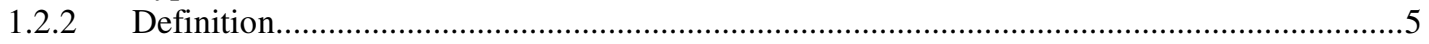

1.2.3 Syntactic distribution of nominal demonstratives ............................................... 10

1.2.4 Morphological features of nominal demonstratives .................................................. 11

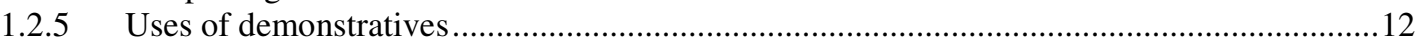

1.3 Traditional approaches to analyzing demonstratives ............................................................ 12

1.4 Alternative approaches to analyzing demonstratives........................................................ 15

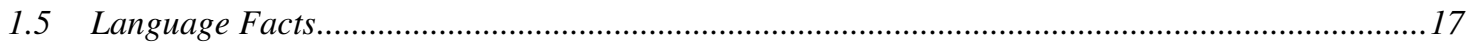

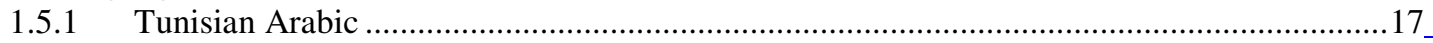

1.5.2 Tunisian Arabic Demonstratives ................................................................................. 18

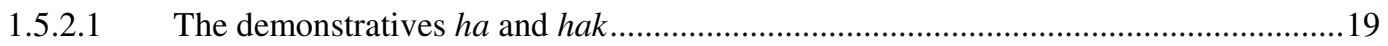

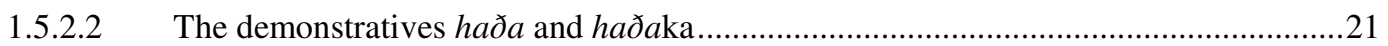

1.5.2.3 Double demonstrative determiners .................................................................24

1.5.2.4 Other characteristics of TA demonstrative determiners ......................................25

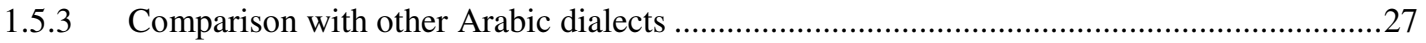

Chapter 2: $\quad$ Cognitive status and demonstrative forms in Tunisian Arabic ......................................30

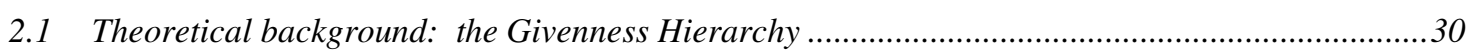

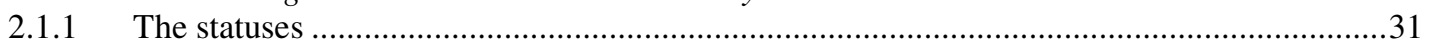

2.1.2 Cognitive status criteria: How does an entity acquire a particular cognitive status? .............34

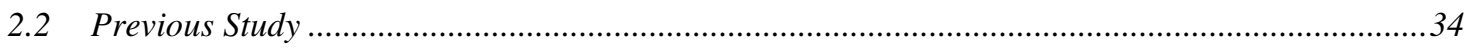

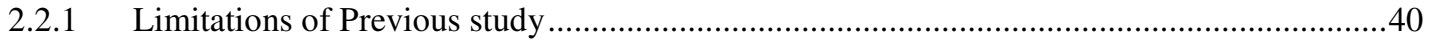

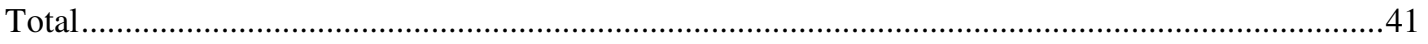

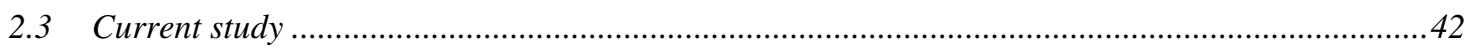

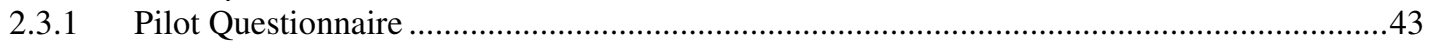

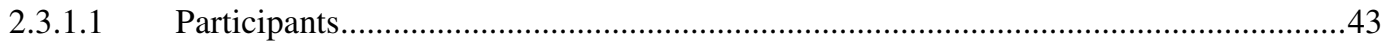

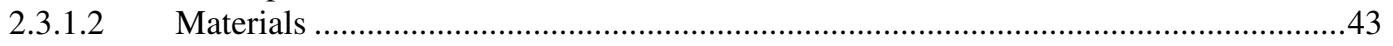

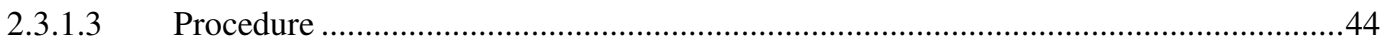

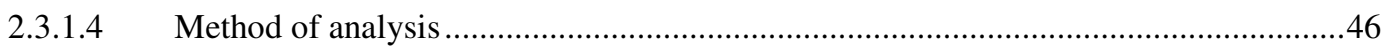

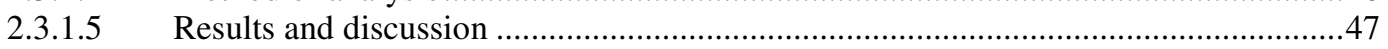

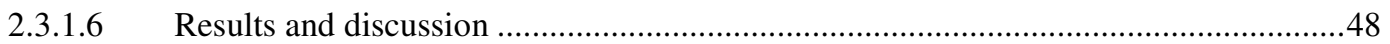

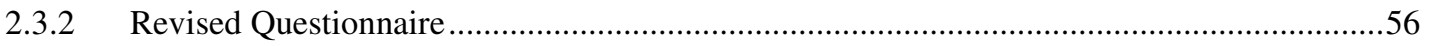

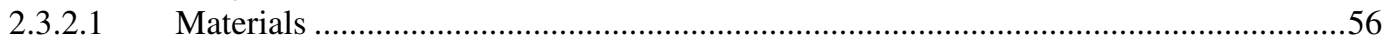

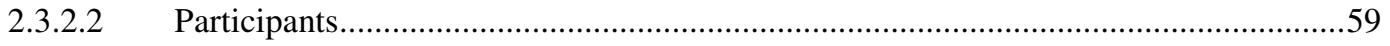

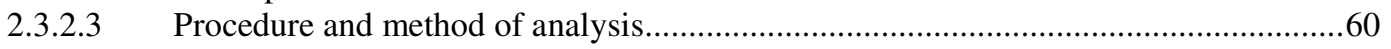

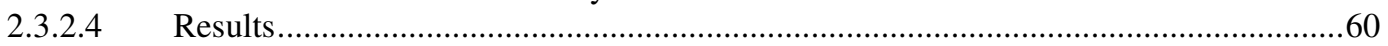

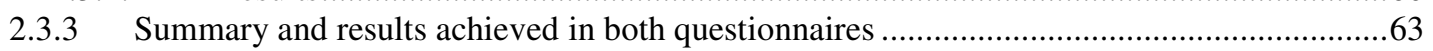


2.3.4 Significance of the choices made by participants in the pilot and the revised questionnaires: other factors that further restrict the use of demonstrative forms .......................................................66

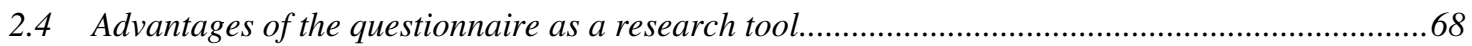

2.5 Limitations of the questionnaire as a research tool: Why do we still need a corpus study?...........69

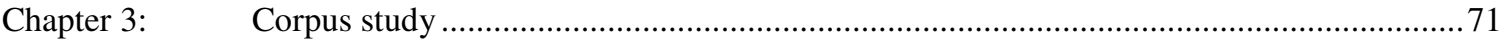

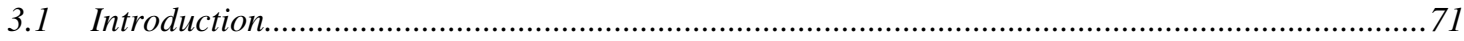

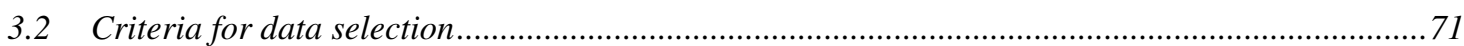

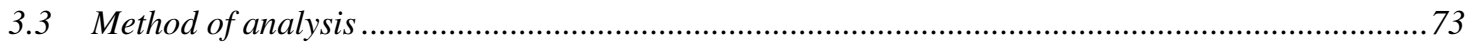

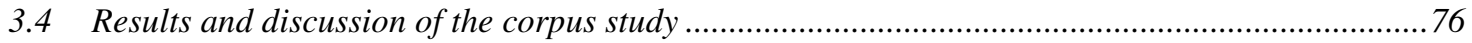

Chapter 4: A Cognitive explanation of communicators' avoidance of ambiguous forms: The case of the demonstrative haða

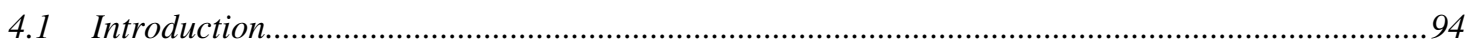

4.2 Factors that further restrict the use of the demonstrative pronoun haða when cognitive status

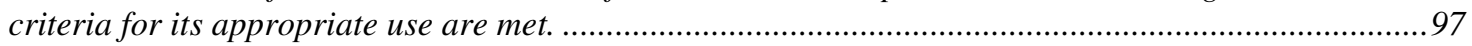

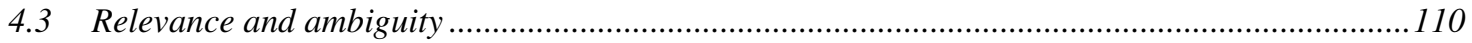

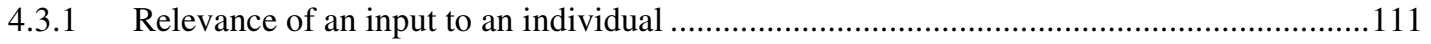

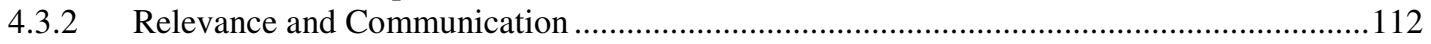

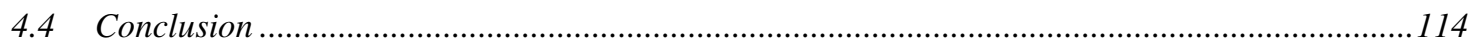

Chapter 5: Concluding remarks and future research ……..............................................................116

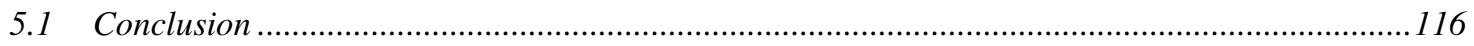

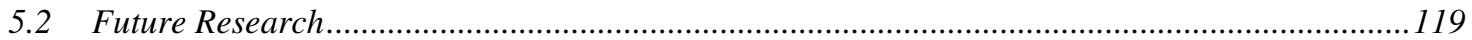

The use of the demonstrative determiner hak for the need of imposed salience................................119

5.2.2 Further restrictions on the demonstrative haðaka: The role of communicators' previous

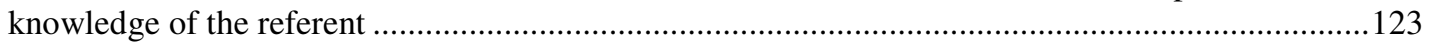

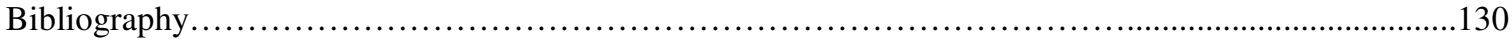

Appendix I : Coding protocol for statuses on the Givenness Hierarchy …............................134

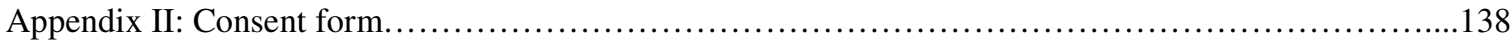

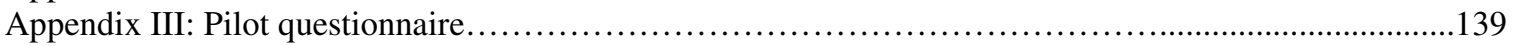

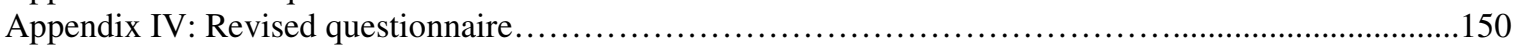

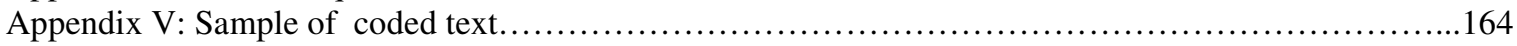




\section{List of Tables}

Table 1: Properties of Demonstratives and related items in English (Dixon 2003:69) ...9

Table 2: The demonstrative ha.19

Table 3: The demonstrative hak .20

Table 4: The demonstrative haða...... .22

Table 5: The demonstrative haðaka .23

Table 6: Hypothesized form-status correlations in the previous study....

Table 7: Distribution of TA demonstratives in the data corpus used in the previous study

Table 8: Distribution of TA demonstratives according to highest cognitive status in the pilot questionnaire

Table 9: Form-status correlations according to results of the pilot questionnaire ....... 56

Table 10: Distribution of TA demonstratives according to the highest cognitive status in the revised questionnaire 60

Table 11: Form-status correlations according to results of the revised questionnaire ....63

Table 12: Distribution of TA demonstratives in the data corpus..... .73 
Table 13: Distribution of TA demonstratives according to highest cognitive status in the

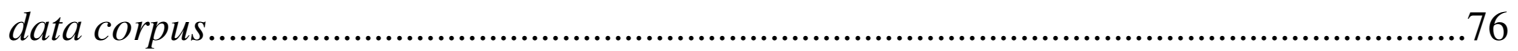

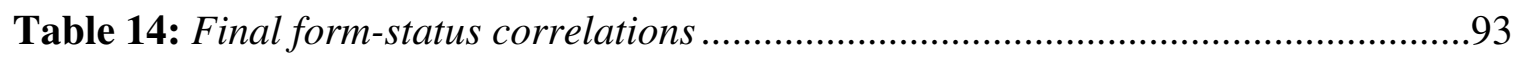




\section{List of Abbreviations}

$\begin{array}{ll}\text { prox1 } & \text { proximate 1 } \\ \text { prox 2 } & \text { proximate 2 } \\ \text { nonprox1 } & \text { nonproximate 1 } \\ \text { nonprox } 2 & \text { nonproximate } 2 \\ \text { p } & \text { plural } \\ \text { s } & \text { singular } \\ \text { emph } & \text { emphatic } \\ 1 & \text { first person } \\ 2 & \text { second person } \\ 3 & \text { third person } \\ \text { voc } & \text { vocative } \\ \text { f } & \text { feminine } \\ \text { m } & \text { masculine } \\ \text { past } & \text { past tense } \\ \text { fut } & \text { future tense } \\ \text { pos } & \text { possessive } \\ \text { neg } & \text { negation } \\ \text { comp } & \text { complementizer } \\ \text { DP } & \text { Determiner phrase }\end{array}$




\section{Chapter 1: Introduction, literature review, \& overview of Tunisian Arabic demonstratives ${ }^{1}$}

\subsection{Introduction}

Demonstratives have traditionally been analyzed as 'pointing words' whose primary function is to indicate relative spatial or temporal distance of a referent from speech participants. Recent research argues that the meaning of demonstratives is not limited to spatial distance and has given alternative accounts for the use of demonstratives that focus on other cognitive and pragmatic meanings. As will be shown in the review of these alternative approaches in section 1.4 of this chapter, some of these studies even argue against the assumption that distance is part of the meaning of demonstratives based on investigations of demonstrative use in context (e.g., Burenhalt 2003, Enfield 2003).

The motivation for this study is to contribute to research that looks at alternative meanings for demonstratives, focusing on Tunisian Arabic (TA). Another important motivation for this dissertation is to contribute to linguistic description of Tunisian Arabic, which is one of the least researched Arabic dialects.

The goal of the dissertation is two-fold. First, working within the Givenness Hierarchy framework (Gundel Hedberg and Zacharski 1993), it aims to show how demonstratives in Tunisian Arabic are used to indicate cognitive status, the assumed memory and attention status that the intended referent has in the mind of the addressee. Based on a combined methodology of questionnaires and corpus analysis, this dissertation will test hypotheses formed in a previous study (Khalfaoui: 2004) about

\footnotetext{
${ }^{1}$ This dissertation is partly based upon work supported by the National Science Foundation under grant No. 0519890 I (PI Jeanette Gundel).
} 
proposed correlations between cognitive status and single demonstrative forms which were very infrequent in the data corpus used for that study. It also extends the analysis to phrases with double demonstrative determiners, one prenominal and one postnominal (e.g., ha-l-ktab haða 'this book') which were not included in that study. Since the two demonstrative forms that co-occur to form a double demonstrative can be used separately as single demonstrative determiners, the dissertation looks at whether those single demonstrative determiners must require the same cognitive status or not, and whether they have the same cognitive status as the double demonstratives they form.

The second goal of this dissertation is to show how other factors further restrict the choice among demonstrative forms that meet the criteria for the same cognitive status, and to provide theoretical explanations for those restrictions. Specifically, it is shown that when there is more than one possible referent that satisfies cognitive status criteria for reference with the demonstrative $h a ð a$, speakers avoid the demonstrative pronoun $h a ð a$, and choose the same form as a determiner even though both the pronoun and the determiner require the same cognitive status and are therefore expected to be interchangeable when cognitive status criteria for their use are met. I argue that Relevance Theory (Sperber and Wilson 1986/1995) provides a cognitive explanation for why communicators choose a phrase with a demonstrative determiner and not a demonstrative pronoun in such cases.

The dissertation is organized as follows: A literature review on types, morphosyntactic structure, and uses of demonstratives is presented in chapter 1 . Next, two approaches to analyzing the use of demonstratives are discussed: 1) traditional approaches that explain the use of demonstratives in terms of spatial distance, and 2) 
alternative approaches that seek to explain demonstrative use in terms of other pragmatic and cognitive factors. After that, an overview of Tunisian Arabic followed by an overview of Tunisian Arabic demonstratives with a comparison with other Arabic dialects is given. In chapter 2, results of the pilot and the revised questionnaires conducted to propose cognitive status-form correlations are presented. Chapter 2 also discusses advantages and limitations of the questionnaire and the corpus analysis as research tools and argues that they complement each other. Results of the corpus analysis conducted to complement the questionnaires are presented in chapter 3. Chapter 4 discusses the factors that further restrict the demonstrative haða when cognitive status criteria for its use are met, and suggests an explanation within Relevance Theory for why communicators avoid the pronominal demonstrative form in the presence of those restricting factors. Concluding remarks and suggestions for future research will be given in chapter 5 .

\subsection{Demonstratives: Types, definition, syntax, morphology, and uses}

\subsubsection{Types}

According to Dixon (2003), there are three types of demonstratives: nominal demonstratives, local adverbial demonstratives, and verbal demonstratives. Nominal demonstratives can occur in a phrase with a noun or a pronoun, or can make complete noun phrases by themselves. For example, in the Australian language Yindinj, the demonstrative determiner yigu can be used with a noun or with a pronoun as shown in (1) and (2) respectively (65). As shown in (3), the demonstrative this in English can make a complete noun phrase (62). 
(1) yanjjdi wanji:na-l yiju dungu

$1 \mathrm{sg}$ do.what-non-past this head

"What shall we do with this head?"

$\begin{array}{llll}\text { (2) yayu } & \text { njundu:banj } & \text { yinu } & \text { badja-r- rala } \\ \text { 1sg } & 2 \text { pl } & \text { this } & \text { leave-Non.past-now } \\ \text { "I'm now leaving these-you." } & \end{array}$

(3) This is hot

Local adverbial demonstratives modify a co-occurring verb. They occur either alone (e.g., "put it here") or with a noun taking local marking (e.g., "put it (on the table) there.") (62). Dixon states that some languages have manner adverbial demonstratives, such as "(do) like this, (do) in this way/manner)" (62). The third type, verbal demonstratives, include examples like "do it like this", with an accompanying mimicking action. Verbal demonstratives can occur as the only verb in a predicate or together with a lexical verb. Dixon states that a small number of languages do not have manner adverbial demonstratives but have a subclass of verbs with demonstrative meaning which involve deictic reference to an action. In (4) for example, the Bouma Fijan verb ene can be glossed "do like this" (72-73).
(4) [o 'ea]s \{'enee
tuu gaa 'eneii $\}$ predicate art3sg do.like.this aspect just do.like.this
"He did just like this." [narrator mimes a spearing action]

The remainder of this section will be concerned with nominal demonstratives, since these are the focus of this dissertation. 


\subsubsection{Definition}

Although there is an agreement in the literature that almost every language has one or more demonstratives, coming up with a list of universal defining characteristics for the class of demonstratives is not an easy task for two reasons. The first reason is that in most languages, $3^{\text {rd }}$ person personal pronouns and the definite article are historically grammaticized from demonstratives. This often makes it difficult to decide whether a given form is a demonstrative when it is going through this process of grammaticization. Even when the definite article and third person pronouns are completely grammaticized, they still share features with demonstratives, making it difficult to find defining features that single out demonstratives as a grammatical class. Dixon points out that there can be synchronic or diachronic connection between articles and nominal demonstratives. In Standard German, for example, the forms die (feminine and plural)/der (masculine)/das (neutral) have definite article function when unstressed and demonstrative function when stressed (67-68). Old English had two nominal demonstratives which were marked for two numbers, three genders, and five cases; from these demonstratives have developed the modern definite article the, and the nominal demonstratives this/these and that/those (Sweet 1898:112-5 cited in Dixon 2003:68). The definite article in French has developed out of the nominal demonstrative ille (that) in Latin; and the nominal demonstratives in modern French come from the Latin nominal demonstrative hic (this) with strengthening from deictic particle ecce (Pope 1934: 322-327 cited in Dixon 2003: 68). Himmelman (1996) points out that "although there is usually general agreement as to what is and what is not considered a demonstrative in a given language, occasionally there is a problem of delimitation" (210). 
The second reason that makes coming up with a universal definition for demonstratives not an easy task is that demonstratives vary from one language to another in terms of types and function, which makes it difficult to find universal features. In this section three approaches to defining demonstratives are introduced and discussed.

\section{Diessel (1999)}

One approach to defining demonstratives is to give a set of characteristics that define this grammatical class. For example, Diessel (1999) gave three criteria for defining demonstratives. First, they are deictic (pointing) expressions serving syntactic functions. Second, they serve certain pragmatic functions by organizing information flow in a conversation, and by focusing the hearer's attention on objects in the speech situation. Third, demonstratives encode a meaning of spatial distance.

The three criteria given by Diessel are all possible characteristics of demonstratives, but they are not universal features. For example, it is not a universal feature of demonstratives to indicate spatial distance. Diessel himself points out that in a few languages in his sample demonstratives are distance-neutral. As for the pragmatic and deictic features, they are not exclusive to the class of demonstratives, and can be shared by phrases headed by the definite article and $3^{\text {rd }}$ person personal pronouns.

\section{Himmelman (1996)}

Being aware of the historical relationship of demonstratives to $3^{\text {rd }}$ person personal pronouns and the definite article, Himmelman (1996) took a different approach by suggesting diagnostic contexts that distinguish demonstratives from the definite article and $3^{\text {rd }}$ personal pronouns. In order to distinguish demonstratives from the definite article, 
he suggested that the following two diagnostic contexts "seem to allow for crosslinguistically valid and applicable identification of 'true' demonstratives” (210).

a. The element must be in a paradigmatic relation to elements which - when used exophorically - locate the entity referred to on a distance scale.

b. The element must not be amenable to the following uses, which are characteristics of the definite article.

- First mention of entities considered unique in a speech community (e.g., \#this/that Queen announced .... $)^{2}$

- Associative-anaphoric use such as referring to a trunk for the first time after mentioning a tree (210).

He also suggests the following four diagnostic contexts given in (a-d) for distinguishing demonstratives from $3^{\text {rd }}$ person personal pronouns, by suggesting four characteristics that pronouns do not share with demonstratives (211-212).

a. In a few languages, third person personal pronouns allow for associative anaphoric use such as referring to the husband for the first time by he after mentioning a couple.

b. $3^{\text {rd }}$ person personal pronouns allow for so-called pronouns of laziness as in (5).

(5) John Doe bequeathed the first house he built to his wife, but Richard Roe deeded it $(*$ this/*that) to his daughter.

c. In a few languages, $3^{\text {rd }}$ person personal pronouns allow for expletive use as in (6).

(6) It is raining

*This/*that is raining

\footnotetext{
${ }^{2}$ The symbol \# is used in this dissertation to tindicate unacceptablility in a given context.
} 
d. The discourse deictic use (reference to an event or proposition) of $3^{\text {rd }}$ person personal pronouns seems to be more heavily constrained and less frequent than that of demonstratives as shown in (7) from the Pear Stories (224).

(7) Then he goes off, ... and that's the end of that story, but then ... it goes back to the farmer.

Himmelman points out that the diagnostic contexts for distinguishing demonstratives from third person personal pronouns that he proposed are "of limited practical value, since they are marginal" (211).

\section{Dixon (2003)}

Since demonstratives vary from one language to another in their number, typology, and functions; and since they share characteristics with personal pronouns and the definite article, another approach for defining demonstratives is to find defining criteria for each language separately. For example, Dixon (2003) argues that "it is useful to compare -- for a given language -- some of the properties of nominal demonstratives, first and second pronouns, and third pronouns and the definite article" (68). Dixon compared these forms in English in terms of eight properties as shown in table 1. 
Table 1: Properties of Demonstratives and related items in English (Dixon 2003:69)

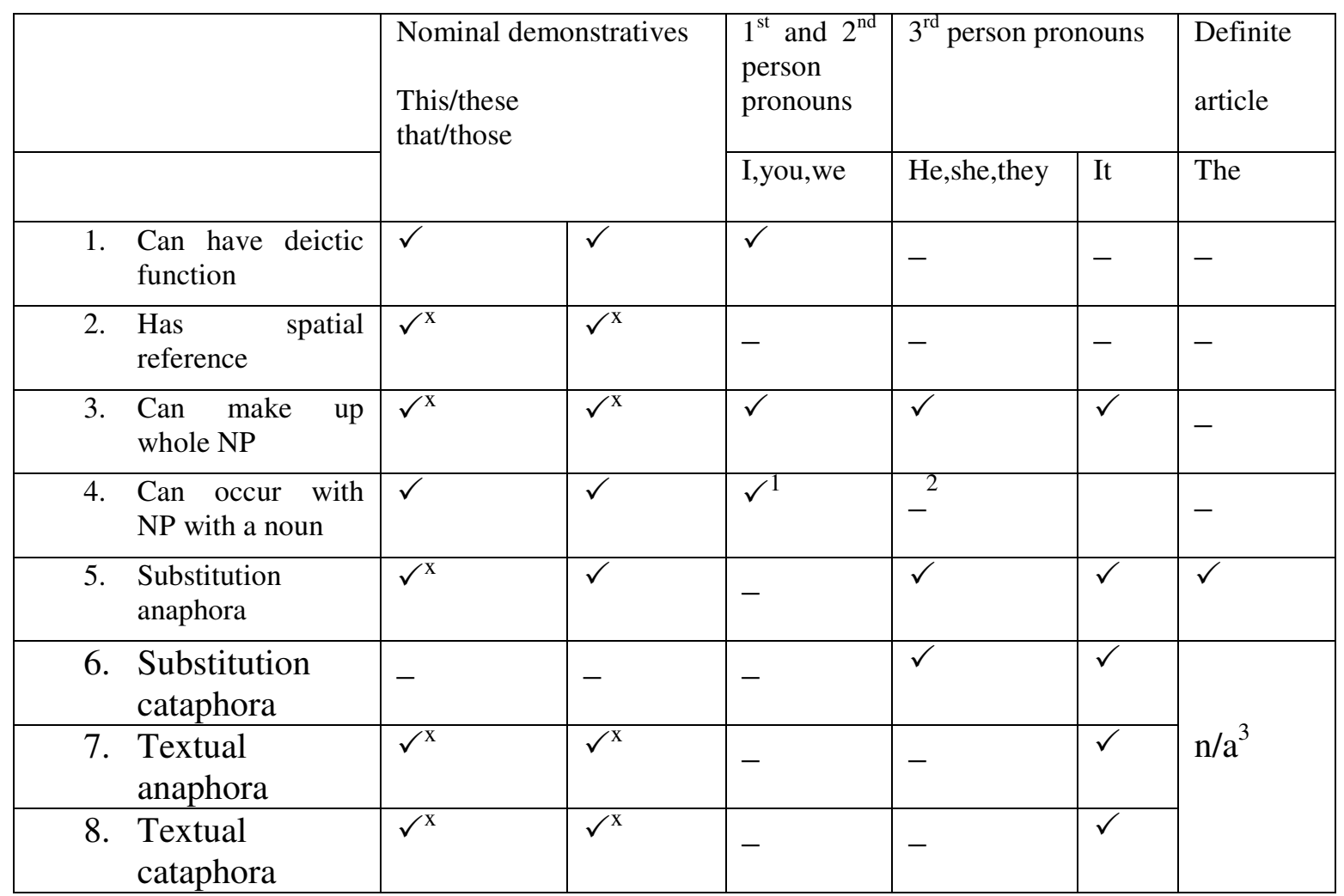

$\mathrm{x}$ Although this is a property of nominal demonstratives in English, it is not shown by demonstratives in all languages.

1 This covers NPs such as you women

2 It is possible to have sentences such as They, the evil spirits, roamed around in the night, but this is regarded as involving two NPs in apposition (they and the evil spirits) rather than a single NP.

3 Not applicable; only items which make up a whole NP can have anaphoric or cataphoric function.

As shown in table 1, English demonstratives share many features with personal pronouns and the definite article. The only feature that is unique to demonstratives in English is spatial reference, but this feature cannot be generalized to demonstratives in general, because it is not a universal feature. Coming up with a set of defining features must be a language specific criterion. For this reason, Dixon defines demonstratives in general as a grammatical word (or, occasionally, a clitic or affix) other than $1^{\text {st }}$ or $2^{\text {nd }}$ person personal pronouns which can have pointing (or deictic) reference. Although this property is not 
exclusive to demonstratives, and can be shared by other grammatical classes such as personal pronouns, it is agreed upon in the literature on demonstrative typology that it is a universal feature of demonstratives to have pointing reference.

\subsubsection{Syntactic distribution of nominal demonstratives}

Nominal demonstratives are classified into adnominal and pronominal demonstratives. This classification corresponds to the syntactic context in which they occur. Pronominal demonstratives occur as independent phrases by themselves while adnominal demonstratives co-occur with a noun or a pronoun. Crosslinguistically, adnominal demonstratives are more frequent than pronominal demonstratives (Dixon 2003, Diessel 1999, Himmelman 1996). There are demonstratives which occur in copular or non-verbal clauses (e.g., this is John). Diessel (1999) calls them identificational demonstratives, and identifies them as a separate category from nominal demonstratives. He supports this argument by the fact that in certain languages they are formally distinguished (79). For example, demonstrative pronouns and demonstrative identifiers are formally distinguished in Ponapean. Example (8) shows a demonstrative pronoun and (9) shows a demonstrative identifier in a nonverbal clause (Regh 1981: 143, 150 cited in Diessel 1999:

(8) met pahn mengila

this will wither

"This will wither."

(9) iet noumw naipen

this/there your knife

"Here is your knife."

To simplify things, identificational demonstratives are treated as pronominal demonstratives in this dissertation. 
Demonstratives are classified into grammatical categories that correspond to their syntactic distribution. Adnominal demonstratives are referred to as demonstrative determiners/adjectives (henceforth determiners). Pronominal demonstratives are typically referred to in the literature as demonstrative pronouns. While in most languages the same form is used as a demonstrative determiner and as demonstrative pronoun, there are languages where demonstrative determiners and demonstrative pronouns are formally distinguished. Some authors (e.g., Diessel 1999) state that unless demonstratives are formally distinguished, they do not belong to different grammatical categories. Furthermore, in some languages demonstratives co-occur with the definite article (e.g., Hausa, Arabic, and Norwegian).

\subsubsection{Morphological features of nominal demonstratives}

As noted in Diessel (1999), in certain languages demonstratives are morphologically invariable (e.g., Korean), while in other languages they are inflected for number and gender and/or case (e.g., Guugu, Yimidhirr, Ewondo) (13-21). Diessel also points out that most demonstratives are phonologically unbound, but some nominal demonstratives can cliticize to a noun phrase (e.g., Kilba (Chadic)). Dixon (2003) also notes that although all the demonstratives in his sample that cliticize are adnominal, pronominal demonstratives can also cliticize in languages such as Kawaiisu (Numic). He also points out that certain demonstratives cliticize to a noun phrase, but they are probably never bound to a specific word. He also points out that some languages have a reduced form of a nominal demonstrative for anaphoric function. For example in Longgu (Austronesian), spoken in the Soloman Islands, the forms nene (this) and nina (that) are shortened to -ne and -na respectively when used anaphorically (22). 


\subsubsection{Uses of demonstratives}

The two main distinctions of demonstratives stated in the literature are exophoric and endophoric. The term "exophoric" refers to demonstratives used to pick out something in the situational context, while "endophoric" is used as a general term for reference within the text. Diessel (1999) furthermore classifies the endophoric use of demonstratives into anaphoric, discourse deictic, and recognitional. Anaphoric and discourse deictic demonstratives refer to elements of the ongoing discourse. Anaphoric demonstratives are used as tracking devices in the discourse to refer back to previously mentioned entities. They are also used to shift the focus of attention to a new topic. Discourse deictic demonstratives refer to aspects of meaning expressed by a piece of discourse such as a clause, a sentence, or a series of sentences. Recognitional demonstratives have two characteristics that distinguish them from all other uses. First, recognitional demonstratives are used only with a noun, and second they do not refer to something in the discourse or the situational context. They are used to activate specific shared knowledge (105).

Diessel also includes among endophoric demonstratives those which do not refer to entities in the discourse or in the situational context and which mark specific indefinite information, such as the unstressed (indefinite) this in English. He notes that what differentiates recognitional demonstratives from the indefinite this is that the latter refer to entities that do not represent shared knowledge (109).

\subsection{Traditional approaches to analyzing demonstratives}

The choice of demonstrative forms has traditionally been explained based on a proximity scale used to indicate temporal or spatial distance from the speech participants. Based on 
a crosslinguistic survey, Dixon (2003) presented a typology of parameters of variation associated with demonstratives. He points out that "the major parameters of reference for demonstratives are: spatial -- sometimes extended to temporal-- location, height and stance, and visibility" (85). He illustrates this description with examples of demonstratives from different languages described in terms of scales of spatial distance, height, and visibility. For example, as shown in (10), he indicates that Boumaa Fijian has a three-term system distinguished in terms of spatial distance from the speech participants (86). Demonstratives in the Arakul dialect of Lak (Northeast Caucasian family), on the other hand, are distinguished in terms of reference not only to distance but also to height, as shown in example (11) (Khaidakov 1966: 12, cited in Dixon 2003: 89). As shown in (12), visibility combines with degrees of spatial distance in Kwakiutl, a Wakashan language, yielding a six-term demonstrative system (Boas 1911: 41, cited in Dixon 2003: 90).

$\begin{array}{lll}\text { (10) Boomaa Fijian } & \\ \text { Yai "this/here" } & \text { near speaker } \\ \text { yaa "that/there" } & \text { mid distance from speaker, often near addressee } \\ \text { mayaa "that/there" } & \text { far distance from speaker and addressee }\end{array}$

$\begin{array}{cl}\text { (11) Lak } & \\ \text { aha } & \text { close to speaker } \\ \text { hava } & \begin{array}{l}\text { farther from speaker, but } \\ \text { not the same level }\end{array} \\ \text { ho } & \begin{array}{l}\text { higher or lower than the } \\ \text { speaker }\end{array}\end{array}$




\section{(12) Kwakiutl}

visible, near me invisible, near me visible, near thee invisible, near thee visible, near him invisible, near him

Halliday and Hasan (1976) argue that in English, "demonstrative reference is essentially a form of verbal pointing. The speaker identifies the referent by locating it on a scale of proximity" (57). They list the nominal demonstratives this and that, and the adverbials here and there; and now and then in terms of a proximity scale of near and far (not near) respectively.

Halliday and Hasan extend the proximity distinction to demonstrative use within the text. For example, they argue that the tendency to use this to refer to utterances made by the speaker himself, and that to refer to utterances made by his interlocutor is clearly related to "that of 'near (the speaker),' versus 'not near'; where 'what I have just mentioned' is, textually speaking, 'near me' whereas 'what you have just mentioned' is not."

Cowell (1964) describes demonstrative pronouns (i.e., nominal demonstratives) in Syrian Arabic in terms of proximity to the speaker and the hearer. He argues that the distal demonstrative hadaak refers to something (or someone) relatively far away from the speaker and the addressee, and the proximal demonstrative haada is used to refer to something near or associated with the person spoken to (552). He also points out that "The demonstrative pronouns are of course not limited to the presentation of objects in a spatial dimension, but they also indicate "distance" in time ... or conceptual "distance" (552). 
Thackston (2000) describes demonstratives in Classical Arabic as "near" demonstratives and "far" demonstratives, where the demonstrative haaðaa indicates "near" and the demonstrative ðaalika indicates "far".

\subsection{Alternative approaches to analyzing demonstratives}

The notion that demonstratives primarily encode spatial distance has been challenged in recent studies. For example, based on an analysis of spontaneous interactions of native Lao speakers collected on video, Enfield (2003) argues that the two Lao demonstrative determiners nii and nan do not encode a meaning of spatial distance. He suggests instead that "pragmatic inference" alone gives rise to the associations of nii with things "NEAR speaker' and/or 'here', and nan with things 'FAR from speaker' (115). He explains that Lao speakers choose between the two demonstratives based on conceptions of here-space determined by such factors as physical barriers, manual and attentional focus and speaker's taking into account of addressee's presumed access to information.

Based on data collected from American English spoken discourse, Strauss (2002) analyzed the forms this, that, and it in terms of an alternative approach of gradient focus where focus means "the degree of attention the hearer should pay to the referent" (135). She argues that it is Low Focus, that is medium focus, and this is High Focus where the degree of focus correlates with the relative newness and importance of the referent.

Based on corpus analysis, $\mathrm{OH}$ (2001) argues against the traditional claims made by a number of linguists (e.g., Greenbaum and Quirk 1990; Halliday and Hasan 1976; Lyons 1977) that "the most basic use of this and that in English is as deictics (i.e., expressions used for pointing), the two being contrasted in terms of proximity to the speaker" (124-125). OH states that the proximity/ nonproximity distinction is limited and 
does not account for all uses of demonstratives. Using Strauss's framework of Gradient Focus (1993a, 1993b) mentioned above, $\mathrm{OH}$ analyzed the three demonstratives in a corpus of written advertisements, and showed that the most critical factor that determines the speaker's choice among it, this, and that in the genre of written advertisements is Focus and not proximity. For example, $\mathrm{OH}$ found that although the demonstrative this is usually used to refer to new and important entities, it is used more frequently than that in central reference (i.e., when the referent is all or part of the advertised product) when referring to entities that are already mentioned in discourse. He argues that this constitutes compelling evidence that this is a high focus form, since it is used to constantly direct the reader's attention to the advertised product. It is used repeatedly to refer to the advertised product, because it signals a meaning of "newness" and "importance".

Burenhalt (2003) investigated the attentional characteristics of ton, a nominal demonstrative in Jahai, a language that belongs to the Northern Aslian subgroup of the Aslian branch of the Mon-Khmer language family, and spoken by groups of foragers in the mountain rainforests of northern Peninsular Malaysia and southernmost Thailand. The demonstrative ton was previously considered to encode spatial proximity. Based on analysis of data from a specific-object-identification task, he argues that ton does not encode spatial meaning, but it encodes that the referent is already attended to by the addressee. The other four demonstratives in Jahai, on the other hand, are used to divert the addressee's attention to a particular referent.

Gundel, Hedberg and Zacharski (1993) argue that the choice among demonstratives, like the choice among other determiners and pronouns is determined by 
cognitive status, the assumed memory and attention status of a speaker's intended referent in the mind of the addressee. Since Gundel et al's Givenness Hierarchy is used in this study; more description of this framework is given in chapter 2.

\subsection{Language Facts}

\subsubsection{Tunisian Arabic}

Tunisian Arabic is spoken in Tunisia, North Africa, by approximately 10 million speakers. It is a dialect of Arabic, a language of the Afroasiatic family. It is one of the Maghreb (North African) dialects which include Tunisian, Algerian, Moroccan, and Libyan Arabic. Although the native languages of the Maghreb in general were varieties of Berber, TA is the mother tongue of the vast majority of Tunisians today (Lawson and Sachdev 2000). In order to distinguish it from Standard Arabic (SA), it is referred to as dari3a, Sammija, or Tunsi.

Although TA is a dialect of Arabic, its syntax, pronunciation, morphology, and vocabulary are quite different from those of SA. Tunisian Arabic is an SVO language while SA is VSO. Its morphology is also different from that of SA. Saada (1967) indicates that the verb type paradigm in Tunisian Arabic is different from SA. For example, SA uses the discontinuous morpheme -u-i-a to derive passives as in kutiba (be written), while TA adds the morpheme $t$ - to the regular stem to indicate the passive as in tiktib (be written). Tunisian Arabic, like many other Maghreb Arabic dialects, has undergone a restructuring in sequences of the type $\mathrm{CvCC}$, which changed to $\mathrm{CCvC}$ (Versteegh 1997). 
One of the major reasons that made TA vocabulary different from that of SA is the extensive use of words borrowed from Italian, Spanish, French, Berber, and Turkish. Verbs of Romance origin are frequently used by different generations in the dialects of Tunis (Talmoudi 1986). For example, bannak (sit down) is derived from the Spanish banco; fakkab (to play scopa) is adopted from $\int k u b b$ a from the Italian scopa.

Tunisia is a classic case of diglossia (Lawson\&Sachdev 2000). TA is the Low variety and SA is the High variety. SA is the official language of Tunisia, but French also continues to be widely used, since Tunisia is a recent colony of France. SA and French are used in literature, newscasts, and newspapers. TA remains limited to spoken domains such as TV and radio talk shows, cinema, and theatre. Written documents in TA exist in

play scripts, folk stories, and folk poems, some of which are out of print. An example of folk tales is the four-volume work of Abdelaziz Al-Irwi (1989) which is now out of print. Hedi Balegh translated The Little Prince into TA, and also published a collection of Tunisian proverbs. A newspaper written in Tunisian Arabic, Al-Sariih, is also out of print.

TA has regional varieties of its own (see Gibson 1998 and Talmoudi 1980). The main regional varieties in Tunisia are: the Tunis dialect, the Sahel dialect, the North-Western Tunisian dialect, the South-Eastern Tunisian dialect, The Sfax dialect, and the SouthEastern Tunisian dialect.

\subsubsection{Tunisian Arabic Demonstratives}

As mentioned in 1.5.1, Tunisian Arabic has regional varieties of its own. Demonstrative forms used in different regional dialects vary primarily at the phonological level. For example, the plural demonstrative is pronounced haðum (a) in the 
dialect of Tunis, haðom (a) in the dialect of the North, and haðukaja in the dialect of the Sahel. What is referred to in this study as Tunisian Arabic is the dialect of Tunis.

Although Tunisian Arabic has local and manner adverbial demonstratives, the demonstratives that will be considered in this dissertation are nominal demonstratives which consist of demonstrative pronouns and demonstrative determiners. Six demonstrative forms are investigated: $h a$ and $h a k$ which occur as determiners only, haða and haðaka which are used as determiners as well as pronouns, and two double demonstratives ha-N haða and hak $N$ haðaka. All uses of demonstratives referred to in the literature as exophoric and endophoric will be used in this dissertation without any special distinctions.

\subsubsection{The demonstratives $h a$ and $h a k$}

The two demonstratives $h a$ and hak function as prenominal determiners only, and do not carry number or gender features. For descriptive convenience, the demonstratives $h a$ and hak will be glossed as prox 1 and nonprox1, respectively.

Table 2: The demonstrative ha

\begin{tabular}{|l|l|l|}
\cline { 3 - 3 } \multicolumn{1}{c|}{} & Masculine & Feminine \\
\hline Singular & \multicolumn{2}{|c|}{ ha-N ${ }^{3}$} \\
\hline Plural & \multicolumn{2}{|c|}{} \\
\hline
\end{tabular}

\footnotetext{
${ }^{3} \mathrm{~N}$ stands for Noun Phrase
} 
As shown in table 2, the prenominal demonstrative determiner ha does not carry number or gender features. In (13), for instance, $h a$ remains invariant before the singular feminine NP $l$ - $m r a$ (the woman) and the singular masculine NP $l$-raa3il (the man). It also remains invariant before the plural feminine NP l-nsaa (the women), and the plural masculine NP l-r3aal (the men) in (14).

(13)

\section{ha}

prox 1

"This woman/man"

$\begin{array}{lll}\text { ha } & \text { l-nsaa/ } & \text { l-r3aal } \\ \text { prox 1 the-women } & \text { the-men }\end{array}$
"these women/men."

\section{l-raa3il}

the-man

The demonstrative ha cannot be used as a pronoun as shown by the ungrammaticality of example (15).

Table 3: The demonstrative hak ${ }^{5}$

\begin{tabular}{|l|l|l|}
\cline { 3 - 3 } \multicolumn{1}{c|}{} & Masculine & Feminine \\
\hline Singular & \multicolumn{2}{|c|}{ hak N } \\
\hline Plural & hak \\
\hline
\end{tabular}

\footnotetext{
${ }^{4}$ The symbol $*$ is used here to indicate ungrammaticality.

${ }^{5}$ Other variants of hak identified in the data corpus used in this dissertation are $a k$ and $a k a$
} 
As shown in table 3, Tunisian Arabic has an invariant prenominal demonstrative determiner, hak, that does not carry number and gender features. For example, in (16) hak is used with the singular masculine $l$-wlid (the boy) and the singular feminine l-bnajja (the girl), and in (17) it is used with the plural masculine NP l-wlaad (the boys) and the plural feminine phrase l-bnaat (the girls).

hak l-wlidl/l-bnajja

nonprox1 the-boy/the girl

"that boy/girl"

hak l-wlaad/l-bnaat

nonprox 1 the boys/the girls

"those boys/girls"

Like the prenominal ha, hak cannot be used as a pronoun as shown by the ungrammaticality of (18).

(18) ${ }^{*}$-hib $\quad$ hak
l-like nonprox1
"I like that"

\subsubsection{The demonstratives $h a ð a^{6}$ and $h a ð a \mathrm{ka}^{7}$}

Tunisian Arabic has two non-reduced postnominal demonstratives, haða and haðaka, which can function as determiners as well as pronouns. They both carry number and gender agreement features in the singular, and number agreement features only in the

\footnotetext{
${ }^{6}$ Another variant of haða identified in the data used in this study is haðaja.

${ }^{7}$ Some tokens of haðaka identified in the data are pronounced without an initial [h]. They are pronounced aðaka.
} 
plural. For descriptive convenience, the demonstrative forms haða and haðaka will be glossed as prox2 and nonprox 2 , respectively.

Table 4: The demonstratives haða

\begin{tabular}{|l|l|l|}
\cline { 2 - 3 } \multicolumn{1}{c|}{} & Masculine & Feminine \\
\hline Singular & (NP) haða & (NP) haði \\
\hline Plural & \multicolumn{2}{|c|}{ (NP) haðum } \\
\hline
\end{tabular}

As shown in table 4, the demonstrative haða is marked for number and gender in the singular, and for number only in the plural. As in (19), the determiner haða agrees with the singular masculine NP $l$-wlid (the boy), and in (20) with the singular feminine NP $l$ bnajja (the girl). As shown in (21), the plural determiner haðum can occur with either the plural feminine phrase l-bnaat or the plural masculine l-wlaad (the boys).

$$
\begin{array}{ll}
\text { l-wlid } & \text { haða } \\
\text { the-boy } & \text { prox } 2.3 \mathrm{~ms} \\
\text { "this boy" } &
\end{array}
$$

$$
\begin{array}{ll}
\text { I-bnajja } & \text { haði } \\
\text { the-girl } & \text { prox } 2.3 f s \\
\text { "this girl" } &
\end{array}
$$

\section{(21) I-bnaat/l-wlaad haðum \\ the-girls/the-boys prox2.p "these girls/boys"}

The demonstrative haða can be used as a determiner as in examples ((19)-(21)), above, or as a pronoun as in (22) and (23). 
(22) A: as 3ib-t?

what bring.past-2s

"What did you bring?"

B: 3ib-t haði

bring.past-1s prox2.3fs

"I brought this (one)"

(23) n-ћib haðum

1-like prox2.p

"I like these"

Table 5: The demonstrative haðaka

\begin{tabular}{|l|c|l|}
\cline { 2 - 3 } \multicolumn{1}{c|}{} & Masculine & Feminine \\
\hline Singular & (N) haðaka & (N) haðika \\
\hline Plural & (N) haðukum & \\
\hline
\end{tabular}

As shown in table 5, the postnominal demonstrative haðaka carries number and gender agreement features in the singular, as in (24) and (25), and number agreement features only in the plural, as in (26). As shown in (26), the plural form haðukum can occur with the masculine phrase $l$-wlaad (the boys) or with the feminine phrase l-bnaat (the girls).

$\begin{array}{ll}\text { l-wlad } & \text { haðaka } \\ \text { the-boy } & \text { nonprox } 2.3 \mathrm{~ms} \\ \text { "that boy" } & \end{array}$




\section{l-bnajja haðika}

the-girl nonprox 2.3fs

"that girl"
l-wlaad/l-bnaat
haðukum
the-boys/the-girls nonprox 2.p
"those boys/girls"

The demonstrative determiner haðaka can be used as a determiner as shown in ((24)(26)) above; and as a pronoun as illustrated in (27) and (28).
A: Skun qal-li-k?
who tell.past.3ms-to-2s
"Who told you?"

\section{B: haðaka \\ nonprox $2.3 \mathrm{~ms}$ \\ "that one"}
(28) n-ћib haðukum
1-like nonprox2.p
"I like those"

\subsubsection{Double demonstrative determiners}

In addition to being used individually, the TA prenominal ha and postnominal haða can co-occur within the same phrase, as shown in (29); and the prenominal hak and postnominal haðaka can co-occur within the same phrase as shown in (30). As when they occur separately, $h a$ and hak must be prenominal and remain invariant, while haða and haðaka must be postnominal, and are inflected for number and gender in the singular, and for number only in the plural. 


$\begin{array}{lccc}\text { ha } & \text { l-raa3il } & \text { haða } & \text { bahi. } \\ \text { prox } 1 & \text { the-man } & \text { prox2.3ms } & \text { nice } \\ \text { "This man is nice." } & & \end{array}$

(30)

\begin{tabular}{|c|c|c|}
\hline $\begin{array}{l}\text { hak } \\
\text { nonprox } 1\end{array}$ & $\begin{array}{l}\text { I-raa3il } \\
\text { the-man }\end{array}$ & $\begin{array}{l}\text { haðaka } \\
\text { nonprox } 2.3 \mathrm{~ms}\end{array}$ \\
\hline
\end{tabular}

The prenominal $h a$ can only occur with the postnominal $h a ð a$ and the prenominal hak can only occur with the postnominal haðaka as shown by the ungrammaticality of (31) and (32).

$\begin{array}{llll}\text { *3a } & \text { hak } & \text { l-raa3il } & \text { haða } \\ \text { come.past.3ms } & \text { nonprox1 } & \text { the-man } & \text { prox2.3ms }\end{array}$

"That man came." (literally, that man this.)

\begin{tabular}{llll} 
*3a & ha & \multicolumn{1}{l}{ l-raa3il } & haðaka \\
come.past.3ms & prox1 & the-man & nonprox2.3ms \\
"This man came." (literally, this man that) &
\end{tabular}

\subsubsection{Other characteristics of TA demonstrative determiners}

TA demonstrative determiners co-occur with the definite article e.g., ha-l-ktaab (literally: this the book), l-ktaab haða (literally, the book this). TA demonstratives can also be used with proper nouns (e.g., Leila haði (literally, Leila this); hak Sami (literally, that Sami) but cannot be used with personal pronouns.

Another characteristic of TA demonstratives, which distinguishes them from many other languages (English, for example) is that they can co-occur with possessive determiners. Possessive constructions in TA can be formed in two ways: 1) The possessive morpheme attaches directly to the possessee (e.g., ktaab-i (my book)) 2) The 
possessive morpheme attaches to separate word mtaa (property) which follows the possessee (e.g., l-ktaab mtaa $\boldsymbol{S}-\boldsymbol{i}$ (my book)). When the possessive marker is attached directly to the possessee, only the postnominal demonstratives haða and haðaka and the double demonstrative determiners, but not the prenominal demonstratives $h a$ and hak can be used with the posssessive constructions; and the definite article is not used as shown in ((33)-(35)).

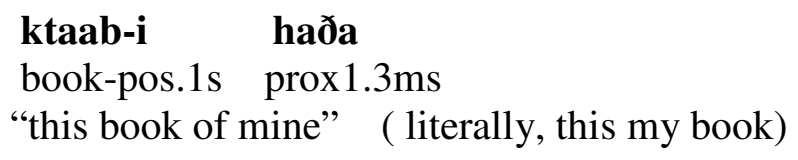

$\begin{array}{lll}\text { hak } & \text { bint-ik } & \text { haðika } \\ \text { nonprox1 } & \text { daughter-pos2s } & \text { nonprox2.3fs }\end{array}$

"that daughter of yours" (literally, that your daughter that)

$\begin{array}{lcc}* \text { ha } & \text { bint-ik } & \text { mfaat } \\ \text { prox 1 } & \text { daughter-pos.2s } & \text { go.past.3fs } \\ \text { "This daughter of yours left." } & \text { (literally, this your daughter) }\end{array}$

When the possessive marker is attached to the separate word mtaai, all demonstrative determiners can be used with possessive constructions, and they co-occur with the definite article as shown in ((36)- (38)).

(36) l-ktaab mtaa 9 haða the-book pos.1s prox $1.3 \mathrm{~ms}$

"This book of mine" 
ha-l-ktaab mtaaYi haða

prox1-the-book pos.1s prox1.3ms

"This book of mine" (literally, this the book mine this)

ha-l-ktaab mtaaSi
prox1-the-book pos.1s
"this book of mine"

\subsubsection{Comparison with other Arabic dialects}

As mentioned in section 1.5.2, Tunisian Arabic has two demonstratives, haða and haðaka, which function as demonstratives and determiners, two prenominal reduced demonstrative determiners $h a$ - and hak, and two double demonstratives $h a-N$ haða and hak $N$ haðaka. In this section I will compare these TA demonstratives to demonstratives in other dialects of Arabic.

\section{The demonstrative forms haða and haðaka:}

Other Arabic dialects also have demonstratives which, like the TA haða and haðaka, function as pronouns and determiners, and are marked for number and gender. The different Arabic dialects, however, differ in terms of the number of such demonstratives and their order within the determiner phrase. For example, like TA, Syrian and Gulf Arabic ${ }^{8}$ have two demonstratives similar to the TA demonstratives haða and haðaka. Syrian Arabic has a proximate demonstrative haada and a nonproximate hadaak ${ }^{9}$ (Cowell 1964: 552). Gulf Arabic has a proximate demonstrative haaða and a nonproximate demonstrative (haa) ðaak ${ }^{10}$ (Holes 1990: 173). Moroccan Arabic has three

\footnotetext{
${ }^{8}$ Holes defines Gulf Arabic as a term used to refer to "a number of related dialects which are spoken along the Gulf littoral from northern Kuwait to Oman in the south-eastern corner of the Arabian Peninsula."

${ }^{9}$ Cowell indicates that there are regional variations in the demonstrative forms.

${ }^{10}$ Holes indicates that there are some regional variations in the demonstrative forms especially in the plurals.
} 
demonstratives. It has a proximate demonstrative hada and nonproximate demonstrative dak (Benmamoun 2000: 137-8). It also has another nonproximate demonstrative hadak (Aoun and Choueiri 1997: 17). Egyptian Arabic has only one demonstrative da (Shlonsky 2002: 51).

The order of demonstrative determiners within a phrase also differs among the Arabic dialects. As mentioned above, The TA demonstrative determiners haða and haðaka always occur postnominally. The order of Moroccan Arabic and Gulf Arabic demonstratives within the DP is not free either. In Moroccan Arabic, the demonstrative hada is postnominal and $d a k$ is prenominal (Benmamoun 2000: 137-138). The proximate demonstrative hada is prenominal (Aoun and Choueiri 1997: 17). The Egyptian demonstrative $d a$ can occur only in a postnominal position ${ }^{11}$ (Shlonsky 2002: 51). The order of Gulf Arabic and Syrian Arabic demonstratives within the DP, however, is more flexible. In Gulf Arabic, haaða and (haa) ðaak can occur prenominally or postnominally (Holes 1990: 175). In Syrian Arabic, the nonproximate hadaak can occur prenominally or postnominally and the proximate haada occurs postnominally and less frequently prenominally (Cowell 1964: 556-557).

\section{The prenominal reduced demonstratives $h a-$ and $h a k$}

The characteristic of having an invariant prenominal demonstrative, which functions as a determiner only is not exclusive to Tunisian Arabic. Syrian Arabic has a reduced demonstrative determiner ha (Cowell 1964: 556). Similarly, Kuwaiti Arabic has

\footnotetext{
${ }^{11}$ Doss (1979:351) indicates that a prenominal demonstrative in Egyptian Arabic can occur in certain constructions such as curses and invocations (e.g., jelian abu di Sifa 'damn this life!'). However, she explains that this order is restricted and non-productive and that "the limited occurrences of Dem-Noun, in the present state, constitute residuals from a previous stage during which the variation of word order was a free one."
} 
a reduced demonstrative determiner ha (Brustad 2000: 115). Lebanese and Palestinian Arabic also have an invariant reduced prenominal demonstrative determiner ha (Omar 1976:17). Moroccan Arabic has two invariant prenominal demonstrative determiners had and diik (Brustad 2000: 117,125).

\section{Double demonstratives}

The characteristic of having a double demonstrative determiner within the same DP is not common to all other Arabic dialects, but is not exclusive to Tunisian Arabic. For example, Like Tunisian Arabic, Syrian Arabic allows two demonstratives to co-occur within the same DP. The reduced $h a$ can co-occur within the same DP with the proximate haada or the nonproximate hadaak (Cowell 1964: 558). Moroccan Arabic also allows double demonstratives within the same DP. The invariant demonstrative had co-occurs

with the proximate demonstrative hada within the same phrase. The proximate demonstrative determiner had co-occurs with hadak, and hadak is doubled in the same DP (Youssi 1992: 166-167). 


\section{Chapter 2: Cognitive status and demonstrative forms in Tunisian Arabic Previous Work and Questionnaires ${ }^{12}$}

\subsection{Theoretical background: the Givenness Hierarchy}

Gundel, Hedberg, and Zacharski (1993) proposed the Givenness Hierarchy (GH), an implicational scale of six cognitive statuses that are relevant in explaining the use of referring expressions in human language. The cognitive statuses on the GH represent the assumptions that speakers make about the memory and attention state of the addressee at the time of the utterance. Gundel et al. argue that different determiners and pronouns have these statuses as part of their conventional meaning. It follows that when speakers choose a particular form, they guide the addressee in restricting possible referents. For example, when speakers use the indefinite article $a$ in English, they are only expecting the addressee to identify the type of the referent, but if they use the demonstrative determiner that, they restrict possible referents to ones that are familiar (i.e., already in memory) for the addressee.

The Givenness Hierarchy (from Gundel et al. 1993, with relevant forms from English)

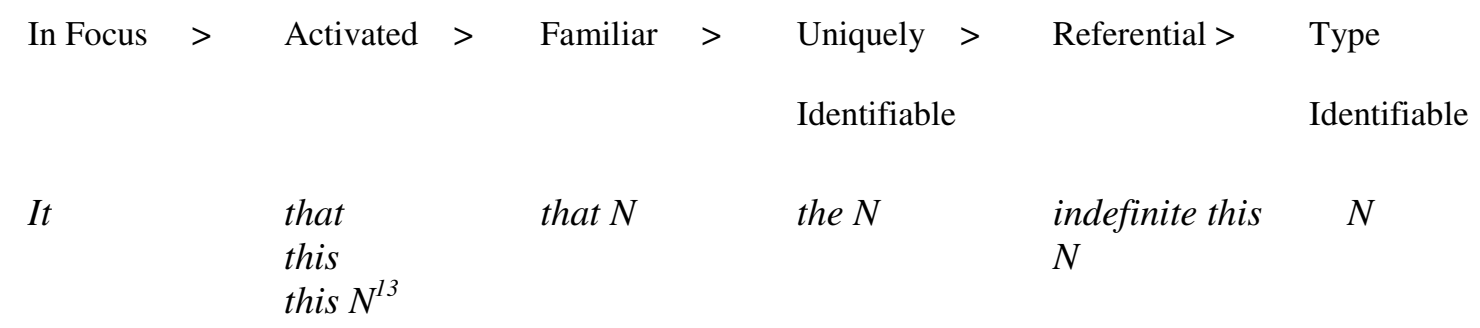

\footnotetext{
${ }^{12}$ An earlier version of this chapter was published in Perspectives on Arabic Linguistics XX, ed. Mustafa E. Mugahzy, 169-186. Amsterdam/Philadelphia: John Benjamins.

${ }^{13} \mathrm{~N}$ stands for noun phrase.
} 


\subsubsection{The statuses ${ }^{14}$}

The statuses on the GH are not mutually exclusive. Every status on the hierarchy entails all the lower statuses to the right. The theory thus predicts that a given form can be used for referents that meet the minimal required status, and can also be used in coding higher statuses. For example, the English demonstrative determiner this, which signals the status Activated, can be used to encode referents that are in focus, since the status In Focus entails the status Activated. Forms signaled by the highest status, In Focus, are the most restrictive, since their referents must meet the requirements for this status, while forms that signal the lowest status, Type Identifiable, are the least restrictive, since they can be used to code entities with any cognitive status on the hierarchy ${ }^{15}$. The six cognitive statuses are briefly characterized below.

Type Identifiable: The addressee is able to access a representation of the type of object described by the expression. This status is necessary and sufficient for the use of the indefinite article $a$ in English. For instance, the use of $a$ in (39) is appropriate if the speaker can assume the addressee can understand what type of thing the phrase $a$ restaurant describes.

(39) I met her in a restaurant.

Referential: The speaker intends to refer to a particular object and thus expects the addressee to not only access an appropriate type-representation, but to either retrieve an

\footnotetext{
${ }^{14}$ Upper case is used when talking about the statuses themselves, and lower case is be used when the statuses are used to describe referents.

${ }^{15}$ Gundel et al 1993 indicate that interaction of the hierarchy with Grice's Quantity Maxim, however, typically gives rise to implicature of non-familiarity when the indefinite article is used, thus further restricting appropriate use in certain contexts .
} 
existing representation of the speaker's intended referent or construct a new representation by the time the sentence has been processed. The status Referential is necessary and sufficient for the appropriate use of the indefinite this in colloquial English. In (40), the speaker is expecting the hearer to access the intended referent by constructing a representation of the guy who stopped him to ask directions to the children's hospital by the time the sentence is processed.

(40) On my way to your house, this guy stopped me and asked me to give him directions to the children's hospital.

Uniquely Identifiable: by using a form that signals this status, the speaker is expecting the addressee to uniquely identify (i.e., associate a unique representation of) the referent based on a previously existing mental representation in his/her memory or to construct a new unique representation by the time the DP is processed. In English, the status Uniquely Identifiable is necessary and sufficient for appropriate use of the definite article the. For instance, the phrase the apartment next to mine in (41) would be acceptable even if the addressee has no previous knowledge of its referent, since it contains enough descriptive content that will allow the addressee to form a unique representation of the apartment.

(41) John lives in the apartment next to mine.

Familiar: The addressee can identify the referent intended by the speaker, because s/he already has a representation of it in memory. In English, the status Familiar is necessary and sufficient for appropriate use of the demonstrative determiner that. In (42), 
the phrase that apartment (next to mine) is appropriate only if the addressee already knows about (has a mental representation of) the apartment the speaker is referring to.

(42) John bought that apartment (next to mine).

Activated: A referent is activated if it is represented in current short-term (working) memory of the addressee. In English the status Activated is necessary and sufficient for the appropriate use of the demonstrative pronoun that, for the demonstrative pronoun and determiner this, and for stressed personal pronouns. For example, the demonstrative pronoun that in (43) can be used appropriately to refer to an apartment that both speaker and addressee can see or have just mentioned.

A: That is a good one.

In Focus: A referent is in focus when it is not only in short-term memory but also the current focus center of attention. In English, this status is necessary for appropriate use of the unstressed pronominals. For instance, in (44) the unstressed personal pronoun it can be used appropriately to refer to the apartment, because its intended referent is previously mentioned in subject position of the previous sentence and can thus be assumed to be in the addressee's focus of attention.

(44) This apartment is huge. It must be very expensive. 


\subsubsection{Cognitive status criteria: How does an entity acquire a particular cognitive status?}

A referent acquires its cognitive status in the memory of the addressee in different ways.

For example, a referent can acquire the status Activated in the mind of the addressee by being mentioned in the previous sentence, or by being in the immediate spatio-temporal context. Gundel et al. (1993) indicate that membership in the in-focus set is partially determined by the syntactic position of the antecedent. For example, "subjects and direct objects of matrix sentences are highly likely to bring a referent into focus" (279). A list of cognitive status criteria (Gundel 2004) used in this study is given in appendix I.

\subsection{Previous Study}

In a previous study (Khalfaoui 2004), I proposed correlations between cognitive status and TA pronouns (personal and demonstrative pronouns) and determiners (the definite article and demonstrative determiners) based on my own intuition as well as the judgments of constructed examples given by two other native speakers of Tunisian Arabic. The hypothesized correlations were tested by an analysis of the distribution of relevant forms in a corpus consisting of a recorded radio drama maal wa hwaal (Money and Situations) and a published play Junuun (Insanity) (Baccar 2001) where the story revolves around the daily life of a young male who has schizophrenia, his struggle with the disease, and his daily interactions with his psychiatrist and his immediate family members. Results indicated that the prenominal demonstrative determiner $h a$, the postnominal determiner and pronoun $h a ð a$, and the postnominal determiner and pronoun haðaka all require at least the status Activated, while the demonstrative determiner hak 
requires only Familiar ${ }^{16}$. For instance, in the constructed example in (45) (Khalfaoui 2004), the use of hak is appropriate, because the addressee already has a representation of the doctor in memory.

$\begin{array}{lll}\text { r3aiti-1-ha } & \text { hak } & \text { 1-tbiiba } \\ \text { return.past.2s-3fs } & \text { nonprox 1 } & \text { the-doctor } \\ \text { "Did you go back to that doctor?" } & \end{array}$

In (46), however, the use of hak is not acceptable, since the car can be assumed to be uniquely identifiable, but not familair to the addressee. The addressee can be expected to construct a unique representation of the referent based on the descriptive content provided in the phrase.

(46) The addressee has no previous knowledge of the car

bifna l-karhba/\#hak l-karhba illi .
sell.past.3p the-car/nonprox1 the-car comp
Srina-ha Samnawil
buy.past.1p-3fs last.year
"We sold the car/\#that car that we bought last year."

In the constructed example in (47), the use of the demonstrative pronoun haðaka, which was determined to require at least activated, is appropriate to refer to the car. The car was determined to be in focus, because it was mentioned twice in the two immediately preceding sentences.

\footnotetext{
${ }^{16}$ Only demonstratives are discussed here, because they are the focus of this dissertation.
} 

A: 1-karhba raalja.
the-car expensive
"The car is expensive."
B: ah mala bas t-bii-ha?
ok so fut 2-sell-3fs

"Ok, so will you sell it?"
A: la la ma-n-biSha- $\int$ haðika
no no neg-1-sell-it-neg nonprox2.3fs
"No, no I don't sell that one."

Similarly, example (48) from a play script shows that the demonstrative pronoun haða can be used to refer to activated entities. In this example, the speaker uses haða to refer to a previous comment he made about himself mentioned in the immediately preceding sentence.

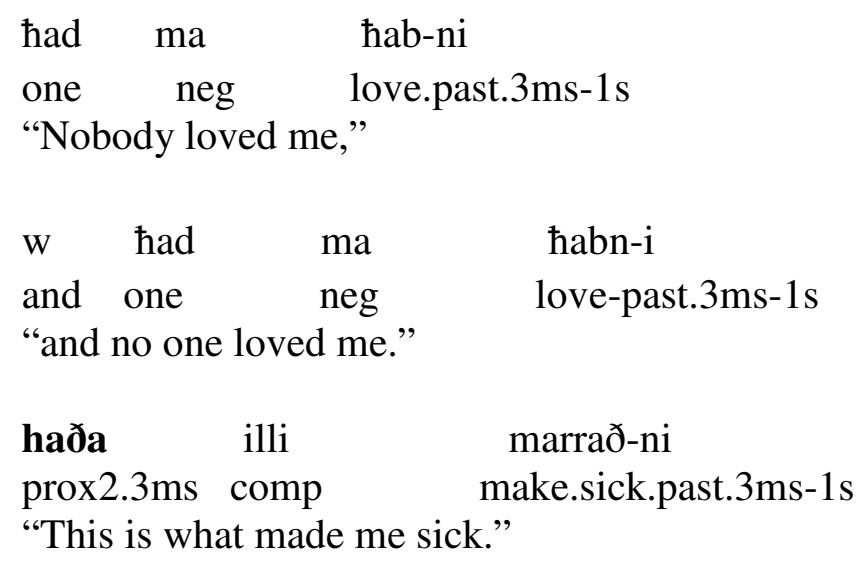

(Junuun (Insanity): 122)

In (49) from a radio play, the use the demonstrative pronoun hað $i$ to refer to the woman is appropriate. The woman was mentioned in the immediately preceding sentence in a prominent syntactic position. As shown in the example, the use of haða, which requires at least Activated, as a determiner is also possible. 
ya rabb-i bas ti-rjai 1-mra.

voc god-pos.1s future 3f-comeback the-woman;

"Oh my God, the woman will come back."

baS ta-Smil-ha $\theta$ niya li-1-marche haði/ l-mra haði

fut 3f-make-3fs way to-the-market prox $2.3 \mathrm{fs} /$ the- woman prox $2.3 \mathrm{fs}$ "This one/this woman will be coming all the time."

\section{(maal wa- hwaal (Money and Situations))}

Example (50), from a radio play, shows that the demonstrative pronoun haðaka can be used to refer to activated entities. The referent of the pronoun haðaka can be assumed to be activated, because it was mentioned in the immediately preceding sentence.

$$
\begin{array}{lcc}
\text { A: itlha } & \text { kuul } \text { w uskut } & \text { inti } \\
\text { keep.2s eat and stop.talking } & \text { you } \\
\text { "You eat and stop talking." } &
\end{array}
$$

B: ahah Sonia, Snuwa "kuul w uskut", yiajjis binti ahah Sonia what eat and stop.talking please "Ahaha Sonia what do you mean by 'eat and stop talking'?"

ana rani n-hib li-htiram w l-qdar, I emph 1s-want the-respect and the-respect "Me, I like respect."

ma-t-kallam- $\int$ wild-i hakka neg-2s-talk-neg son-pos.1s like that "Do not talk to my son like this."

$\begin{array}{lcl}\text { haðaka } & \text { nhaar } & \text { aaxir } \\ \text { nonprox } 2.3 \mathrm{~ms} & \text { day } & \text { another }\end{array}$

bas j-walli aqrab-li-k hatta min xuu-k

fut 3s-become closer-to-2s even from brother-pos. $2 \mathrm{~s}$

"That one, one day will be closer to you than your brother." (maal wa-hwaal (Money and Situations)) 
Example 0 shows that the demonstrative $h a ð a$ as a pronoun and as a determiner cannot be used to refer to lower than Activated, supporting the hypothesis that this demonstrative form requires at least Activated.

(51) The addressee has no previous knowledge of the doctor kun-t Pand hak l-tbiiba/\# l-tbiiba haði/ \#haði be-past.1s at nonprox 1 the-doctor/ the-docotr prox $2.3 \mathrm{fs} / \mathrm{prox} 2.3 \mathrm{fs}$ "I saw that doctor/\#this doctor/\#this."

Example (52), from a radio play, shows that if we replace hak with the demonstrative determiner $h a$ or the demonstrative pronoun haðaka, the result is infelicitous, since hak requires the referent to be at least familiar, while the determiner $h a$ and the pronoun haðaka require the referent to be at least Activated. This supports the hypothesis that these two forms require at least activated. The referent of the DP hak l-ћufra (that hole (meaning that small room)) was determined to be familiar, because the addressee has previous knowledge of the room the speaker is referring to, but the room hasn't been recently mentioned in the conversation. 


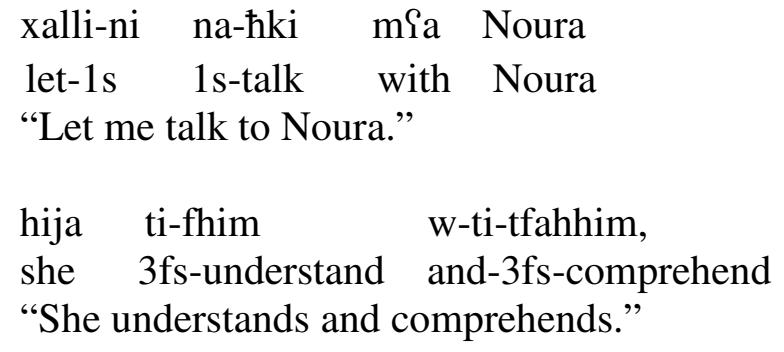

la j-dawwir ba-trafik ћbayyib."

neg 1s-approach with-edges a friend

"You are unapproachable."

$\begin{array}{lll}\text { Saad } & \text { qut-li-k ja } & \text { Noura } \\ \text { so } & \text { tell-to-2s voc } & \text { Noura } \\ \text { "so Noura, I told you," } & \end{array}$

law kaan buu-kum t-bafbs-u bii-h

if be.past.3ms father-pos.3p 2-pamper with-3ms

"If you pamper your father,"

w t-hinnu 2lii-h

and 2-be.kind on-3ms

"and be kind to him."

w t-xarr3uu-h

and 2-takeout-3ms

min hak l-hufra/ \# ha l-hufra/\# haðika

from prox2 the-hole/ prox1-the-hole/ nonprox2.3fs

"and take him out of that small room/\#this small room/\#that one"

w ta-Pmlu-1-u kaar w qdar

and 2-make-to-3ms respect and respect

"and give him respect,"

ra-hu ma xammam- $\int$ fi-l-Yirs

emph-3ms neg think.past.3ms-neg in-the-marriage

"He wouldn't have thought of marriage."

(maal waћwaal (Money and Situations)) 
The final hypothesized correlations between TA demonstrative forms and cognitive status according to Khalfaoui (2004) are given in Table 6.

Table 6: Hypothesized form-status correlations in the previous study

\begin{tabular}{|l|l|l|l|l|l|}
\hline In Focus & Activated & Familiar & $\begin{array}{l}\text { Uniquely } \\
\text { Identifaible }\end{array}$ & Referential & $\begin{array}{l}\text { Type } \\
\text { Identifiable }\end{array}$ \\
\hline huwa & ha-N & hakN & $l$ - & & \\
$\varnothing$ & haða & & & & \\
& N haðaka & & & & \\
& haðaka & & & & \\
\hline
\end{tabular}

\subsubsection{Limitations of Previous study}

One limitation of the previous study is that the tokens of demonstrative forms identified in the data were very infrequent. The distribution of TA referring expressions according to the highest cognitive status in the corpus analysis used in Khalfaoui (2004) is given in table 7. 
Table 7: Distribution of TA demonstratives

in the data corpus used in the previous study

\begin{tabular}{|l|l|}
\hline \multicolumn{1}{|c|}{ Form } & Total \\
\hline$\varnothing$ & 206 \\
& \\
\hline huwa & 311 \\
\hline haða & $\mathbf{4}$ \\
\hline haðaka & $\mathbf{3}$ \\
\hline ha $\boldsymbol{N}$ & $\mathbf{6}$ \\
\hline N haða & $\mathbf{5}$ \\
\hline N haðaka & $\mathbf{1}$ \\
\hline hak $N$ & $\mathbf{1}$ \\
\hline - & 156 \\
\hline bare noun $(\mathrm{N})$ & 151 \\
\hline
\end{tabular}

As shown in table 7, while tokens of personal pronouns and determiners (the definite article) identified in the data used in the previous study were frequent, the number of tokens of demonstrative forms was very infrequent. For example, only one token for each of the demonstrative determiners haðaka and hak was identified in the data ${ }^{17}$. This limitation makes the results achieved for demonstratives inconclusive and further research to confirm them was needed. One form that especially requires further investigation is the postnominal demonstrative determiner haðaka, which was determined in the previous study to require at least Activated. Based on my personal intuition and my observations of TA native speakers' interactions, I suspect that this form requires the

\footnotetext{
${ }^{17}$ Relative infrequency of demonstratives compared to articles or personal pronouns is common across languages (see Gundel et al. 2003 and Ariel 1988).
} 
lower status Familiar, but is used very infrequently for this status, and much more frequently for the higher status Activated. Another limitation of the previous study is that it included only single demonstratives, since double demonstratives were not included when eliciting data and none were identified in the data corpus.

\subsection{Current study}

The current study consists of a combined methodology of constructed questionnaires and corpus analysis. This study builds on Khalfaoui 2004 to test form-status correlations for single demonstratives proposed in that study, and to extend the analysis to double demonstratives which were not included in the previous study. The current study also aims to look at whether the distribution of the demonstrative forms according to highest cognitive status in the questionnaires and the corpus analysis reveals other factors that further restrict the use of TA demonstratives which encode the same cognitive status.

The methodology used in this study was improved compared to the methodology used in the previous study. For example, while the previous study used oral elicitations, the current study used paper and pencil questionnaires. Also, while in the oral elicitations conducted in the previous study, only one example was used to test for form-status correlations using one biasing criteria, more than one example to test for every cognitive status were used in the questionnaires. In every example, a different biasing criterion was used. Finally, the database used in the corpus analysis conducted in the current study has been increased in order to increase the chance of identifying more tokens of the demonstrative forms, since the demonstratives identified in the data used in the previous study were very infrequent . 


\subsubsection{Pilot Questionnaire}

\subsubsection{Participants}

A total of 13 participants, 6 female and 7 male, filled in a paper and pencil questionnaire. All participants are adult native speakers of Tunisian Arabic from different educational backgrounds, and are all comfortable reading Arabic. All six female participants and four of the male participants have lived all their lives in Tunisia. The other three male participants have been living in the US for four years or less, and had lived in Tunisia prior to coming to the US. Each participant signed an informed consent that had been approved by the University of Minnesota Institutional Review Board. The informed consent form is provided in appendix II.

\subsubsection{Materials}

The questionnaire devised for this study was written in Tunisian Arabic using Arabic script. Since participants came from different educational backgrounds, everyday language that did not include technical or specialized jargon was used. The questionnaire consists of 11 questions. Each question has a sentence or short conversation with a blank space in it followed by 11 phrases to choose from. Each sentence or short conversation is biased toward a different cognitive status on the Givenness Hierarchy by placing the referent in a particular syntactic position or by placing a preceding indication of the memory and attention state of the addressee with respect to the referent of the phrase that needs to be placed in the blank space. Of the 11 sentences or short conversations, two were biased toward the status In Focus, three toward the status Activated, two toward the status Familiar, two toward the status Uniquely Identifiable, one toward the status 
Referential, and one toward the status Type Identifiable. Since a form can acquire a cognitive status in different ways, when more than one sentence or short conversation is biased toward the same cognitive status, different coding criteria were used for biasing each sentence or short conversation.

The 11 phrases that follow each sentence or short conversation consist of 8 phrases with the 8 TA demonstrative determiners and pronouns considered in this study, and three filler phrases that did not contain demonstrative forms. The first filler phrase contains the definite article $l$-, the second one is a bare noun, and the third filler phrase is either a phrase which has a possessive, or a phrase that contains a different word for the referent and which consists of either a bare noun or the definite article. The 11 sentences and short conversations were presented in random order.

\subsubsection{Procedure}

In the written instructions that precede the questionnaire, participants were asked to read each short conversation and the context information that precedes it, and then circle on lists of 11 noun phrases the ones they judged to be acceptable to be placed in a blank space in each short conversation. Two examples from the questionnaire translated into English are provided in (53) and (54). The full questionnaire with English gloss and translation is provided in appendix III. In (53), the context is biased toward the status Familiar by criterion 2 (A referent is Familiar if it can be assumed to be known by the hearer through cultural/encyclopedic knowledge or shared personal experience with the

speaker). The information about the addressee's memory and attention state with regard to the gift is given in the explanation that precedes the short conversation. 
(53) Speaker B knows that somebody gave Sonia a gift but she was not thinking about it [the gift] before speaker A mentioned it.
A: Sonia S3ib-ha...........
Sonia please.past.3ms-3fs
"Sonia was pleased by

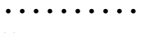

\section{,}
B: Sraf-t-u
bas ji-\$3ib-ha.
know.past.1s-3ms fut 3ms-please-3fs
"I knew it was going to please her."

\author{
1. hak 1-kado haðaka (that gift (literally,that gift that)) \\ 2. kaduha (her gift) \\ 3. ha- 1-kado (this gift) \\ 4. 1-kado mtaiha (her gift) \\ 5. 1-kado haða (this gift) \\ 6. haðaka (that) \\ 7. 1-kado haðaka (that gift) \\ 8. ha-1-kado haða (this gift (literally, this gift this)) \\ 9. 1-kado (the gift) \\ 10. haða (this) \\ 11. hak 1-kado (that gift)
}

In example (54), the context is biased toward the status In Focus by criterion 1 in the coding guidelines (the referent is assumed to be in focus if it is in a syntactically prominent position in the immediately preceding sentence). In this example, the referent, the doctor, occurs in a prominent syntactic position in the immediately preceding sentence. 
(54) Speaker B doesn't know the doctor that speaker A is talking about

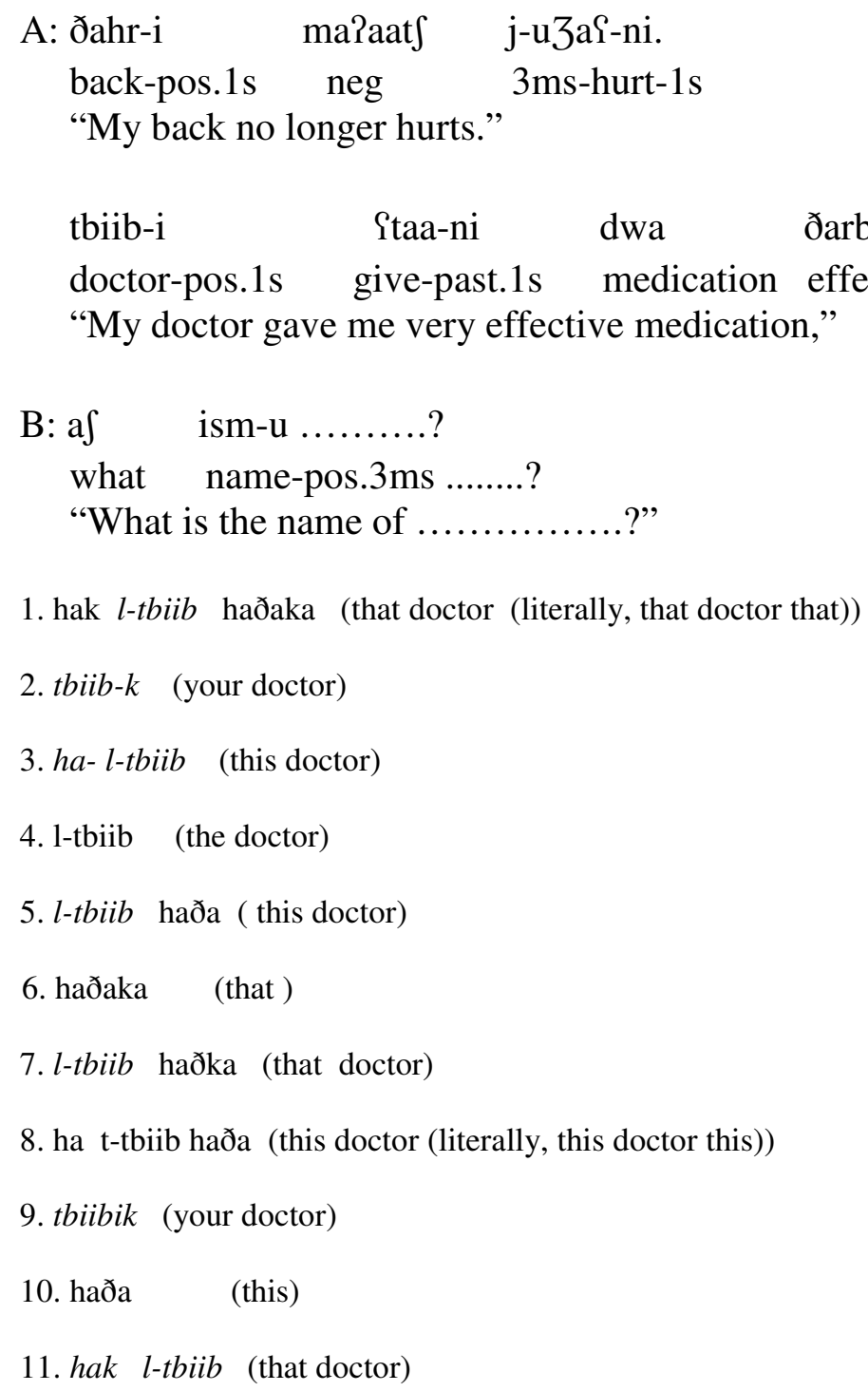

\subsubsection{Method of analysis}

When a form was chosen by participants to be placed in contexts biased toward a particular cognitive status or higher statuses, but not chosen by any participant to be placed in contexts biased toward lower cognitive statuses, that status is determined as the one that is necessary for the appropriate use of that form. For example, if a form is placed in contexts that are biased toward the status Familiar or higher, but not toward the 
statuses Uniquely Identifiable, Referential or Type Identifiable, the cognitive status Familiar was determined as the one that is necessary for the appropriate use of that form.

\subsubsection{Results and discussion}

Table 8 shows results of the questionnaire conducted to test hypothesized correlations between cognitive status and TA demonstrative pronouns and determiners based on the previous study. The table shows the distribution of single as well as double demonstrative forms according to the highest cognitive status they were chosen for in the particular context.

Table 8: Distribution of TA demonstratives according to highest cognitive status in the pilot questionnaire

\begin{tabular}{|l|l|l|l|l|l|l|}
\cline { 2 - 7 } \multicolumn{1}{c|}{} & $\begin{array}{l}\text { Referent } \\
\text { In Focus }\end{array}$ & $\begin{array}{l}\text { Referent } \\
\text { Activated }\end{array}$ & $\begin{array}{l}\text { Referent } \\
\text { Familiar }\end{array}$ & & & \\
\hline ha-N & 20 & 28 & & & & \\
\hline N haða & 12 & 32 & & & & \\
\hline haða & 0 & 4 & 9 & & & \\
\hline haðaka & 1 & 26 & & & & \\
\hline N haðaka & 11 & 16 & 23 & & & \\
\hline hak-N & 8 & 28 & & & & \\
\hline ha-N- haða & 8 & 14 & 5 & & & \\
\hline hak-N- haðaka & 6 & & & & & \\
\hline
\end{tabular}

As mentioned in the previous section, when a form was chosen to be placed in a context biased toward a particular status, and not in contexts biased toward any lower statuses, that status is determined as the one that is necessary and sufficient for the appropriate use of that form. For instance, the prenominal demonstrative determiner hak was determined to require at least Familiar, since as shown in table 8, it was chosen by 
participants to be placed in contexts biased toward the status Familiar and higher, but not in contexts biased toward any one of the lower cognitive statuses.

The distribution of the demonstrative forms according to highest status shows that no demonstrative form was placed in contexts biased toward a status below Familiar, and no demonstrative form was placed in a context biased toward the status In Focus only, indicating that the two minimally required statuses for demonstratives in Tunisian Arabic are Familiar and Activated. Examples based on participants' responses to the pilot questionnaire are given in section 2.3.1.6.

\subsubsection{Results and discussion}

As shown in Table 8, results of the pilot questionnaire confirm that the two demonstrative pronouns haða and haðaka, and the demonstrative determiners ha and haða require the status Activated, as these forms were chosen by participants to be placed in contexts biased toward the status Activated, but none of the participants placed them in contexts biased toward the lower status Familiar. Results also show that the double demonstrative ha-N haða, which was not considered in the previous study, requires the status Activated, as this form was not placed in contexts biased toward statuses Familiar or lower.

\section{$\underline{h a-N}$}

In (55) the phrase ha-l-his (this noise) was chosen by participants to be appropriate to refer to the noise. The referent of the noise can be assumed to be activated, since, as mentioned in the context information, both speaker and addressee could hear it at the time of the utterance. 
(55) Both speaker and addressee can hear a noise.

qallaq-ni ha-1-his
bother.past.3ms-1s prox1-the-noise
"This noise is bothering me"

in (56) where the context is biased toward at most Familiar, however, none of the participants selected the phrase ha-l-kuntaabli (this accountant) to refer to the accountant, confirming that ha minimally requires the status Activated. The accountant here can be assumed to be at most Familiar, since, as mentioned in the context information, the addressee has previous knowledge of the accountant, but he was not thinking about him at the time of the utterance.

(56) The addressee knows the accountant, but he was not thinking about him before the speaker mentioned him (the accountant).

talb-ik \# ha-l-kuntaabli.

call.past.3s prox1-the-accountant.

"This accountant called you."

\section{$\underline{\text { Nhaða }}$}

In 0 , the phrase with, $l$ - $\hbar k a a j a ~ h a ð i$ (this story), was determined to be acceptable to refer to the fact that Leila changes her mind every day, indicating that this form can be used for the status Activated. The referent here can be assumed to be activated, since it refers to a fact that is inferable from the preceding sentence. 
(57) The addressee already knows that Leila changes her mind every day. The speaker knows that the addressee already knows that Leila changes her mind every day.

Leila kul juum t-baddil raj-ha.

Leila every day 3f-change mind-pos.3fs

"Leila changes her mind every day."

w l-haq l-hkaja haði
and the truth the-story prox $2.3 \mathrm{fs}$
"And this fact is really bothering me."

None of the participants, however, chose the phrase l-kado haða (this gift) to be placed in (58) where the context is biased toward the status Familiar. The gift can be assumed to be at most familiar, since both speaker and addressee know that somebody gave Sonia a gift yesterday, but, as mentioned in the context information, the addressee was not thinking about the gift before it was mentioned to her, and it could not therefore have been activated. This supports the hypothesis formulated in the previous study that the determiner haða requires at least Activated.

(58) Speaker B knows that somebody gave Sonia a gift but she was not thinking about it [the gift] before speaker A mentioned it.
A: sonia $\quad$ \#3ib-ha l-kado haða
sonia please.past.3ms-3fs the-gift prox2.3ms
"This gift pleased Sonia"
B: Sraf-t-u bas ji-\{3ib-ha.
know.past-1s-3ms fut 3ms-please-3fs
"I knew it was going to please her"




\section{$\underline{h a-N h a ð a}$}

Participants chose the double demonstrative $h a-N$ haða to be placed in (59) where the context is biased for the status Activated. The referent of the apartment can be assumed to be activated, because it is mentioned in the immediately preceding sentence.

(59) Speaker B knows the apartment that speaker A is talking about, but she was not thinking about it [the apartment] before A mentioned it.

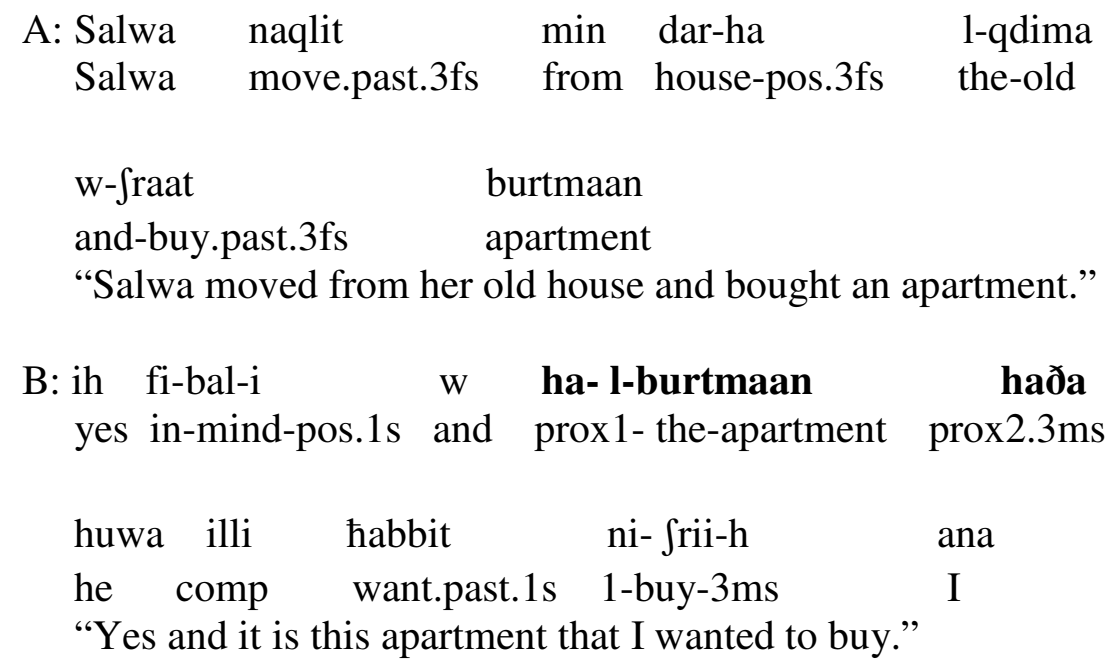

Evidence that the double demonstrative $h a-N$ haða requires the status Activated is that none of the participants chose to place this form in contexts biased toward the cognitive status Familiar or lower. For example, none of the participants chose this form to be placed in (60) where the context is biased toward the status Familiar, since as shown in the context information, the addressee has previous knowledge of the gift but she was not thinking about it at the time the speaker mentioned it. 
(60) B knows that somebody gave Sonia a gift but she was not thinking about it [the gift] before speaker A mentioned it.
A: Sonia S3ib-ha
\#ha l-kado haða
Sonia please.past.3ms-3fs
"This gift pleased Sonia"
B: Sraf-t-u bas ji-\{3ib-ha.
know.past-1s-3ms fut 3ms-please-3fs
"I knew it was going to please her"

\section{$\underline{\text { hak-N }}$}

Distribution of the demonstrative forms in table 8 confirms that the prenominal demonstrative hak requires only the status Familiar, since this form was placed in contexts biased for referents that were at most familiar but not in contexts biased toward any of the lower statuses. Results of the pilot questionnaire also show that the double demonstrative hak $N$ haðaka, which was not considered in the previous study, requires only the status Familiar. In (61) the referent of hak l-kado can be assumed to be familiar, since both speaker and addressee know that somebody gave Sonia a gift yesterday, but when speaker A mentioned the gift, there was no reason to assume the addressee was thinking about it, and therefore it could not have been already activated.

(61) Speaker B knows that somebody gave Sonia a gift but she was not thinking about it [the gift] before speaker A mentioned it.
Sonia please.past.3ms-3fs nonprox1 the- gift
"That gift pleased Sonia"
A: Sonia $\quad$ 93ib-ha hak 1-kado
B: Sraf-t-u bas ji-ৎZib-ha.
know.past-1s-3ms fut 3ms-please-3fs
"I knew it was going to please her"


None of the participants, however, chose the demonstrative hak to be placed in (62) where the context is biased toward at most uniquely identifiable, confirming results of the previous study that hak requires familiarity and hence its choice in contexts where it is used for at most Uniquely Identifiable would be unacceptable. In (62), the speaker is asking the addressee about a house that she (the speaker) has never seen before. The addressee answers the question by giving information about the house and also about a kitchen in the new house. The referent of the kitchen can be assumed to be uniquely identifiable, having acquired this status via bridging to the DP l-daar 1-3diida (the new house) which is already activated. The speaker cannot assume that the addressee has a previous representation of the kitchen in memory and therefore, she is not justified to assume that it is familiar.
A: baahja 1-daar 1-3diida?
good the-house the-new
"Is the new house a good one?"
B: ih ama l-ku 3ina/ \#hak l-ku3ina zyiira yes but the-kitchen/nonprox 1 the-kitchen small "Yes, but the kitchen is small"

\section{$\underline{\text { hak N haðaka }}$}

Participants chose the double demonstrative hak N haðaka to be placed in (63) where the context is biased toward the status Familiar. This shows that this form can be used to refer to familiar entities. 
(63) The addressee knows the accountant, but he was not thinking about him before the speaker mentioned him (the accountant).

\begin{tabular}{|c|c|c|c|}
\hline $\begin{array}{l}\text { talb-ik } \\
\text { call.past.3s }\end{array}$ & $\begin{array}{l}\text { hak } \\
\text { nonprox1 }\end{array}$ & $\begin{array}{l}\text { l-kuntaabli } \\
\text { the-accountant. }\end{array}$ & $\begin{array}{l}\text { haðaka } \\
\text { nonprox } 2.3 \mathrm{~ms}\end{array}$ \\
\hline
\end{tabular}

Evidence that the double demonstrative hak $N$ haðaka requires Familiar is that none of the participants determined it to be acceptable to be placed in (64) where the context is biased toward the status Uniquely Identifiable. In (64), the speaker knows that the hearer has no previous knowledge of the grocer and is not therefore expecting him to retrieve a representation from memory. The only expectation the speaker can have is that the addressee can construct an individuated representation of the referent based on the phrase 1-Sattaar lli bi-Znab-na (the grocer next door).

(64) Speaker A and speaker B are sitting in their office at work talking. Speaker A doesn't know the grocer that speaker B is talking about.

A: tu-ftur fi l-daar 1-sbaah?

2s-eat in the-house the-morning?

"Do you eat at home in the morning?"

B: ma nu-ftur- $\int$ 1-sbaah fi-l-daar. kul juum ni-tiadda neg 1-eat-neg the-morning in-the-house every day 1-pass

l-\# hak l-9attaar lli bi-3nab-na haðaka

to-nonprox 1 the-grocer comp in-side-pos.1p nonprox $2.3 \mathrm{~ms}$

ni-Sri kaskruut

buy sandwich

"I don't eat at home in the morning. I stop everyday by that grocer next door and buy a sandwich." 
The choices made by the participants who filled in the pilot questionnaire confirm results of the previous study about single demonstratives. Based on personal intuition, and observations of interactions of native speakers, I suspect that the demonstrative determiner haðaka requires the status Familiar and not the higher status Activated as was indicated by results of the previous study and the pilot questionnaire conducted in the current study.

As mentioned in section 2.3, one goal of the current study is to extend the analysis to double demonstratives which were not included in the previous study. Results of the pilot questionnaire suggest that while $h a N$ haða requires the same cognitive status, Activated, as the two single demonstratives that form it, hak $N$ haðaka requires the same status, Familiar, as the prenominal hak but not as the postnominal haðaka which requires at least Activated ${ }^{18}$. Form status correlations according to the pilot questionnaire results are given in table 9.

\footnotetext{
${ }^{18}$ Results of the revised questionnaire and corpus study however, indicated, that hak N haðaka also requires the same cognitive status as the two single demonstratives that form it.
} 
Table 9: Form-Status correlations according to results of the pilot questionnaire ${ }^{19}$

\begin{tabular}{|l|l|l|l|l|l|}
\hline $\begin{array}{l}\text { In } \\
\text { Focus }\end{array}$ & Activated & Familiar & $\begin{array}{l}\text { Uniquely } \\
\text { Identifiable }\end{array}$ & Referential & $\begin{array}{l}\text { Type } \\
\text { Identifiable }\end{array}$ \\
\hline & ha-N & hak $N$ & & \\
haða & hak N haðaka & & & \\
haðaka & & & & \\
$N$ haðaka & & & & \\
ha-N haða & & & & \\
\hline
\end{tabular}

\subsubsection{Revised Questionnaire}

In this section, I will explain how the pilot questionnaire was revised in terms of content, number of questions, and number of participants, and give reasons for those revisions. The full revised questionnaire with English gloss and translation is provided in appendix IV.

\subsubsection{Materials}

The questions given in the pilot questionnaire are maintained in the revised questionnaire. The written instructions, the context information that precede the sentences or short conversations as well as the sentences and short conversations, however, were improved based on written comments made by three participants who filled in the pilot questionnaire, and on suggestions made by Jeanette Gundel. An example of how the context that precedes short conversations was improved is given in (65). The context

\footnotetext{
${ }^{19}$ The forms marked in boldface were not considered in the previous study (Khalfaoui 2004).
} 
explanation provided in (65) from the pilot questionnaire explicitly states that the addressee has no previous knowledge of the referent, but it does not explicitly eliminate the possibility that the referent is in the immediate spatio-temporal context.

(65) B doesn't know the grocer that A is talking about. A knows that B doesn't know the grocer.

A: tu-ftur fi 1-daar 1-sbaah?

2-eat.2s in the-house the-morning

"Do you eat at home in the morning?"

B: ma nu-ftur- $\int \quad$ l-sbaah fi-l-dar.

neg 1-eat-neg the-morning in-the-house.

"I don't eat at home in the morning."

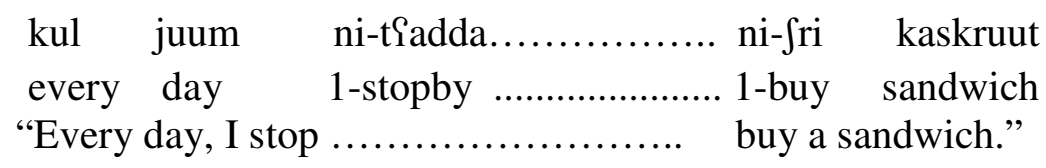

Information about presence in the extralinguistic context is very crucial, because if participants in the questionnaire assume that the speech participants can see the grocer at the time the conversation was taking place, they may assume that the referent is activated by being in the immediate spatio-temporal context, and therefore choose a form that requires at least Activated ${ }^{20}$. As shown in (66), it was indicated in the biasing context in the example from the revised questionnaire that both speaker A and speaker B are sitting in their office at work. This additional information eliminates the possibility of assuming that the referent, the grocer, is in the immediate spatio-temporal context.

\footnotetext{
${ }^{20}$ It was verbally clarified to participants in the pilot questionnaire that the grocer was not in the immediate spatio-temporal context.
} 
(66) A and B are sitting in their office at work talking. A does not know the grocer that $\mathrm{B}$ is talking about
A: tu-ftur fi 1-daar 1-sbaah?
2-eat.2s in the-house the-morning
"Do you have breakfast at home in the morning?"
B: ma nu-ftur- $\int$ 1-sbaah fi-l-daar.
neg 1-eat-neg the-morning in-the-house.
"I don't have breakfast at home in the morning."
kul juum ni-tiadda...................... ni-fri kaskruut
every day 1-stopby ..................... 1-buy sandwich "Every day I stop ................... I buy a sandwich."

In addition to making improvements to the questions of the pilot questionnaire, three more questions were added, thus increasing the number of questions from 11 to 14 . One of the added questions was biased toward the status In Focus, and two questions toward the status Activated. The cognitive status biasing criteria used in the added questions in the revised questionnaire were not used in the pilot questionnaire. For example, the context in (67) is biased toward the status Activated, using the criterion (It is something in the immediate spatio-temporal context that is activated by means of a simultaneous gesture or eye gaze). This criterion was not used when biasing for the cognitive status Activated in the pilot questionnaire. 
(67) The speaker is standing in front a watermelon merchant. He pointed to one watermelon and said:

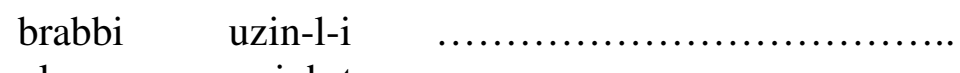

please weigh-to-me

"Could you please weigh .................. for me."

1. hak 1-dillaSa haði ka (that watermelon (literally, that watermelon that))

2. 1-dillaia ( the watermelon)

3. ha-1-dillaia (this watermelon)

4. dillaiti (my watermelon)

5. 1-dillafa haði ( this watermelon)

6. haðika (that)

7. 1-dillaia haðika (that watermelon)

8. ha 1-dillaia haði (this watermelon)

9. dillaia (watermelon)

10. hak 1-dillaia (that watermelon)

11. haði (this )

\subsubsection{Participants}

The number of participants in the revised questionnaire was increased from 13 to 20 .

Of the 20 participants, nine participants are the same as in the revised questionnaire, and 11 are new participants. The 20 participants who filled in the revised questionnaire consist of 10 females and 10 males. One major reason for increasing the number of participants is that based on my personal intuition and my observations of TA native speakers' interactions, I suspect that the demonstrative determiner haðaka might require the status Familiar and not the status Activated. It is possible that the reason participants 
did not choose this form to refer to familiar entities is that although this form might require the status familiar, it is used more frequently to refer to activated and in-focus entities. Since the pilot questionnaire did not confirm my suspicion, the number of participants was increased in order to increase the chance for this demonstrative form to be used.

\subsubsection{Procedure and method of analysis}

The same procedure and method of analysis used in the pilot questionnaire was used in the revised questionnaire.

\subsubsection{Results}

Table 10: Distribution of TA demonstratives according to highest cognitive status in the revised questionnaire

\begin{tabular}{|l|l|l|l|l|l|l|}
\cline { 2 - 7 } \multicolumn{1}{c|}{} & In Focus & Activated & Familiar & $\begin{array}{l}\text { Uniquely } \\
\text { Identifiable }\end{array}$ & Referential & $\begin{array}{l}\text { Type } \\
\text { Identifiable }\end{array}$ \\
\hline ha-N & 40 & 68 & & & & \\
\hline haða & 1 & 15 & & & & \\
\hline Nhaða & 33 & 74 & & & & \\
\hline hak $N$ & 20 & 36 & 36 & & & \\
\hline haðaka & 4 & 19 & & & & \\
\hline N haðaka hI $_{\text {ha-N haða }}^{21}$ & 20 & 47 & $\mathbf{1 7}$ & & & \\
\hline hak Nhaðaka & 29 & 51 & & & & \\
\hline & 17 & 41 & 11 & & & \\
\hline
\end{tabular}

Table 10 shows the results of the revised questionnaire. The table shows the distribution of the single as well as the double demonstrative forms according to the highest cognitive status for which they were chosen. The revised questionnaire confirmed results of the

\footnotetext{
${ }^{21}$ This form is marked in boldface, because the result is different from the pilot questionnaire.
} 
pilot study about the demonstrative pronouns haða and haðakaka; The double demonstrative determiners ha-N haða and hak $N$ haðaka as well as the demonstrative determiners $h a$, hak and haða, but not the postnominal determiner haðaka. While in the pilot questionnaire, none of the participants chose the determiner haðaka to be placed in contexts biased toward statuses lower than Activated, Table 10 shows that 17 tokens of haðaka were placed in contexts biased toward the status Familiar, indicating that the status Familiar and not Activated is sufficient for the use of this form. I suggested in 2.3.1.5 that the reason participants did not choose the demonstrative determiner haðaka to be placed in contexts lower than Activated is that although this form requires the cognitive status Familiar, it is used more frequently for the higher statuses Activated and In Focus. Increasing the number of participants in the revised questionnaire increased the chance of this form to be used. As shown in Table 10 and in examples (68) and (69), the demonstrative determiner haðaka was placed in both contexts biased toward the status Familiar in the revised questionnaire.

(68) Speaker A knows the gift but she was not thinking about it [the gift] before speaker B mentioned it.

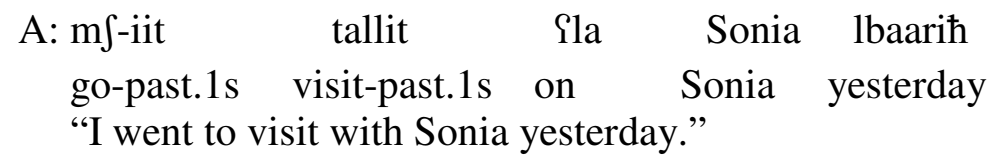

B: brabbi G3ib-ha l-kado haðaka please please.past.3ms-3fs the-gift nonprox $2.3 \mathrm{~ms}$ "Did she like that gift?" 
(69) Both A and B know the accountant but speaker A was not thinking about him (the accountant) before B mentioned him.
A: ma tlab-ni had?
neg call.past.3ms-1s someone"
"Did anyone call me?"
B: talb-ik
l-kuntaabli haðaka
call.past.3ms-2s the-accountant nonprox $2.3 \mathrm{~ms}$
"That accountant called you"

Results achieved in the revised questionnaire about the demonstrative haðaka confirm my suspicion that this form requires the lower cognitive status Familiar and not Activated as was indicated by results of the previous study and the pilot questionnaire discussed in this chapter.

Distribution of the two demonstratives hak and haðaka also supports my suspicion that although both demonstrative forms require at least Familiar, the demonstrative hak is used more frequently than haðaka to refer to at most Familiar entities. Although both hak and haðaka require at least Familiar, the number of tokens of the demonstrative hak chosen by participants is much higher than the number of tokens chosen for haðaka. As shown in table 10, 36 tokens of hak and only 17 tokens of haðaka were chosen to refer to familiar entities.

The finding that the determiner haðaka requires at least Familiar and not the higher cognitive status Activated is also important with respect to the double demonstrative hak $N$ haðaka. We can make the conclusion that this double demonstrative encodes the same cognitive status, Familiar, as the single demonstratives that form it.

We can therefore make the general conclusion that in terms of cognitive status, double demonstratives in Tunisian Arabic can only be formed from single demonstrative forms 
that require the same cognitive status, and that double demonstratives require the same cognitive status as the single demonstratives that form them.

Table 11: Form-status correlations according to results of the revised questionnaire

\begin{tabular}{|c|c|c|c|c|c|}
\hline In Focus & Activated & Familiar & $\begin{array}{l}\text { Uniquely } \\
\text { Identifiable }\end{array}$ & Referential & $\begin{array}{l}\text { Type } \\
\text { Identifiable }\end{array}$ \\
\hline & $\begin{array}{l}\text { ha-N } \\
N \text { haða } \\
\text { haða } \\
\text { haðaka } \\
\text { ha-N haða }\end{array}$ & $\begin{array}{l}\text { hakN } \\
\text { hak N haðaka } \\
\text { N haðaka } \\
\text { ha }\end{array}$ & & & \\
\hline
\end{tabular}

\subsubsection{Summary and results achieved in both questionnaires}

As shown in table 11, all TA demonstratives require at least the status Familiar (i.e., in memory). A similar characteristic is found in studies of other languages. For example, Gundel et al. (1993) conducted a crosslinguistic study where they proposed correlations between the different statuses on the Givenness Hierarchy and various pronouns and

\footnotetext{
${ }^{22}$ This demonstrative form is marked in boldface, because the result is different from that of the pilot questionnaire.
} 
determiners in Mandarin Chinese, English, Japanese, Russian, and Spanish. They found that except for Chinese, where the distal demonstrative determiner nèi only requires the status Uniquely Identifiable, all demonstrative forms in these languages require the status Familiar or higher ${ }^{23}$. Ariel (1988) also argues that demonstrative phrases are mid accessibility markers which refer to less accessible information than personal pronouns, and to higher accessible information than full definite DPs without a demonstrative determiner. She found in her empirical study that demonstratives refer to something previously mentioned in the text or present in the physical surroundings. Botley and McEnery (2001) conducted a corpus study of English demonstratives and found that they have an accessibility status intermediate between that of pronouns and definite article DPs.

Other referring expressions that were used in the filler phrases, however, were chosen by participants to be placed in contexts biased toward statuses lower than Familiar. For instance, none of the participants chose a demonstrative form to be placed in (70) where the context is biased toward the context Uniquely Identifiable. Participants, however, chose the definite article $l$ - to be placed in (70). In this example, the kitchen is not in memory, but the addressee can construct a unique representation of the kitchen by way of a bridging inference to the house, which is activated. A demonstrative would not be acceptable, since the speaker cannot expect the addressee to have a representation of the kitchen in memory.

\footnotetext{
${ }^{23}$ Gundel et al. noted that "the fact that the highest number of demonstrative determiners was found in the Chinese data would appear to support observations that the demonstrative determiner is beginning to function like a definite article in Chinese" (300).
} 
(70) Speaker B bought a house and speaker A is asking her about it, because she has not seen it yet.
A: bahija 1-daar 1-3dida?
good the-house the-new?
"Is the new house nice?"

\begin{tabular}{|c|c|c|}
\hline B: ih & $\begin{array}{l}\text { ama } \\
\text { but }\end{array}$ & $\begin{array}{l}\text { l-ku3ina } \\
\text { the-kitchen }\end{array}$ \\
\hline
\end{tabular}

Similarly, none of the participants chose a demonstrative to be placed in (71) where the context is biased toward the status Referential. In (71) the speaker is expecting the addressee to construct a representation of the referent (the book she saw in the library) by the time she finishes processing the sentence. Participants, however, chose the bare noun karhba (car) to be placed in (71).

(71) Speaker A is not talking about a particular car.

$\begin{array}{lllll}\text { A: smai-t } & \text { illi } & \text { Leila t-hib } & \text { ti-fri } & \text { karhba } \\ \text { hear.past-1s comp Leila } & \text { 3s-want } & \text { 3fs-buy } & \text { car } \\ \text { "I heard that Leila wants to buy a car." } & & & \end{array}$

Results of the pilot and the revised questionnaires given in table 8 and table 10 , respectively also indicate that except for the proximate demonstrative pronoun haða, all forms were also chosen to be placed in contexts higher than the required ones. This is expected, since every status on the GH entails all lower statuses. For example, in (72), the double demonstrative ha-N haða, which requires at least activated, was judged to be acceptable in a context biased for the higher status In Focus. The referent of the phrase 
ha-l-mra haði (this woman) can be assumed to be in focus, since it was mentioned in a syntactically prominent position in the immediately preceding sentence.

(72) The addressee knows the neighbor that the speaker is talking about.

A: Zarti hija illi Sawnit-ni Sla tanðif 1-daar. neighbor-pos.1s she comp help.past.3fs-1s on cleaning the- house "It is my neighbor who helped me clean the house."

1-ћaq nas mlaah $\quad \begin{aligned} & \text { ha-l-mra } \\ & \text { the truth nice }\end{aligned}$ prox 1-the-woman prox2.3fs
"This woman is really nice" (literally, this woman this is really nice).

\subsubsection{Significance of the choices made by participants in the pilot and the revised questionnaires: other factors that further restrict the use of demonstrative forms}

Since one of the goals of this dissertation is to look at factors other than cognitive status that further restrict the choice among demonstrative forms, breaking down results of the questionnaires given in tables 8 and 10 by context shows that even when certain forms meet the cognitive status criteria for appropriate use in certain contexts, none of the participants placed them in those contexts, indicating that there are other factors that further restrict the choice of those forms. For example, participants placed the demonstrative $h a ð a$ as a determiner in (73), but none of the participants placed $h a ð a$ as a pronoun in this context, even though both forms require at least Activated, and are therefore expected to be interchangeable in this context. In this example, the noise in can be assumed to be activated, because both the speaker and the addressee can hear it at the time of the utterance. 
(73) both speaker and addressee can hear a noise.

qallaq-ni l-his haða /\# haða

bother.past.3ms-1s the-noise prox $2.3 \mathrm{~ms} /$ prox $2.3 \mathrm{~ms}$

"This noise/\#this is bothering me"

Participants, however, chose haða both as a pronoun and as determiner to be placed

in other contexts biased for the status Activated. Chapter 4 will look at factors that render the choice of haða as a determiner but not as pronoun possible in contexts where both forms satisfy the same cognitive status criteria. An explanation within the framework of Relevance Theory (Sperber \& Wilson 1986/1995) for why speakers avoid the demonstrative pronoun haða when those factors are present will also be given.

Results of the questionnaire studies also revealed that in certain contexts, participants chose the demonstrative determiners haða and haðaka and in other contexts they chose only haða, even though both forms satisfy cognitive status criteria for use when the referent is activated or in focus. For example, participants chose the demonstrative determiner haða but not haðaka in (74) where the context is biased toward the status In Focus, even though both forms satisfy the criteria for use when the referent is in focus. 
(74) B doesn't know the doctor that $\mathrm{A}$ is talking about
A: ðahr-i maiat $\quad$ ju-Zai-ni. back-pos.1s neg 3m-hurt-1s
"My back does not hurt anymore."
tbiib-i Sta-ni dwa ðarba ðarba doctor-pos.1s give-past.3ms-1s medication effective effective "My doctor gave me very effective medication."
B: as ism-u l-tbiib haða/\# l-tbiib haðaka what name-pos.ms the-doctor prox $2.3 \mathrm{~ms} /$ the-doctor nonprox $2.3 \mathrm{~ms}$ "What is the name of this doctor/ \# that doctor?"

A brief analysis of the factors which restrict the choice of the demonstrative haðaka will be given in the future research section in chapter 5 , and a possible explanation in terms of the importance of interlocutors' previous knowledge of the referent prior to the current conversation will be explored. It is possible that even if haðaka satisfies cognitive status criteria, speech participants must have shared knowledge of the referent prior to the current conversation.

\subsection{Advantages of the questionnaire as a research tool}

One advantage of using the questionnaire as a research tool to determine form-status correlations is that it is a controlled environment which allows for all demonstrative forms to be tested against all cognitive statuses. This advantage avoids the possibility of associating a form with a higher status than the one it requires, a result that might occur when relying only on corpus data if all the tokens of a particular form in the data corpus happen to be used for higher cognitive statuses than the one it minimally requires. The questionnaire also allows for determining cognitive status for forms that occur infrequently in a data corpus. 
Another advantage of the questionnaire is that since participants are asked to determine whether the different forms are acceptable in the different contexts, their choices reveal other factors that further restrict the use of the different forms. As will be shown in chapters four and five, even though certain forms meet cognitive status criteria for being used in certain contexts, participants decided they were not acceptable in those contexts, indicating that there are further factors that determine the choice among demonstrative forms.

\subsection{Limitations of the questionnaire as a research tool: Why do we still need a corpus study?}

One limitation of the questionnaire as a research tool is that it was not possible to use cognitive status criteria that require a large amount of text. Specifically, it was not possible when designing the questionnaire to bias for the status Familiar using the criterion which requires a referent to be mentioned anywhere previously in the discourse, but not recently enough to be activated. Such data was available, however, in the corpus study. For example, in (75), from a folk story, the referent of the phrase hak l-miskiin (that poor man) was determined to be familiar, because its referent, the man to whom the narrator is referring, was mentioned earlier in the story.

(75) $\mathrm{w} \quad$ ra3i-u
and return-past.3p to-nak
"and they returned to that poor man,"
xar3-uu-h $\quad$ min l-habsiin
release-past.3p-3ms from the-jail
"and released him from jail"

(hikayaat Al-Irwi: 12) 
Another shortcoming of constructed short pieces of text is that they do not reflect the influence of discourse type on the distribution of demonstrative forms which satisfy criteria for use for the same cognitive status, a finding that has been supported by other studies on demonstratives (e.g., OH 2001, Mulkern 2003). In order to compensate for the shortcomings of the questionnaire, a corpus study was conducted to complement the questionnaires. The corpus study is discussed in chapter 3 .

Using different research techniques in order to support the same conclusion is referred to as converging evidence (Stanovich 2004). Stanovich points out "When evidence from a wide range of experiments, each flawed in somewhat different way, or carried out with techniques of differing strengths and weaknesses, points in a similar direction, then the evidence has converged" (119). 


\section{Chapter 3: Corpus study ${ }^{24}$}

\subsection{Introduction}

A corpus analysis was conducted to complement the questionnaires discussed in chapter 2. The goal of the corpus study is to see if the distribution of the TA demonstrative forms according to highest cognitive status they are used for in naturally occurring data supports the results achieved in the constructed data of the questionnaire studies. The corpus study also made it possible to determine cognitive-status correlations using certain cognitive status criteria that were not possible to use in the short text and fragments in the questionnaire. Another important goal of the corpus study as a different research tool is to see if it reveals other factors that further influence the choice among demonstrative forms which satisfy criteria for use for the same cognitive status. Specifically, this study aims to see whether discourse type in Tunisian Arabic influences the choice among demonstrative forms as indicated in other studies of other languges (e.g., OH 2001, Mulkern 2003).

\subsection{Criteria for data selection}

A conscious effort was made to include text from different genres to avoid genre-specific influence on the results. As mentioned in section 1.5.2, demonstratives used in different regional dialects in Tunisia vary primarily at the phonological level. For consistency, all the data selected for this study consist of the same demonstrative forms used in the questionnaires and described in section 1.5.2 in terms of syntactic distribution and phonological form. Finally, the data includes both written and spoken discourse, as well

\footnotetext{
${ }^{24}$ An earlier version of this chapter was presented at the North American Conference on Afroasiatic Linguistics 36 (NACAL 36), Chicago, Illinois, March 14-16, 2006.
} 
as planned and spontaneous discourse. The data corpus used in this dissertation consists of a folk story entitled l-fitaan w l-ћaddad (The Devil and the Blacksmith) written down from memory by a TA native speaker in his late thirties; a recorded radio drama entitled maal wa hwaal (Money and Situations) about a woman who is trying to convince her two nieces to prevent their father from marrying his fiancée; two episodes of the American soap opera Days of our Lives retold in Tunisian Arabic from memory by a male TA native speaker in his late thirties, and recorded; Volume I and Volume IV from the published folk tales Hikaajaat Al-Irwi (The Tales of Al-Irwi) (Al-Irwi, vol.1 \& vol.4, 1989) ; two articles from an out-of-print newspaper Al-Sariih; texts from a published translation of the book The Little Prince (Balegh 1997); a recorded spontaneous conversation between two male native speakers of Tunisian Arabic in their twenties, discussing three possible blue prints for a house that is being built; a published play Junuun (Insanity) (Baccar 2001) where the story revolves around the daily life of the main character, a young male who has schizophrenia, his struggle with the disease, and his daily interactions with his psychiatrist and his immediate family members; and a published play script entitled Masrah Ali Al-Douaji (Baccar 2002). The recorded radio drama maal wa Æwaal (Money and Situations) and the play script Junuun (Insanity) were used in the previous study discussed in chapter 2. A total of 167 tokens of all the TA demonstrative forms were identified in this data corpus. The distribution of the tokens of each demonstrative form identified in the data corpus used in the corpus study is given in table 12. 
Table 12: Distribution of TA demonstratives in the data corpus

\begin{tabular}{|l|c|}
\hline $\begin{array}{l}\text { Demonstrative } \\
\text { from }\end{array}$ & Number of tokens \\
\hline ha-N & 39 \\
\hline haða & 10 \\
\hline N haða & 43 \\
\hline hak N & 25 \\
\hline haðaka & 19 \\
\hline N haðaka & 5 \\
\hline ha-N haða & 8 \\
\hline hak N haðaka & \\
\hline
\end{tabular}

\subsection{Method of analysis}

Written and recorded data were transcribed using the unified IPA code Doulos SIL, glossed word-by-word, and translated into English. In coding for cognitive status, three steps were followed. First, every phrase with a demonstrative form was identified. Second, the referent of every phrase was identified. Third, the highest cognitive status of the referent of each phrase with a demonstrative form was determined. Coding was done by the primary investigator, a native speaker of Tunisian Arabic. Two other trained coders who do not know Tunisian Arabic were consulted on coding decisions ${ }^{25}$. In determining the highest cognitive status of a referent, the same coding guidelines ${ }^{26}$ used

\footnotetext{
${ }^{25}$ The secondary coders are Jeanette Gundel and Linda Humnick.

${ }^{26}$ As noted earlier, the coding guidelines are provided in appendix I.
} 
for the questionnaire studies were used. For example, in (76) from a recorded retelling of an American soap opera, the referent of the demonstrative pronoun haðika satisfies criterion 1 in the coding guidelines for the In Focus status (The referent is mentioned in a syntactically prominent position). It is the subject of the main clause of the preceding sentence.

$\begin{array}{llllll}\text { dima ti-flim bi-ha } & \text { hija } & \text { l-blasa } \quad \text { w hija } & \text { zXira } \\ \text { always } & \text { 3fs-dream with-fs } & \text { she } & \text { the-place when she } & \text { little } \\ \text { "She always saw the place in her dreams when she was little." }\end{array}$

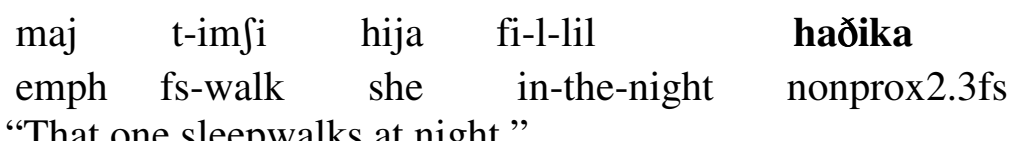

"That one sleepwalks at night."

(Soap Opera)

In (77), however, the phrase with the double demonstrative haka l-spanisilli $\hbar k i t-l i-k$ Sli-

$h$ haðaka (that Hispanic man I talked to you about) does not meet the criteria for In Focus or Activated. It does, however, meet criterion 1 for the status Familiar (the referent was mentioned at any time previously in the discourse). The Hispanic man to whom the speaker is referring is previously known by both speaker and addressee, but has not been recently mentioned, and therefore cannot be assumed by the speaker to be activated. 
(77)

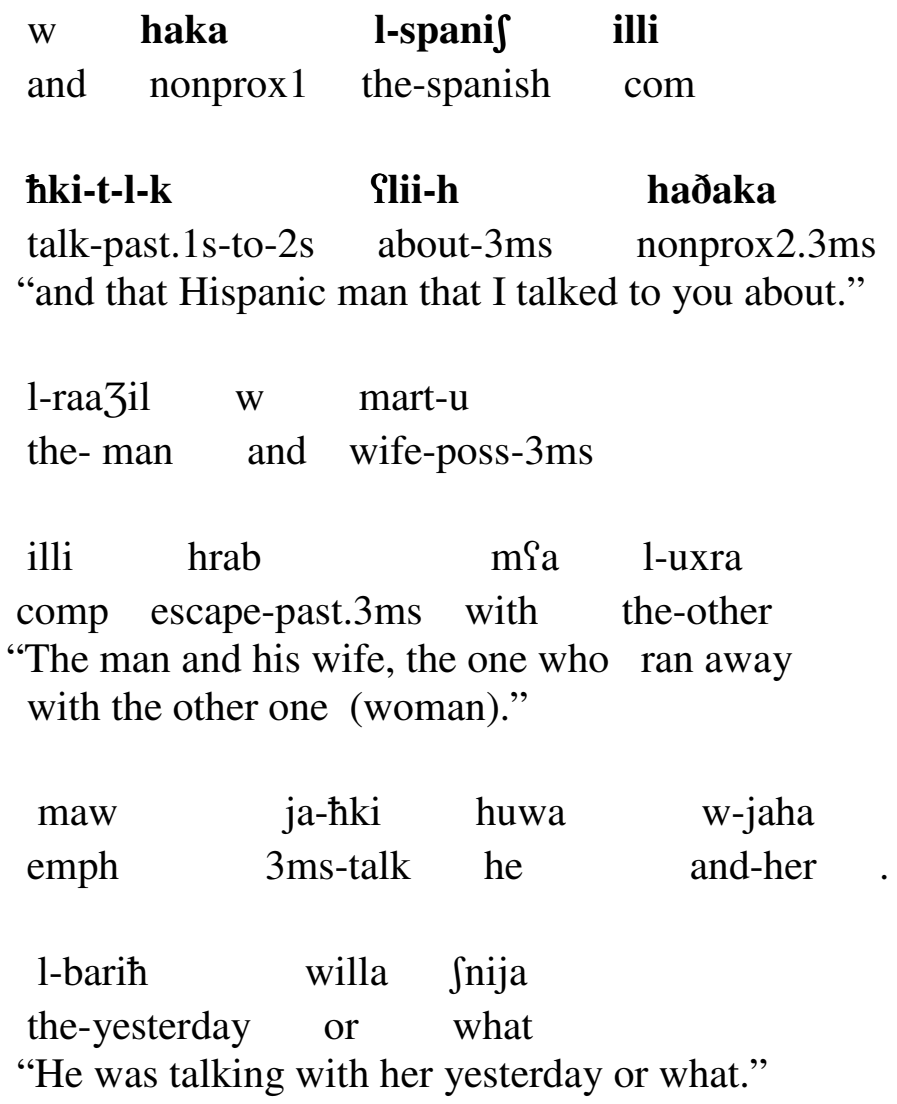

(Soap Opera)

As will be shown in the examples discussed in this section, results of the corpus study will show that a form can be used for the status it minimally requires but also for higher statuses. Further evidence that a form requires a particular cognitive status will be indicated by showing its unacceptability to refer to entities that have a lower cognitive status than the one it minimally requires. In making these acceptability judgments, I mostly relied on my own intuition and the intuition of two other native speakers of Tunisian Arabic. 


\subsection{Results and discussion of the corpus study}

Table 13: Distribution of TA demonstratives according to highest cognitive status in the data corpus

\begin{tabular}{|c|c|c|c|c|c|c|}
\hline & $\begin{array}{c}\text { In } \\
\text { Focus }\end{array}$ & Activated & Familiar & $\begin{array}{c}\text { Uniquely } \\
\text { Identifiable }\end{array}$ & Referential & $\begin{array}{c}\text { Type } \\
\text { Identifiable }\end{array}$ \\
\hline ha- $N$ & 2 & 15 & & & & \\
\hline haða & 16 & 23 & & & & \\
\hline N haða & 1 & 9 & & & & \\
\hline hak N & 6 & 5 & 32 & & & \\
\hline haðaka & 17 & 8 & & & & \\
\hline N haðaka & 8 & 3 & 8 & & & \\
\hline ha-N haða & & 5 & & & & \\
\hline hak N haðaka & 1 & 3 & 4 & & & \\
\hline
\end{tabular}

Table 13 shows the distribution of TA demonstrative forms in the data corpus according to the highest cognitive status they are used for. As shown in the table, these results strongly confirm results of the pilot questionnaire with respect to all demonstrative forms except the demonstrative determiner haðaka which was determined to require at least Activated in that study, and confirms results of the revised questionnaire with respect to all demonstrative forms. The table also shows that all the TA demonstrative forms examined in the corpus analysis were used for cognitive statuses they were determined to minimally require in the questionnaire study, or for higher statuses, but not for lower cognitive statuses. 
Table 13 shows that the demonstrative determiners ha-, haða and the double demonstrative $h a-N$ haða as well as the demonstrative pronouns haða and haðaka were used to refer to entities that are at least activated, but not to entities with cognitive statuses lower than Activated, confirming results of the questionnaire studies that these demonstratives require at least Activated. The Examples given in this section support the conclusion that these forms can be used to refer to entities that are activated, but not to entities that have a cognitive status lower than Activated.

\section{$\underline{\text { Nhaða }}$}

Example (78) shows that the demonstrative determiner haða can be used to refer to activated entities. In (78), the speaker is asking the addressee about a closet on the blue print they are discussing. The referent of the phrase l-plakaar aðaja (this closet) is activated by a simultaneous gesture made by the speaker pointing to the blue print they are both looking at.

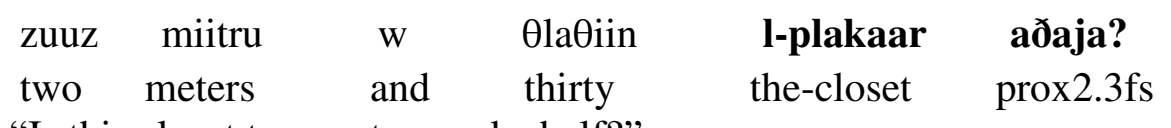
"Is this closet two meters and a half?"

(Blue Print)

Evidence that the determiner haða minimally requires the status Activated is that it cannot be used to refer to at most familiar entities. For example, in (79), the demonstrative determiner haða cannot replace the demonstrative haðaka, which requires at most Familiar, to refer to the second blue print, since the blue print cannot be assumed to be activated. In (79), both the speaker and the addressee know the second blue print, 
but the blue print has not been recently mentioned, and is not in front of them. The addressee cannot therefore expect it to be activated in the mind of the addressee.

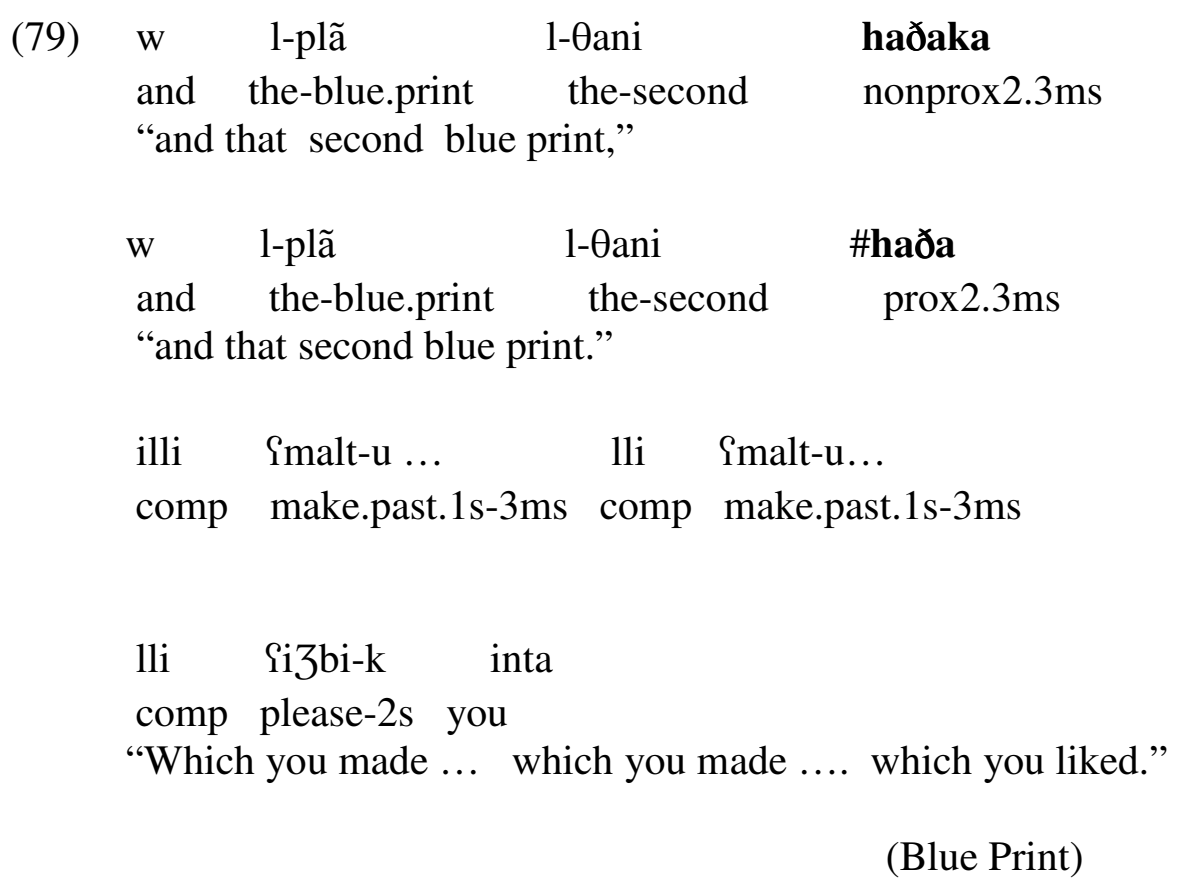

$\underline{h a-N}$

Example (80) from a radio play shows that the demonstrative determiner ha can be used to refer to activated entities that are activated. Speaker B uses the phrase ha-l-klaam (these words) to refer to the utterance just made by speaker A. 
(80)

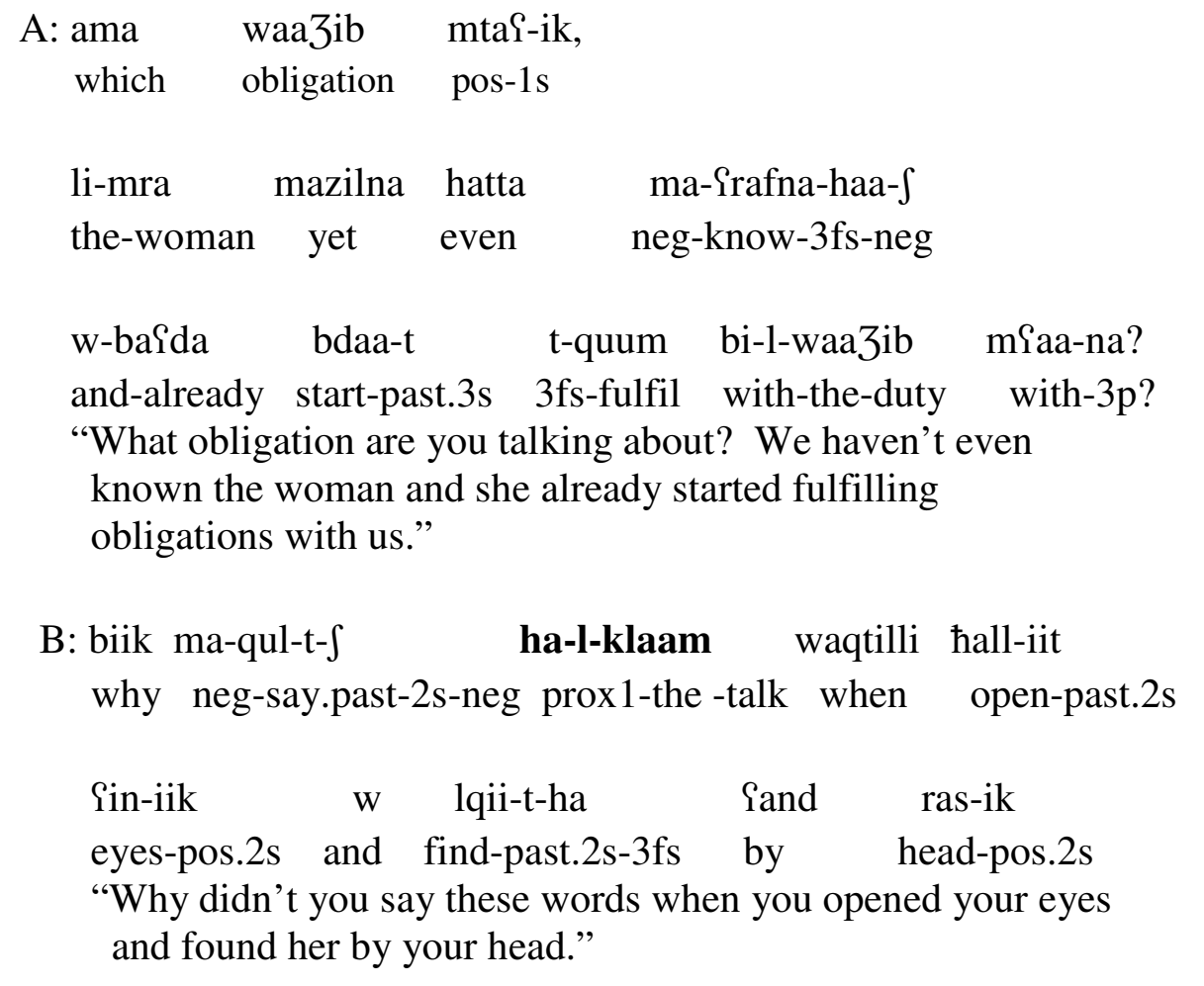

(maal waћwaal (Money and Situations))

Example (81) from the same radio play shows that the demonstrative ha cannot replace hak, which requires only Familiar. The referent of the phrase hak l-Æufra (that small room) was determined to be Familiar, because the addressee has previous knowledge of the room the speaker is referring to, but there is no reason to believe it is already familiar. This supports the hypothesis formulated in the questionnaires that the demonstrative form $h a$ requires at least Activated. 
(81)

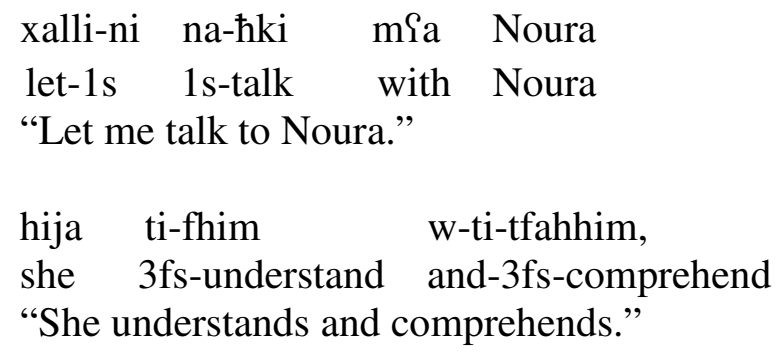




\section{$\underline{h a-N ~ h a ð a}$}

As shown in (82), the double demonstrative $h a-N$ haða can refer to

activated entities. The speaker uses the phrase ha-l-mћal haða (this store) to refer

to the location where he and the speaker are exchanging a conversation. The location is activated by being in the immediate spatio-temporal context.

$$
\begin{array}{llrrrr}
\begin{array}{l}
\text { qaal-1-u } \\
\text { tell.past.3ms }
\end{array} & \text { ja } & \text { soc } & \text { sidi } & \text { ana } & \text { saariq. } \\
\text { thief } & \\
\text { ama tawwa } & \text { fi } & \text { ha-l-mhal } & \text { haða } & \text { tub-t } \\
\text { but now } & \text { in } & \text { prox1-the-place } & \text { prox } 2.3 \mathrm{~ms} & \text { repent-past.1s }
\end{array}
$$

ama tawwa fi ha-l-mhal haða tub-t

"Sir, I am a thief, but now in this place I repented."

(Hikajaat Al-Irwi (Tales of Al-Irwi): 125)

The double demonstrative, however, cannot replace the demonstrative determiner haðaka in (83), since the referent of the phrase Zarik haðaka (that neighbor of yours) is at most familiar. This confirms results of the questionnaire studies that the double demonstrative ha-N haða requires at least Activated.

$$
\begin{aligned}
& \text { 1-druu3 mainaha ma-j-baan- } \quad \text { l-barra. } \\
& \text { the-strairs that is neg-1ms-appear-neg the-outside } \\
& \text { "which means that the stairs don't show on the outside." }
\end{aligned}
$$

$\varnothing$ ma ja-imillik- $\int \quad$ mufkla mia 3ar-ik aðaka neg 3m-do-to-you-neg problem with neighbor-pos.2s nonprox $2.3 \mathrm{~ms}$ "They won't cause you a problem with your neighbor (literally, that your neighbor)"

(Blue Print) 


\section{$\underline{\text { haðaka }}$}

Example (84) shows that haðaka as a pronoun can be used for the cognitive status Activated. The boy can be assumed to be activated, since he was mentioned in one of the immediately preceding sentences.

ajja tiktib 1-sdaaq Sarris 1-wlid
so written the-marriage contract get.married.past.3ms the-boy. "So the marriage contract was written and the boy got married."

lakin la-Srusa bint akaabir w haðaka barrani but the-bride daughter high-class and nonprox $2.3 \mathrm{~ms}$ outsider "However, the bride is the daughter of a high class family and he is an outsider."

(Hikajaat Al-Irwi (Tales of Al-Irwi): 125)

Evidence that the pronoun haðaka requires at least Activated is that it cannot replace forms that require only Familiar. For example, haðaka cannot replace the phrase with the double demonstrative aka l-spanish illi hki-t-l-k Slii-h haðaka (That Hispanic man I talked to you about) in (85), because the Hispanic man cannot be assumed to be activated in the mind of the addressee. He is previously known by both speaker and addressee, but he has not been recently mentioned by the speaker in the retelling of a soap opera. 


\begin{tabular}{|c|c|c|c|}
\hline A: maj & $\begin{array}{l}\text { wild-it } \quad \ldots . \\
\text { give-birth-past } 3 \mathrm{fs}\end{array}$ & $\begin{array}{l}\text { Sadda } \\
\text { holding }\end{array}$ & $\begin{array}{c}\text { wlajd } \\
\text { bov }\end{array}$ \\
\hline
\end{tabular}

"She gave birth ... she was holding one of the boys."

$\mathrm{mu}$ Sarif as ta-hki

neg know what 3fs-say

"I don't know what she was saying."

B: bnaja bnajja. Snija axir

girl girl what else

"A girl, a girl, what else?"

\section{A: w haka l-spanif}

and nonprox 1 the-spanish

\section{illi hki-t-l-k $\quad$ lii-h haðaka}

com talk-past.1s-to-2s about-3ms nonprox $2.3 \mathrm{~ms}$

"and that Hispanic man that I talked to you about."

1-raa3il w mart-u

the- man and wife-poss-3ms

illi hrab mia 1-uxra

comp escape-past.3ms with the-other

"The man and his wife. The one who ran away with the other one (woman)."

maw ja-hki huwa w-jaha

emph 3ms-talk he and-her

1-barih willa Snija

the-yesterday or what.

"He was talking with her yesterday or what."

(Soap Opera) 


\section{$\underline{\text { haða }}$}

In (86) from the folk story The Devil and the Blacksmith, the blacksmith blamed the devil for being in jail. He used the demonstrative pronoun haða to refer to his current situation. The referent of the phrase haði (this) was determined to be activated by being part of the immediate context.

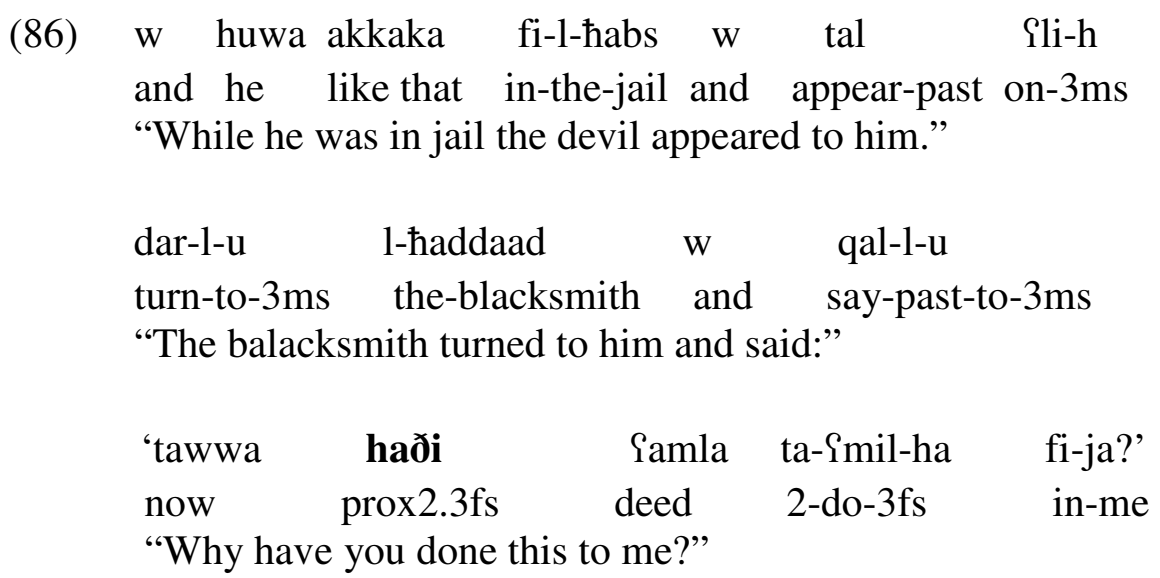

(The Devil and the Blacksmith)

As shown in table 13, the demonstrative determiners hak, haðaka, as well as the double demonstrative determiner hak $N$ haðaka were used to refer to referents that can be assumed to be familiar, activated, and in focus, but none of them was determined to refer to entities that have lower statuses, confirming results achieved in the questionnaires that these three forms require only Familiar. The examples given in this section support the conclusion that these forms can be used to refer to entities that are familiar, but not to entities that have a cognitive status lower than Familiar. 


\section{$\underline{\operatorname{hak} N}$}

Example (87), from a published folk story shows that the demonstrative determiner hak can be used to refer to at most familiar entities. The referents of both phrases hak $l$ sil Sa (that merchandise), and hak l-Siffa (that hut) were determined to be at most familiar, because they were mentioned previously in the story, but have not been mentioned recently enough to be activated.

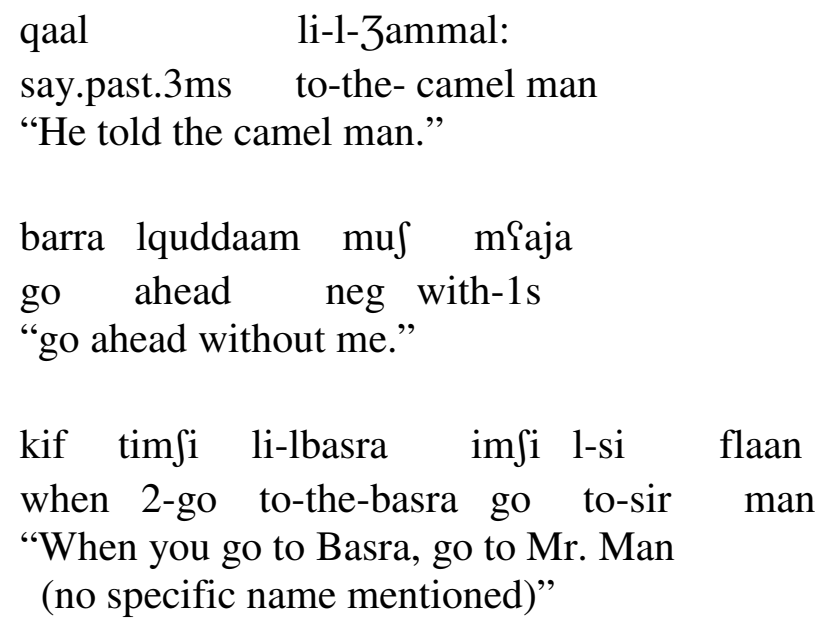


As shown in (88), if we replace the definite article in the phrase $l$-druu 3 (the stairs), whose referent is at most uniquely identifiable, with hak, we cannot expect the addressee to identify the intended referent, since the definite article $l$ - requires that the addressee is only expected to assign a unique representation of the speaker's intended referent. In (88) the referent of the phrase $l$-druu 3 (the stairs) was determined to be uniquely identifiable, because the speaker is referring to the stairs that will be built, but the stairs haven't been mentioned anytime earlier in the conversation. The speaker, therefore, can expect the hearer to only assign a unique representation to the stairs. The fact that hak cannot replace the definite artilce $l$ - in this example supports results of the questionnaires that hak requires at least the status Familiar.

$\begin{array}{cccc}\text { bas } & \mathrm{j}-3 \mathrm{i} & \text { min-na } & \text { 1-druu3 } \\ \text { fut } & 1 \mathrm{~s}-\text { become } & \text { from-here } & \text { the-strairs }\end{array}$
"The stairs will be on this side."

$\begin{array}{lcccc}\text { ba } & \text { j-3i } & \text { min-na } & \text { \#hak } & \text { l-druu3 } \\ \text { fut } & \text { 1s-become } & \text { from-here } & \text { nonprox1 the-strairs } \\ \text { "\#Those stairs will be on this side." } & \end{array}$

(Blue Print)

\section{$\underline{\text { hak Nhaðaka }}$}

Example (89) shows that the double demonstrative hak $N$ haðaka can be used to refer to

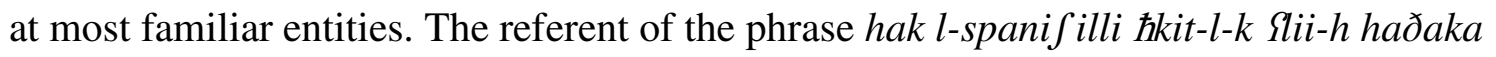
(that Hispanic I talked to you about) was determined to be familiar, since the speaker already mentioned the Hispanic man earlier in the retelling of the soap opera. 


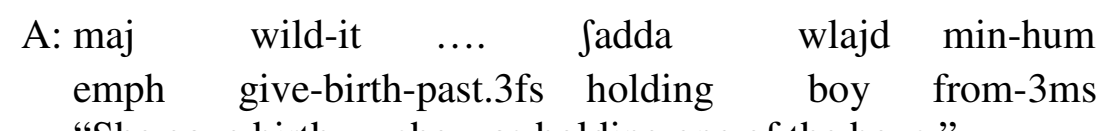

"She gave birth ... she was holding one of the boys."

$\begin{array}{lccr}\text { mus } & \text { Sarif as ta- } \hbar k i \\ \text { neg know } & \text { what } 3 f s-s a y\end{array}$

"I don't know what she was saying."

B: bnajja bnajja. Jnija axir

girl girl what else

"a girl, a girl. What else?"

\section{A: w hak l-spanis}

and nonprox 1 the-spanish

\section{illi hki-t-l-k Slii-h haðaka}

com talk-past.1s-to-2s about-3ms nonprox $2.3 \mathrm{~ms}$

"and that Hispanic man that I talked to you about."

1-raa3il w-mart-u

the- man and wife-poss-3ms

illi hrab mia l-uxra

comp escape-past.3ms with the-other

"The man and his wife, the one who ran away with the other one (woman)."

$\begin{array}{lllll}\text { maw } & \text { ja-hki } & \text { huwa } & \text { w } & \text { jaha } \\ \text { emph } & 3 \text { ms-talk } & \text { he } & \text { and } & \text { her }\end{array}$

1-barih willa Snija

the-yesterday or what.

"He was talking with her yesterday, or what."

(Soap Opera)

None of the tokens of the double demonstrative hak $N$ haðaka identified in the data used for this study was determined to refer to at most uniquely identifiable entities confirming results of the questionnaires that it requires at least Familiar. For example in (90) from a 
radio play, if we replace the definite article $l$ - in the phrases $l$-mabsim (the smile) or $l$ mantiq (the words) with the double demonstrative hak $N$ haðaka, the result would be infelicitous. Both phrases were determined to be uniquely identifiable by bridging to the phrase Saxtuura (a beautiful woman), which is already activated, but they were not themselves already mentioned anytime earlier in the discourse.

$$
\begin{aligned}
& \text { fiq-t Sla } \quad \text { Saxtuura } \\
& \text { wake up.past-1s on } \quad \text { beautiful woman } \\
& \text { "I woke up and found a beautiful lady" }
\end{aligned}
$$

l-mabsim/ \# hak l-mabsim haðaka tabruri the-smile/ nonprox 1 the-smile nonprox $2.3 \mathrm{~ms}$ sleet "The smile/that smile (literally that smile that) is beautiful,

W l-mantiq/\# hak l-mantiq haðaka isal and the-words/ nonprox 1 the-words nonprox $2.3 \mathrm{~ms}$ honey "and the words are charming,"

w t-hib-ni n-qul-ha Skuun-k willa Slaas 3iit

and 2-want-1s 1-say-3fs who-2s or why come.past.1s "and you want me to ask her who she was or why she came."

(maal wa-hwal (Money and Situations))

\section{N haðaka}

The corpus study confirmed the results achieved in the revised questionnaire, but not in the pilot questionnaire that the demonstrative determiner haðaka minimally requires the status Familiar. In (91) for instance, the DP ћmuha haðaka (literally, her father-in-law that) was determined to be at most familiar, because it was mentioned earlier in the story, but not more recently. 
(91)

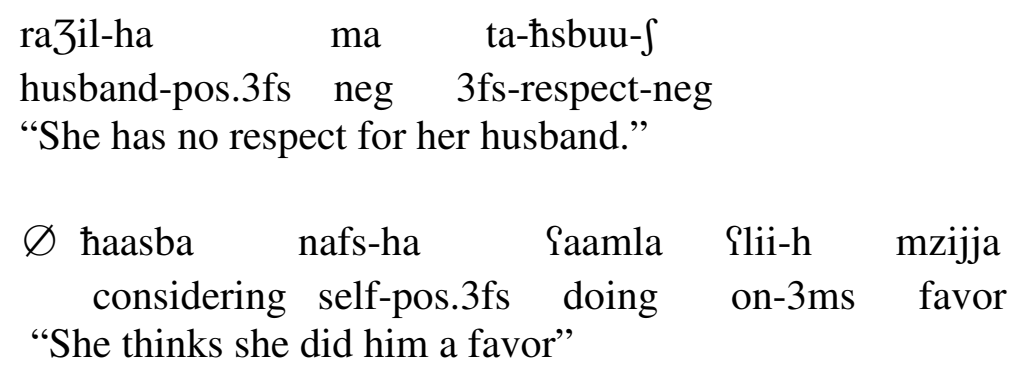

kiif rðaat w-xðaat-u.

when accept.past.3fs and marry.past.3fs-3ms

"when she accepted to marry him."

tu-ћkum fii-h

3fs-control in-3ms

"She controls him."

ama hmu-ha haðaka Paqal min tafja Sand-ha as father.in.law-pos.3fs nonprox $2.3 \mathrm{~ms}$ less than small.thing for-3fs "As for her father-in-law (literally her father-in-law that), he has no importance for her."

(Hikajaat Al-Irwi (Tales of Al-Irwi) 125)

As shown in (92) from retelling of a soap opera, the demonstrative determiner haðaka, however, cannot replace the definite article $l$ - in the phrase l-sikritira mtasu (his secretary), confirming that it requires at least Familiar. The referent of the phrase $l$ sikritira mta@u was determined to be at most uniquely identifiable, since it contains enough descriptive content to create a unique referent, but the addressee has no previous knowledge of her. 

A: bu-ha
ma
maat- $\int$
ju-ðhur-1-i
father-3fs neg die-past.3ms-neg 3ms-appear-to-3ms
"Her father didn't die, I think."

(the hearer confirming what speaker A just said)
B: ih ma mat- $\int$ ih
yes neg die.past.3ms-neg yes

"Yes, yes, he didn't die."

\section{A: ih huwa w l-sikritira mtaSu/ \# l-sikritira mtaiu haðika \\ yes he and the-secretary pos. $3 \mathrm{~ms} /$ the-secretary pos. $3 \mathrm{~ms}$ prox $2.3 \mathrm{fs}$ \\ j-Sissu Sli-ha \\ 3p-watch on-her \\ "Yes he was watching her with his secretary."}

(Soap Opera)

Consistent with the Givenness Hierarchy claim that each cognitive status entails all lower statuses, results of the corpus study showed that demonstrative forms were used for the cognitive statuses they minimally require, but also for higher statuses. In (93), the demonstrative pronoun haðaka which encodes the cognitive status Activated, was used twice for the cognitive status In Focus. Referents of both tokens of the demonstrative haðaka were determined to be In Focus by criterion 1 (It is the referent of a DP in a syntactically prominent position in the main clause of the immediately preceding sentence.) 


\begin{tabular}{|c|c|c|c|c|}
\hline (93) & $\begin{array}{l}\text { w famma } \\
\text { and there } \\
\text { "and there is th } \\
\text { ("the one" here }\end{array}$ & $\begin{array}{l}\text { illi } \\
\text { comp } \\
\text { one which has a st } \\
\text { refers to another bly }\end{array}$ & $\begin{array}{l}\text { fi-h } \\
\text { in-3ms } \\
\text { dio" } \\
\text { te print) }\end{array}$ & $\begin{array}{l}\text { stydjo } \\
\text { studio }\end{array}$ \\
\hline & $\begin{array}{l}\text { illi } \quad \mathrm{m} \\
\text { comp neg } \\
\text { "That one whic }\end{array}$ & $\begin{array}{l}\text { a-Yi3b-ik- } \\
\text { please.past-2s.-neg } \\
\text { you did not like." }\end{array}$ & $\begin{array}{l}\text { inta } \\
\text { you }\end{array}$ & $\begin{array}{c}\text { haðaka } \\
\text { nonporx } 2.3 \mathrm{~ms}\end{array}$ \\
\hline & $\begin{array}{l}\text { haðaka } \\
\text { nonprox } 2.3 \mathrm{~ms}\end{array}$ & $\begin{array}{l}\text { 1-avãtaße } \\
\text { the-advantage }\end{array}$ & $\begin{array}{l}\text { mtai-u, } \\
\text { pos-3ms }\end{array}$ & \\
\hline & $\begin{array}{ll}\text { fi } & \text { kawnu } \\
\text { in } & \text { being }\end{array}$ & $\begin{array}{l}\text { 1-dru3 } \\
\text { the-strairs }\end{array}$ & $\begin{array}{l}\text { ldaxil. } \\
\text { inside }\end{array}$ & \\
\hline
\end{tabular}

(Blue Print)

Similarly, example (94) shows that the double demonstrative hak $N$ haðaka which encodes the status Familiar is used for the higher status Activated. The referent of the phrase hak l-buliis haðaka (that policeman) was determined to be activated, because it is mentioned in the immediately preceding sentence.

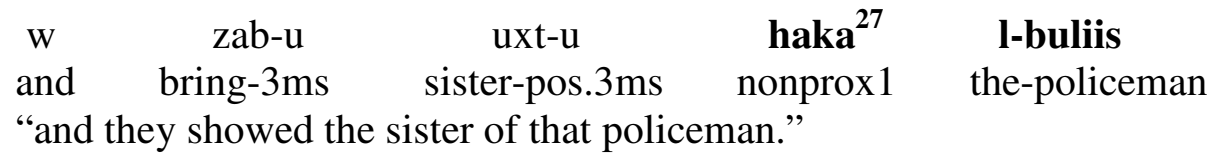

hak l-buliis haðaka bidu

nonprox 1 the-policeman nonprox $2.3 \mathrm{~ms}$ emph

uxt-u fi-l-sbitar haazza wlad
sister-pos.3ms in-the-hospital holding boy
"That policeman himself, his sister is in the hospital holding a baby"

(Soap Opera)

${ }^{27}$ haka is a variant of hak. 
Example (95) from the same soap opera shows that the demonstrative determiner haðaka, which only requires familiarity, is used for the cognitive status In Focus. The referent of the phrase uxtha haðika (literally, that her sister) was determined to be in focus, because it is the subject of the immediately preceding clause.

$$
\begin{array}{ll}
\varnothing \text { hattu-ha fil-habs w mfat-l-ha } & \text { uxt-ha .... } \\
\text { put-past.3p-3fs in-the-jail and go-past.3fs-to-3fs } & \text { sister-pos-3fs } \\
\text { "They put her in jail and her sister went to visit her...." }
\end{array}
$$

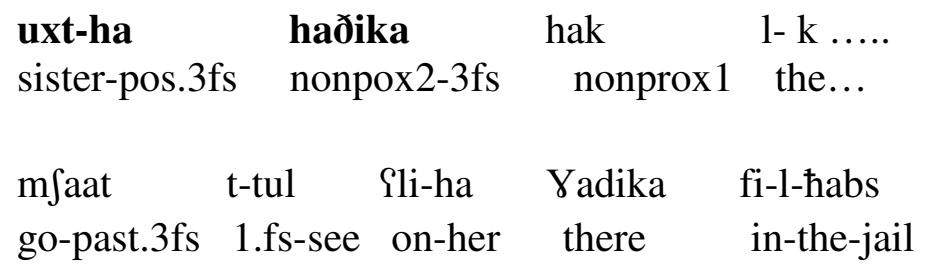
"That sister, that ... (unfinished phrase) went to see her there in the jail."

(Soap Opera)

Results of the corpus study also support the result achieved in the revised questionnaire, but not in the pilot questionnaire, that the demonstrative determiner haðaka requires the cognitive status Familiar and not Activated. Distribution of this form according to the highest status it was chosen for given in Table 12 also supports the suggestion that although this form requires at least the status Familiar, it is used more frequently for the higher statuses Activated and In Focus. As shown in the table, of the 19 tokens of haðaka identified in the data, 8 were used to refer to familiar entities and 11 were used to refer to activated and in-focus entities.

One goal of the corpus study was to see if discourse type influences the distribution of certain demonstrative forms, as was found in previous studies (OH 2001, Mulkern 2003). Results of the corpus study given in table 13 indicate that of the 43 
tokens of the demonstrative hak that were identified in the data corpus, 32 were used to refer to familiar entities, 5 to activated entities, and 6 to in-focus entities. Breaking down the results of the corpus study by discourse type indicates that all the tokens of hak that were used to refer to activated or in focus entities occurred in narrative discourse. A brief discussion of this finding and a possible explanation using Mulkern's notion of Imposed Salience (Mulkern 2003) will be explored in the future research section in chapter 5. The final form-status correlations according to results of the questionnaires and the corpus study are given in table 14 .

Table 14: Final form-status correlations ${ }^{28}$.

\begin{tabular}{|l|l|l|l|l|l|}
\hline In Focus & Activated & Familiar & $\begin{array}{l}\text { Uniquely } \\
\text { Identifiable }\end{array}$ & Referential & $\begin{array}{l}\text { Type } \\
\text { Identifiable }\end{array}$ \\
\hline & ha-N & hak $N$ & & \\
haða $h a ð a$ & hak Nhaðaka & & & \\
haðaka & Nha-Nhaða & & & & \\
& & & & & \\
& & & & & \\
\hline
\end{tabular}

${ }^{28}$ Summary of the results of the questionnaires and the corpus study were presented at the $10^{\text {th }}$ International Pragmatic Conference, Göteborg, Sweden, July 8-13, 2007. 


\section{Chapter 4: A Cognitive explanation of communicators' avoidance of ambiguous forms: The case of the demonstrative haða ${ }^{29}$}

\subsection{Introduction}

Results of the questionnaires and the corpus study presented in Chapters 2 and 3 indicate that the demonstrative $h a ð a$ as a pronoun and as a determiner encodes the cognitive status Activated. Consistent with the Givenness Hierarchy claim that a form can be used for the cognitive status it minimally requires and also for higher statuses, results of these studies showed that haða as a pronoun and as a determiner was also used to refer to in-focus entities.

An examination of the questionnaires conducted in this dissertation, however, indicated that in some contexts where the demonstrative pronoun and the demonstrative determiner meet cognitive status criteria (i.e., Activated or In Focus), participants chose only the demonstrative determiner and not the demonstrative pronoun while in other contexts, they chose both forms, indicating that there are other factors that further restrict the use of the demonstrative pronoun. For example, in (96) participants chose both the demonstrative pronoun and the phrase with the demonstrative determiner l-kalb haða (this dog), in order to refer to the dog.

\footnotetext{
${ }^{29}$ Previous versions of this study were presented at the I North American Workshop on Pragmatics (I NAWPRA), Glendon College, York University, Toronto, Canada, October 3-5, 2008 and at the $23^{\text {rd }}$ Arabic Linguistic Symposium, University of Wisconsin, Milwaukee, USA, April 3-5, 2009.
} 
(96) Speaker B knows the dog that $\mathrm{A}$ is talking about

A: kalb-na sYiir barfa ma j-na33im- $\int$ j-Siss Sla 1-daar dog-pos.1s small a lot neg 3ms-can-neg 3ms-watch on the-house "Our dog is very small. It can't watch the house."

B: mniin Jrit-u inti l-kalb haða/ haða? where buy-3ms you the-dog prox $2.3 \mathrm{~ms} /$ prox $2.3 \mathrm{~ms}$ "Where did you buy this dog/this one?"

in (97) from the pilot questionnaire, however, none of the 13 participants who filled in the questionnaire selected the demonstrative pronoun haða alone to refer to the doctor, while 6 participants chose the phrase with the demonstrative determiner l-tbiib hada (this doctor) to be placed in this context.

(97) B doesn't know the doctor that $\mathrm{A}$ is talking about
A: ðahr-i maiats ju-3ai-ni.
back-pos.1s neg 3m-hurt-1s
"My back does not hurt anymore."

$\begin{array}{lllll}\text { tbiib-i } & \text { Sta-ni } & \text { dwa } & \text { ðarba } & \text { ðarba } \\ \text { doctor-pos.1s } & \text { give-past.3ms-1s } & \text { medication } & \text { efficient } & \text { efficient } \\ \text { "My doctor gave me very efficient } & \text { medication." } & & \end{array}$
B: as ism-u l-tbiib haða
what name-pos.3ms the-doctor prox $2.3 \mathrm{~ms}$
"What is the name of this doctor?"

This chapter will be concerned with investigating contexts where the two forms can be interchangeable and contexts where only the demonstrative determiner is possible. Remarks on avoiding pronouns and using full noun phrases are given by Himmelman (1996) and Schiffrin (2006) who argued that pronouns are avoided when there is more than one possible referent. Himmelman explains that one reason full NP demonstrative 
expressions replace pronouns is when there is more than one possible antecedent (227). Schiffrin points out that "next-mention pronouns are less frequent when their referent is potentially ambiguous than when there is no potential for ambiguity" (172). This chapter builds on this explanation and further uses the Givenness Hierarchy Theory to explain why both the determiner and the pronoun can pick out the same referent, and why it is theoretically possible for an ambiguous demonstrative pronoun to pick out all the possible referents. This study also uses Relevance Theory to give an explanation for why communicators avoid the demonstrative pronoun when they expect it to be ambiguous. The chapter also highlights the importance of grammatical agreement and non-verbal communication in disambiguating the intended referent. Specifically, this chapter will address two questions: 1) What factors other than cognitive status further restrict the choice of the demonstrative pronoun $h a ð a$ when cognitive status criteria for its use are met? 2) Why do communicators avoid the demonstrative pronoun and choose the demonstrative determiner with a noun in the presence of those restricting factors? First, this chapter discusses the factors that restrict the choice of the demonstrative pronoun haða in contexts where cognitive status criteria for its use are met (i.e., when the referent is at least activated). Next, I argue that Relevance Theory provides a cognitive explanation for why communicators do not use the pronoun, but rather choose the demonstrative determiner with a noun when those restricting factors are present.

Examples used in this chapter are taken from the questionnaires discussed in chapter 2 as well as seven pieces of data from the data corpus used in this dissertation: Volume I and Volume IV from the published folk tales Hikaajaat Al-Irwi (The Tales of Al-Irwi) (Al-Irwi, vol.1 \& vol.4, 1989) ; two episodes of the American soap opera Days 
of our Lives retold in Tunisian Arabic from memory by a male native speaker of Tunisian Arabic, and recorded; two articles from an out-of-print newspaper Al-Sariih; texts from a published translation of the book The Little Prince (Balegh 1997); a recorded spontaneous conversation between two male native speakers of Tunisian Arabic in their twenties, discussing three possible blue prints for a house that is being built; a published play Junuun (Insanity) (Baccar 2001) where the story revolves around the daily life of a young man who has schizophrenia, his struggle with the disease, and his daily interactions with his psychiatrist and his immediate family members; and a published play script entitled Masrah Ali Al-Douaji (Baccar 2002).

\subsection{Factors that further restrict the use of the demonstrative pronoun haða when cognitive status criteria for its appropriate use are met.}

As noted in the introduction of this chapter, there are certain examples where none of the participants chose the demonstrative pronoun haða even when the referent was at least activated. An examination of these cases indicates that the demonstrative pronoun was avoided, because there was more than one possible referent that meets cognitive status criteria for its use, and which shares the same agreement features with it. In (97), for example, none of the participants chose the demonstrative pronoun haða to refer to the doctor who had been activated and in fact brought into focus by way of mention in subsequent position of the previous sentence. The demonstrative pronoun haða in this example can refer to either the doctor or the medication, which are both at least activated and are both singular masculine. The phrase with the demonstrative determiner l-tbiib haða (this doctor) allows the speaker to refer unambiguously to the doctor, because the 
conceptual content of the noun explicitly indicates that it is the doctor and not the medication that the speaker is referring to.

Example (98) further supports the argument that speakers do not choose a demonstrative pronoun, but rather choose a phrase with the demonstrative determiner, when there is a competing referent that satisfies cognitive status criteria that allow reference with the demonstrative haða. In (98), when the merchant told the Little Prince that taking certain pills saves fifty three minutes, the Little Prince asked him about the reason for saving fifty-three minutes. In his question, he used the phrase with the demonstrative determiner $l$ - $\theta l a a \theta a w$ xamsiin dqiiqa haði (these fifty-three minutes). In this example, a demonstrative pronoun might not lead the addressee to identify the fiftythree minutes as the intended referent, since the pronoun can refer to either the fifty- three minutes or the pills. Both of these possible referents are are at least activated and are singular feminine. The only way the speaker can expect the addressee to pick out the intended referent is by using the phrase with the demonstrative determiner to state that his question is about the fifty- three minutes and not the pills. 

A: Slaas t-biif fi l-hraabs, sall-u 1-?amiir 1-sayiir why 2-sell in the-pills, ask-past.3sm-3sm the-prince the-little "Why do you sell the pills the little prince asked him."

B: t-rabbih barfa waqt! 3aawb-u 1-taa3ir. 3fs-benefit a lot time reply.past.3sm-3sm the-merchant "It saves a lot of time replied the merchant."

1-xubaraa Samlu hsabaat-hum the-experts make-past.3p calculations-pos.3p "The experts made their calculations."

t-rabbih $\quad$ laa $\theta a$ w xamsiin dqiiqa 3fs-makegain three and fifty minute "It saves fifty-three minutes."

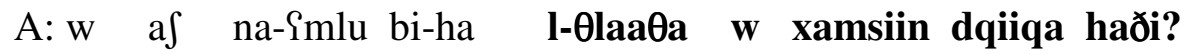
and what 1-do with-3fs the -three and fifty minute prox2.3fs "And what do we do with these fifty three minutes?"

(Al-Aamiir Al-sayiir (The Little Prince: 109)

While in examples (97) and (98) above, there is only one competing referent that meets the criteria for being referred to with the demonstrative haða, examples (99) and (100) show that the competing referent can be a possible one among many. In (99), the Little Prince referred to his body as $l$-bdan haða (this body), because a demonstrative pronoun could refer to multiple things in the immediate spatio-temporal context, including the Little Prince's body. Even if the speaker uses extralinguistic means like a gesture, it might not pick out the referent as the entire body and not, for instance, part of The Little Prince's body. By using the phrase with the determiner, on the other hand, the speaker can expect the addressee to identify the intended referent. 


$\begin{array}{llcc}\text { fhim-t? } & \text { 1-buqfa } & \text { bSida } & \text { jaasir! } \\ \text { understand-2s } & \text { the-place } & \text { far } & \text { a lot }\end{array}$

l-bdan haða ma n-na33im- $\int$ n-hizz-u

the-body prox $2.3 \mathrm{~ms}$ neg 1-can-neg 1-carry-3ms

"Do you understand? the place is very far!, and I can't carry this body."

(Al-Amiir Al-sayiir (The Little Prince): 131)

Similarly, in example (100) from the pilot questionnaire, the noise can be assumed to be activated, since both interlocutors could hear it. The use of a demonstrative pronoun to refer to the noise, however, might not guide the addressee to identify it as the intended referent. Although the referent is in the immediate spatio-temporal context, it is not possible to use non-linguistic communication, such as eye gaze or a gesture to disambiguate it. The competing referent can be anything or anyone that could be a source of annoyance at the moment the sentence was uttered. A phrase with a determiner, on the other hand, can guide the hearer to identify the referent, since the conceptual content of the noun specifies that what is being referred to is the noise that was taking place at that time.

(100) Both speaker and addressee can hear a noise.

qallaq-ni l-his haða

bother.past.3ms-1s the-noise prox $2.3 \mathrm{~ms}$

"This noise is bothering me."

Similarly, in example (101) from a newspaper article, speaker A is discussing a blue print with speaker B. He points to a closet and refers to it by using a demonstrative determiner and a noun. Since there are other closets and other things on the blue print that could also 
be at least activated, the referent of the demonstrative pronoun could be the intended closet or anything else on the blue print. Even the use of a gesture here might not be helpful in distinguishing the shape of the closet from other shapes on the blue print.

(101) A: 3u3 mitru w $\quad$ oläin l-plakaar
two meters and thirty the-closet prox ?
"Is this closet two meters and a half?"

(Blue Print)

When there is no competing referent that satisfies the criteria for being referred to with the demonstrative haða, the demonstrative pronoun can be used without causing any ambiguity. In (96) repeated here in (102), both the demonstrative pronoun and the demonstrative determiner were judged to be acceptable. The pronoun haða can be used to refer to the dog without causing any ambiguity, since the dog is the only referent that meets cognitive status criteria to be referred to with the demonstrative determiner.

(102) A: kalb-na sYiir barfa ma j-na33im- $\int$ j-Siss fla 1-daar dog-pos.1s small very neg 3ms-can-neg 3ms-watch on the-house "Our dog is very small. It can't watch the house."

\section{B: mniin Srit-u inti l-kalb haða/haða where buy-3ms you the-dog prox $2.3 \mathrm{~ms} /$ prox $2.3 \mathrm{~ms}$ "Where did you buy this dog/this (one)"}

Similarly, in (103), the speaker is a journalist who is sarcastically commenting on a singer who waits a long time before producing a new work. The use of the pronoun here is not ambiguous, since the new work is the only activated third person referent that can be referred to with the pronoun haða. 
(103) as qul-t t-haððir fi intaa3 3diid?

what say-past.3ms. 2s-prepare in work new

"What did you say ... you are preparing a new work?"

ah haða illi qul-t

ah prox $2.3 \mathrm{~ms}$ comp say-past. $2 \mathrm{~s}$

bas t-qaddim- hu-1-na Saam 3000

fut 2s-present-3ms-to-3p year 3000 .

"Ah this one is the one you said you would present to us in the year 3000."

(Al-Sarih Tuesday, May 20 ${ }^{\text {th, }} 1997$, p.20)

Similarly, in example (104) from a play script, the speaker uses a demonstrative pronoun to refer to a previous comment he made about himself. The addressee here can be expected to unambiguously identify the speaker's comment about himself, that no one loves him as the intended referent, since there is no other activated referent that can be appropriately referred to with the pronoun.

(104) had ma hab-ni
one neg love.past.3ms-1s
"No one loved me,"
w had ma habn-i
and one neg love-past.3ms-1s
"and no one loved me."
'haða illi $\quad$ marrað-ni'
prox2.3ms comp make.sick.past.3ms-1s
"This is what made me sick."

(Junuun (Insanity): 122) 
Examples ((96)-(104)) discussed so far in this section indicate that when there is a competing referent that satisfies cognitive status criteria for being referred to with the demonstrative pronoun haða, speakers avoid the pronoun, and use a phrase with a demonstrative determiner. The conceptual content of the noun can be expected to help guide the addressee to the intended referent. As was indicated in examples ((102)- (104)), in the absence of a competing referent that causes ambiguity, both the demonstrative pronoun and the demonstrative determiner can guide the addressee to identify the intended referent.

As will be shown in examples ((105)-(109)), however, communicators do not always avoid the demonstrative pronoun when there is a competing activated referent. As will be shown in the examples, when communicators have available linguistic means such as grammatical agreement between the demonstrative and the referent or nonlinguistic means such as eye gaze or a gesture that can help them explicitly and unambiguously indicate the intended referent, they still use the pronoun. As the examples show, when the referent is mentioned anytime previously in the text, speakers use linguistic means to disambiguate the referent. When the referent is in the spatio-temporal context, speakers use linguistic and/or non-linguistic means. For example, in (105) a boy whose father has always told him stories about how lions are strong and brave is commenting to his father on a weak lion they saw. The demonstrative pronoun does not give rise to ambiguity here; since, as mentioned in the example, the boy was able to use eye gaze when referring to the lion. He also gave the addressee linguistic information by using the word siid (lion) later in the sentence. By using these non-linguistic and 
linguistic means, the speaker can expect the addressee to identify the intended referent as the lion, and not another entity in the spatio-temporal context.

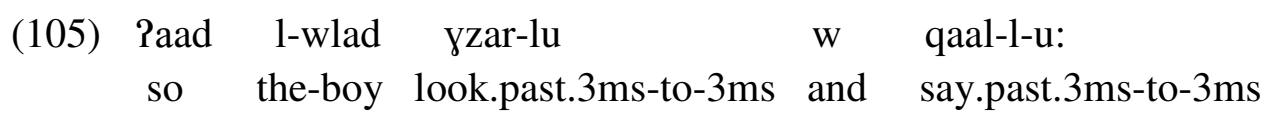
"So the boy looked at the lion and said:"

$\begin{array}{lllll}\text { ya baba amma haða } & \text { mu } & \text { siid? } \\ \text { voc dad but prox2.3ms } & \text { neg } & \text { lion } \\ \text { "Dad, but isn't this a lion?" } & & & \end{array}$

(Al-Sariih, Tuesday, March 25 $5^{\text {th }}$ 1997: 9)

In (106) from the pilot and the revised questionnaires, participants who filled in the questionnaires chose both the demonstrative determiner and the demonstrative pronoun to refer to the apartment. In this example, both the house and the apartment can be assumed to be activated, and are therefore candidates to be referred to with the pronoun $h a ð a$. However, since the house is marked for feminine grammatical gender, and the apartment for masculine grammatical gender, choosing the demonstrative pronoun that is marked for masculine grammatical gender, makes it possible for the speaker to guide the addressee to the intended referent, which is the apartment. 
(106) A knows the apartment that B is talking about

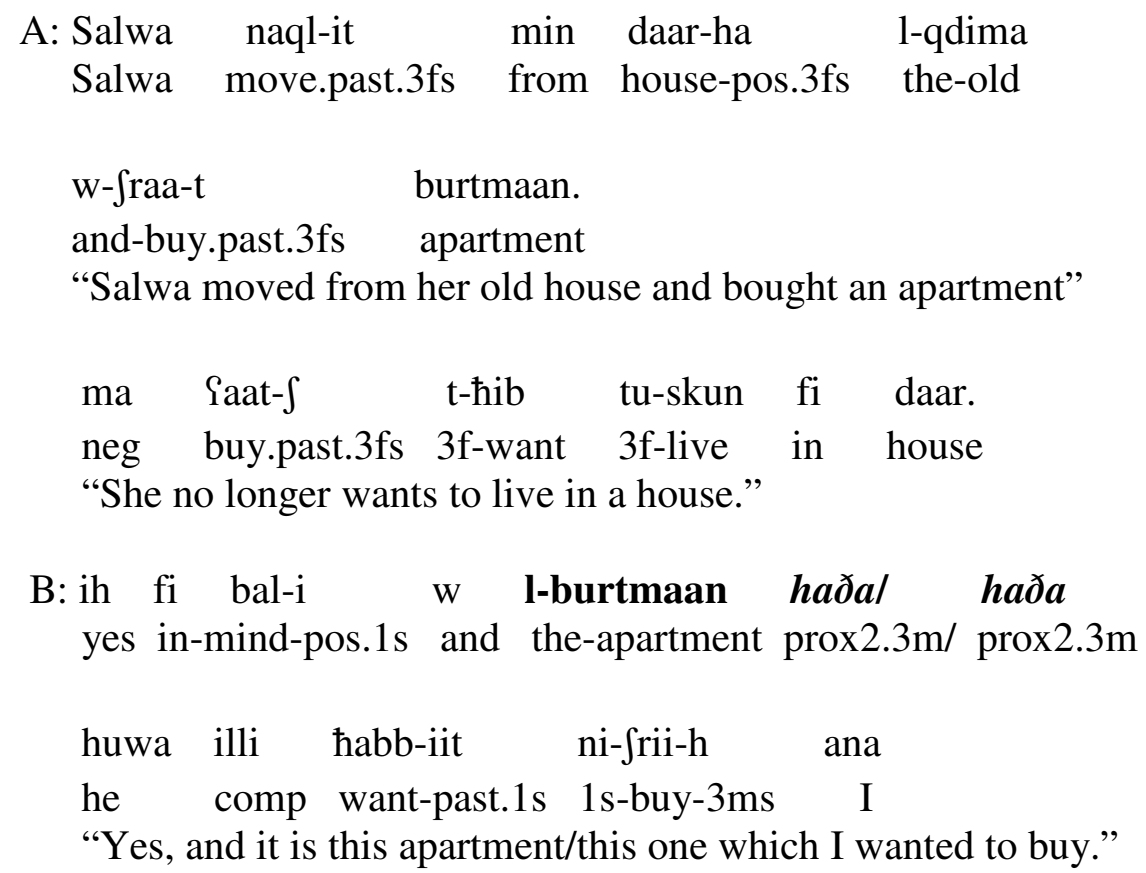

In example (107), from the revised questionnaire, participants in the questionnaire chose both a demonstrative pronoun and a demonstrative determiner to refer to the watermelon. The speaker is standing in front of a watermelon pile, points to a particular watermelon, and asks the grocer to weigh it for him. If the speaker uses a pronoun alone s/he might not expect the addressee to identify the intended watermelon. By adding a hand gesture, the speaker helps guide the addressee to identify the watermelon he wants to buy and distinguish it from the other watermelons in the pile.

(107) The speaker is standing in front a watermelon merchant. He pointed to one watermelon and said:

$\begin{array}{lccc}\text { brabbi } & \text { uzin-l-i } & \text { l-dilla9a } & \text { haði } \\ \text { please } & \text { weigh-to-me } & \text { the-watermelon prox2.3fs } \\ \text { "Can you please weigh this watermelon for me." }\end{array}$


In (108) from a published play script, a woman is commenting to her maid on the age of an electrician who came to the house to do some repairs. The use of the demonstrative pronoun only here is possible, since, as shown in the example, the two women have had a recent conversation about the electrician's age. Using the phrase haða illi qult s fiir (Is this the one you said was young) helps guide the addressee to the intended referent, and singles him out from among other possible competing referents in the immediate context.

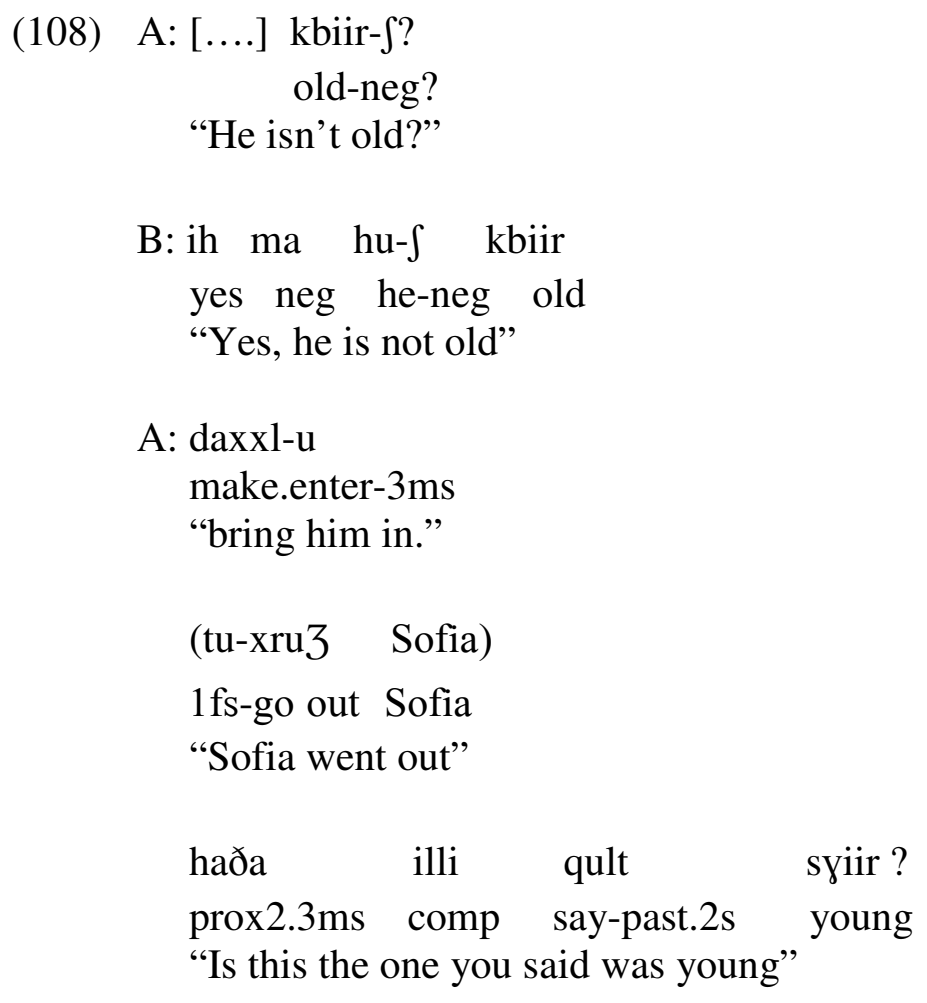

(Masrah Ali al-douaji (The theatre of Ali Al-douaji): 28)

In (109) from a published folk story, the speaker gave his friend's son a bag full of money and asked him to take it to his father, and to say hi to him. The gesture of handing the bag to the boy explicitly indicates that the intended referent of the demonstrative 
pronoun is the bag and not something else in the surrounding context. As shown in the example, a demonstrative determiner with a noun is also possible here.

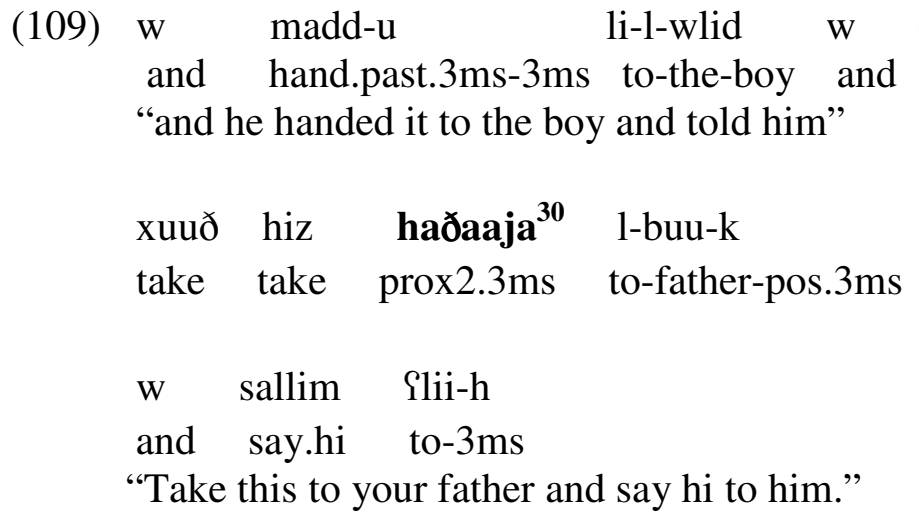

(Hikayat Al-Irwi (The tales of Al-Irwi): 34)

The argument that has been made in the discussion of the examples given above is that speakers use the demonstrative pronoun haða to refer to activated or in-focus entities when there is no competing referent, or when they can use linguistic or non-linguistic means to disambiguate the referent. When there is a competing referent that cannot be resolved based on the pronoun alone, speakers use a phrase with the determiner, because the conceptual content of the noun helps guide the addressee to identify the intended referent. The use of a phrase with a demonstrative determiner, however, is not used only for the need of disambiguating the intended referent. In example (103) repeated here in (110), a phrase with the demonstrative determiner can also be used, indicating that a phrase with the demonstrative determiner is not used only when the referent is ambiguous.

\footnotetext{
${ }^{30}$ haðaaja is a variant of haða.
} 
(110) as qul-t t-haððir fi intaa3 3diid? what say-past.3ms. 2s-prepare in work new "What did you say ... you are preparing a new work?"

$\begin{array}{lllll}\text { ah haða/ l-intaa3 haða } & \text { illi } & \text { qul-t } \\ \text { ah } & \text { prox2.3ms/the-work prox2.3ms } & \text { comp } & \text { say-past.2s }\end{array}$

Ah this (one)/this work is the one you said you would present to us in the year 3000."

(Al-Sarih Tuesday, May $20^{\text {th, }} 1997$, p.20)

Examples (111) and (112) give further evidence that a phrase with a demonstrative determiner is not used only when there is ambiguity. In both examples the speakers use a phrase with the demonstrative determiner haða even though there is only one possible referent. In example (111), speaker A uses the phrase l-trajji h haða (this try) to refer to speaker B's comment that the street is his home.
(111) A: jilzmik t-rawwah need 2s-go.home "You need to go home."
B: daar-i huuni home-pos.1s here "My home is here."
A: maa jaakil-s l-trajjiћ haða miaa-ja neg work-neg the-attempt prox $2.3 \mathrm{~ms}$ with-1s "This try doesn't work with me."

(Junuun (Insanity): 122) 
Similarly, in (112) the speaker uses the phrase with haða as a determiner, sałibna

haða,(this friend of ours) to refer to the Little Prince, although there is no other activated referent that competes with the Little Prince.

immala $\min$ quwwit 1-dahfa

so from strength the-astonishment

"So from the power of astonishment,"

w min @3ab.rabbi qiadt baahit

and from amazement staty.past.1s astonished

"and from the amazement, I stayed astonished."

w Sin-ayya maћlula qad l-maahja

and eyes-pos.1s open wide

"with my eyes widely open."

fi l-wlajjad haða illi hbat

in the-boy prox $2.3 \mathrm{~ms}$ comp comedown.past. $3 \mathrm{~ms}$

"in this boy who came"

$\begin{array}{ccc}\text { ma } & \text { na-irif } & \text { mn-iin } \\ \text { neg } & \text { 1s-knwo } & \text { from-where } \\ & \text { "I don't know from where" }\end{array}$

ma ta-nsaawif illi kun-t wahdi

neg 2s-forget comp be.1spat alone

fi 1-xla w 1-qifaar

in the-wilderness and the wilderness

"don't forget that I was alone in the desert,"

Pakधar min ?alf kilu metr

more than thousand kilo meter

"more than a thousand kilometers."

bfiid Sla Raqrib buqia maskuna

far from closest place inhabited

"far from the closest inhabited place." 


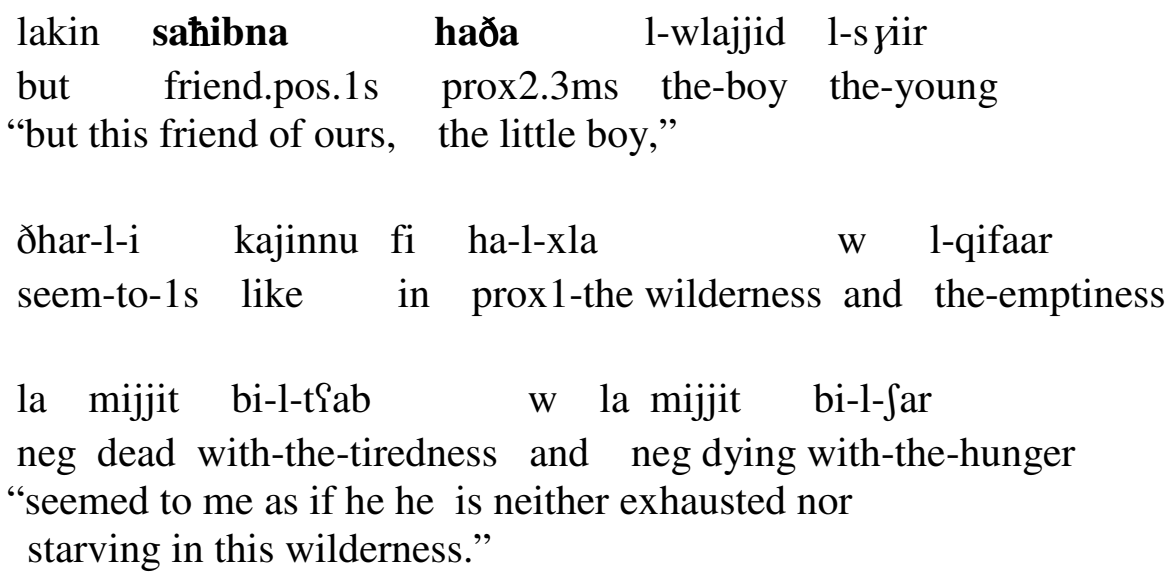

(al-Pamiir al-sa yiir (The Little Prince):7)

The question that remains is: why do communicators avoid the use of a pronoun when its referent cannot be unambiguously identified. In the next section, I will argue that Relevance Theory provides a principled answer to this question.

\subsection{Relevance and ambiguity}

The Givenness Hierarchy Theory explains the appropriate use of the demonstrative hað $a$ as a determiner and as a pronoun in terms of cognitive status. Part of the meaning of the demonstrative haða as a determiner and as pronoun is that it picks out entities that are activated, and since In Focus entails Activated, haða can also refer to in-focus entities. It was shown in section 2 , however, that when speakers do not expect their addressees to be able to unambiguously identify their intended referent, they do not choose the pronoun, but rather choose a demonstrative determiner with a noun, even if the referent is at least activated. The Givenness Hierarchy explains that both forms can be used to refer to entities that are activated or in focus, but it does not explain why speakers do not choose a pronoun when there is more than one possible activated referent. In the remainder of 
this chapter, I argue that Relevance Theory (Sperber \& Wilson 1986/1995) provides a cognitive explanation for why speakers do not choose a demonstrative pronoun when there is more than one activated referent.

\subsubsection{Relevance of an input to an individual}

According to Relevance Theory, an input such as an utterance is relevant to an individual when it yields a positive contextual/cognitive effect: a worthwhile conclusion that matters to her/him (Sperber \& Wilson 2006: 608). An input may yield positive contextual effects in different ways: It may yield contextual implications, it may strengthen an existing assumption, and it may contradict an existing assumption (Sperber \& Wilson 1995: 108-117). Sperber and Wilson also point out that the most important type of contextual effect is contextual implication. Contextual implications are context-dependent assumptions derived by combining the input with background information. For example, if I meet a speaker of English at a conference, and I cannot tell whether he is from England or New Zealand, when I hear him mentioning that he likes the coffee in New Zealand, I may draw the conclusion that this person is from New Zealand. Positive contextual effects are a necessary condition for relevance. If an input does not add worthwhile change to a person's representation of the world, it is not relevant. For example, false conclusions yield contextual effects, but they are not positive contextual effects. Moreover, according to Relevance Theory, relevance is not only a matter of cognitive effects. Deriving positive contextual effects costs time and effort on the part of the addressee. Thus, relevance may be assessed in terms of cognitive effects and processing effort. According to Relevance Theory: 
a. Other things being equal, the greater the positive cognitive effects achieved by processing an input, the greater the relevance of the input to the individual at the time.

b. Other things being equal, the greater the processing effort expended, the lower the relevance of the input to the individual at that time (2006: 609).

According to Relevance Theory, humans have an automatic tendency to maximize relevance. It follows from this that addressees tend to pick out the most relevant inputs and process them so as to maximize their relevance. This universal tendency is described in the Cognitive Principle of Relevance: Human cognition tends to be geared to the maximization of relevance (2006: 610).

\subsubsection{Relevance and Communication}

Sperber and Wilson (2006) argue that this universal tendency to maximize relevance makes it possible for communicators to predict and manipulate the mental states of their addressees (610). As they point out, "Knowing your tendency to pick out the most relevant inputs and process them so as to maximize their relevance, I may be able to produce a stimulus which is likely to attract your attention, activate an appropriate set of contextual assumptions, and point you toward an intended conclusion" (2006: 610).

But how do communicators achieve this goal? Sperber and Wilson explain that if communicators stop at the stage of having the intention to communicate their meaning to the addressees, communication does not take place. In order to give evidence to the addressees that there is a meaning to be communicated, communicators produce an ostensive stimulus such as an utterance, a sound, or a gesture. According to Relevance Theory, an ostensive stimulus carries not only the information or the meaning a communicator wants to transmit, but also the message that there is something worth processing. Therefore, part of the reason for designing an ostensive stimulus is to attract 
the audience's attention and encourage them to presume that it is relevant enough to be worth processing (2006: 611). This is described in the Communicative Principle of Relevance: Every ostensive stimulus conveys a presumption of its own optimal relevance. Optimal relevance here means that the input is worth the addressees' processing effort, and that it is the most relevant message in terms of the speaker's abilities and preferences (2006: 612).

A communicator has to choose from a range of stimuli the one that s/he can expect to attract their audience's attention. Sperber and Wilson argue that it is to the interest of the communicator to be understood, "and therefore, to make as easy as possible for the addressee to understand her. An addressee who doubts that the communicator has chosen the most relevant stimulus compatible with her communicative and informative intentions - a hearer, say, who believes that he is being addressed with deliberate and unnecessary obscurity - might doubt that genuine communication was intended, and might justifiably refuse to make the processing effort required" (1995: 157).

Thus, since communicators are aware that their audience picks out only relevant inputs, they do not choose the demonstrative pronoun haða when they cannot expect their audience to unambiguously identify the intended referent. Their addressee might conclude that the input does not yield sufficient contextual effects to be worth the processing effort. As Sperber and Wilson point out "What if two essentially different interpretations seem to come simultaneously to the mind of the addressee, and they are both consistent with the principle of relevance? In that case the addressee will be unable to decide what the informative intention was, and communication will fail" (1995: 169). 
In this sense, whether or not the addressee engages in processing a demonstrative pronoun whose referent cannot be expected to be unambiguously identified, they cannot be expected to derive the speaker's intended meaning.

Communicators know, therefore, that it is to their advantage to choose a phrase with a demonstrative determiner in such cases, because they expect it to seem relevant enough to their addressees to attract their attention, and to direct them to the intended referent. The conceptual content of the noun makes it possible for the addressee to access only one possible referent and derive worthwhile conclusions that matter to him/her. When communicators can utilize linguistic means such as grammatical agreement, or extra linguistic means such as a gesture or eye gaze that can make the pronoun a relevant enough input that can direct their audience to the intended referent, they still use the pronoun.

\subsection{Conclusion}

This chapter has provided a theoretical explanation for why a demonstrative pronoun can be ambiguous and why communicators in such cases avoid using a demonstrative pronoun and use a phrase with a determiner instead. First, I argued that communicators avoid a demonstrative pronoun and use a phrase with a demonstrative determiner instead when there is more than one referent which is at least activated and which carry the same grammatical agreement as the demonstrative pronoun. The use of a demonstrative pronoun results in ambiguity, because it can pick out any one of the possible activated referents. When there is more than one possible referent, the conceptual content of the noun in a phrase with a determiner can be expected to explicitly guide the addressee to the intended referent. It was also shown that 
communicators use the pronoun haða even when there is more than one activated referent when they can use disambiguating means such as a gesture, eye gaze, or grammatical agreement.

Second, I argued that Relevance Theory provides a cognitive explanation for the reason communicators choose a phrase with the demonstrative determiner when they do not expect a pronoun to unambiguously pick out the intended referent. Being aware of the human tendency to pick out only relevant inputs, speakers do not choose the pronoun, because they do not expect it to attract their audience's attention and guide them to the intended conclusion. A phrase with a determiner on the other hand, can explicitly lead the addressees to identify the intended referent and derive worthwhile conclusions that matter to them.

Although the focus of this chapter is the distribution of referring expressions in Tunisian Arabic, it is not claimed that the explanation for why speakers choose a phrase with a demonstrative determiner when they expect a pronoun to be ambiguous is specific to Tunisian Arabic. With respect to demonstrative pronouns, however, the potential for ambiguity in such a case is more frequent in languages like Tunisian Arabic than in languages such as English, because demonstrative pronouns in Tunisian Arabic can refer to both animate and non-animate entities. On the other hand, speakers of Tunisian Arabic have more linguistic means to disambiguate the referent of the pronoun, because demonstratives are marked not only for number agreements, but also for agreement in gender. 


\section{Chapter 5: Concluding remarks and future research}

\subsection{Conclusion}

This dissertation has contributed to research which argues that the meaning of demonstratives is not limited to relative spatial distance from the speaker/hearer, by showing how the interpretation and distribution of demonstratives in Tunisian Arabic is determined by pragmatic and cognitive factors. First, working within the Givenness Hierarchy framework, it was shown how the appropriate use of demonstratives in Tunisian Arabic is determined by the cognitive status encoded by demonstrative forms. Results of the questionnaires and the corpus study conducted in this dissertation indicated that the demonstrative pronouns haða, haðaka; the demonstrative determiners ha and haða; and the double demonstrative $h a-N$ haða require the cognitive status Activated, while the demonstrative determiners hak, haðaka, and the double demonstrative hak $N$ haða require only Familiar. Consistent with the Givenness Hierarchy predictions, results of the questionnaires and the corpus study indicate that demonstrative forms were used not only for the statuses they minimally require, but also for higher statuses. It was also shown that, in terms of cognitive status, double demonstratives are only formed from single demonstrative forms that require the same cognitive status, and that double demonstratives require the same cognitive status as the single demonstratives that form them.

In addressing the question of whether there are other factors that further explain the choice among demonstrative forms that satisfy the same cognitive status criteria, results of the questionnaires and the corpus study indicated that there are other factors that further restrict or influence speaker's choices of the demonstrative forms. One of 
these factors was discussed in chapter 4 where it was argued that irresolvable ambiguity restricts the use of the demonstrative pronoun $h a ð a$, even when cognitive status criteria for its use are met. I argued that Relevance Theory provides a cognitive explanation for why communicators avoid an ambiguous pronoun in such cases. Communicators avoid an ambiguous demonstrative pronoun, because they do not expect it to attract the attention of their addressees and direct them to the intended referent. By using a phrase with a demonstrative determiner, on the other hand, they can explicitly lead their addressees to identify the intended referent and derive worthwhile conclusions that matter to them.

Two more factors will be discussed in the future research section in this chapter, and will be addressed in future studies. The first one is the influence of the speech participants' shared knowledge of the referent on the use of the demonstrative haðaka when cognitive status criteria for its use are met. The second is the influence of Mulkern's notion of Imposed Salience (Mulkern: 2003) on the distribution of the demonstrative $h a k$ in narrative discourse.

The dissertation also highlighted research methodology. Both research tools that were used were discussed in terms of their limitations, and in terms of how they complement each other. As a research tool, the questionnaire has some advantages over the corpus study in determining form-status correlations. It increases the chance of avoiding the possibility of associating a form with a higher cognitive status than the one it minimally requires, since it is a controlled environment that allows for testing every demonstrative form against every cognitive status, a result which might occur in text analysis. For example, the demonstrative determiner haðaka which is rarely used for the 
status it minimally requires, Familiar, can be mistakenly misanalyzed as requiring the higher status Activated. The questionnaire as a research tool also allows for determining correlations between cognitive status and forms which are not used very frequently, and might be hard to identify in a data corpus. For example, since speakers of Tunisian Arabic do not use double demonstratives very frequently, only five tokens of the double demonstrative hak $N$ haðaka were identified in the data corpus. Another advantage of the questionnaire is that participants' choices give further insights into other factors that further restrict the choice among demonstrative forms. As shown in chapter four, and will be shown in the future research section of this chapter, when communicators avoid a demonstrative form when cognitive status criteria for its use are met, it indicates that there are other factors that further restrict its use.

It was also indicated that the corpus analysis was needed to complement the questionnaires. The larger texts in the data corpus allows one to code for the cognitive status Familiar using the criterion: the referent is mentioned anytime previously in the discourse. This criterion was not possible to use in the questionnaire, because it is formed of short conversations. The corpus analysis also allowed for investigating the influence of discourse type on the distribution of demonstrative forms according to the highest cognitive status they are chosen for. As will be discussed in the future research section in this chapter, the corpus analysis conducted in this dissertation suggests that narrative discourse might influence the distribution of the demonstrative hak according to the highest cognitive status it is used for.

Finally, this study has contributed to linguistic description of Tunisian Arabic, which is one of the least researched Arabic dialects. 


\subsection{Future Research}

\section{The use of the demonstrative determiner hak for the need of imposed salience}

Results of the corpus study given in table 12 indicate that of the 43 tokens of the demonstrative hak that were identified, 32 were used for the status that this form conventionally encodes, Familiar, while only 11 were used for the higher statuses Activated and In Focus. Breaking down the results of the corpus study by discourse type indicates that all the tokens of hak that were used to refer to activated or in-focus entities occurred in folk stories. In (113), for example, the referent of the phrase hak l-taa 3ir (that merchant) can be assumed to be activated, because it is mentioned in one of the two immediately preceding sentences.

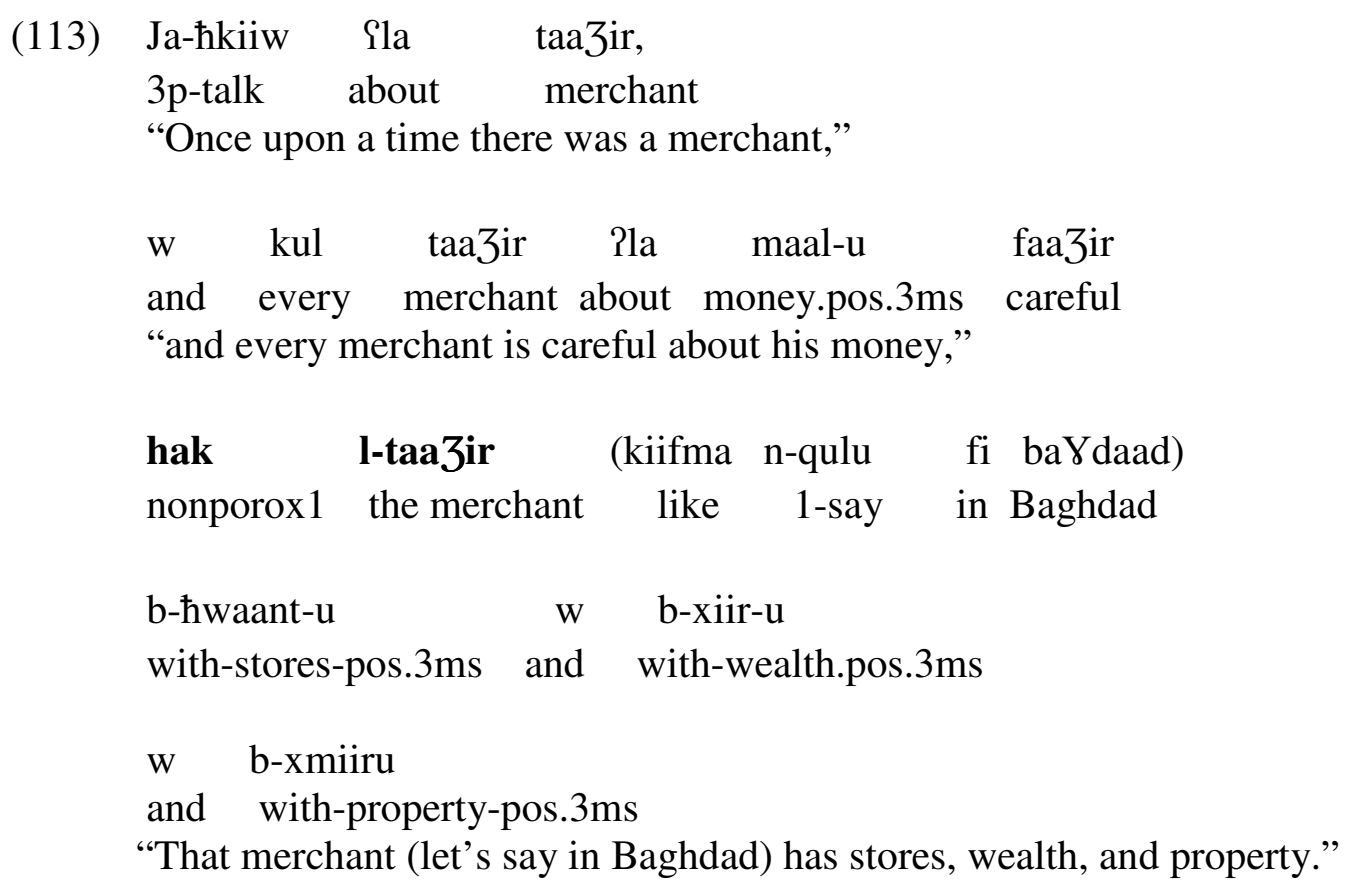


Similarly, in (114) the referent of the phrase hak l-haddad (that blacksmith) was determined to be in focus, because it is mentioned in a prominent syntactic position in the immediately preceding sentence.
(114) min yudwa sbah aka ${ }^{31}$ 1-haddad tbiib from tomorrow bcome.past.3ms nonprox 1 the-blacksmith doctor "The following day, that blacksmith became a doctor."

$\begin{array}{lllll}\text { illi } & \text { Sand-u } & \text { rukba } & \text { tu-3ai } & \text { fi-h } \\ \text { com } & \text { pos-3sm } & \text { knee } & 3 \mathrm{~m}-\text { hurt } & \text { in-3ms }\end{array}$
ja-ðrb-u hak l-haddad bi-l-mtarqa fli-ha ja-rtaah 3ms-tap-3ms nonpox 1 the-blacksmith with-the-hammer on-3fs 3ms-heal "If a person has arthritis in his back, the blacksmith hits him on it with the hammer and s/he heals; and if someone has a stomach pain ...."

(The Devil and the Blacksmith)

Two questions arise here: First, why is it that all the tokens of hak used to refer to entities higher than Familiar occurred in folk stories? Second, why was hak not used for statuses higher than Familiar in non-narrative discourse?

A possible answer to the first question is that the use of hak more frequently to refer to activated or in-focus entities in folk stories results from the influence of narrative discourse. Specifically, it is possible that speakers use hak to impose greater salience on important characters in the story.

Other studies found that discourse type influences the use of demonstratives or other referring expressions. For example, as mentioned in section 1.4, $\mathrm{OH}$ argues that the most critical factor that determines the speaker's choice among the English

\footnotetext{
${ }^{31}$ As mentioned above, the form aka is a variant of the demonstrative form hak.
} 
demonstratives it, this, and that in the genre of written advertisements is Focus, where Focus means the degree of attention the hearer should pay to the referent. For example, $\mathrm{OH}$ found that although the English demonstrative this is usually used to refer to new and important entities, it is used more frequently than that in central reference (i.e., when the referent is all or part of the advertised product) when referring to entities that are already mentioned in discourse. He argues that this constitutes compelling evidence that the demonstrative form this is a high focus form; since it is used to constantly direct the reader's attention to the advertised product. It is used repeatedly to refer to the advertised product, because it signals a meaning of "newness" and "importance" (135-136).

Mulkern (2003) introduces the notion of imposed salience: The "amount of prominence or foregrounding given to an entity by the speaker in an utterance for the purpose of signaling how the speaker intends the hearer to rank discourse entities relative to one another" (24-25). She argues that one important way speakers impose greater salience on a particular entity is through their use of referring expressions. When a speaker uses an expression which is lower on the Givenness Hierarchy (Gundel et al. 2003) than expected, s/he imposes greater salience on that entity by indicating to the addressee that there are additional contextual assumptions (25). Mulkern points out that since processing an expression that is lower in cognitive status requires more processing effort, "the expectation on the part of the addressee, then, is that this effort will yield additional contextual effects, such as more information about the referent, or information about the speaker's attitude toward the referent" (27).

Thus, it is possible that in narrative discourse, hak is used to refer to certain infocus or activated entities such as prominent characters or important objects, for the 
purpose for adding contextual effects by informing the addressee of the attitude of the speaker toward those characters. However, since results of the questionnaires conducted in this dissertation also indicate that participants chose the demonstrative hak to refer to entities which are familiar, but also to activated and in-focus entities, follow up work is needed to investigate whether the use of hak for the purpose of imposed salience is limited to narrative discourse.

The remaining question is: why was hak used only for the status it conventionally encodes, Familiar, but not for the higher statuses, Activated and In Focus, in nonnarrative discourse? It is possible that the infrequent use of hak to refer to entities with a cognitive status higher than Familiar results from an interaction of the Givenness Hierarchy with Grice Quantity Maxim (Grice 1975). Gundel et al. (1993) and Gundel and Mulkern (1998) suggest that since the Givenness Hierarchy forms an implicational scale, it gives rise to conversational implicature. Gundel et al. point out that "although the conventional meaning of the indefinite article in English (what it explicitly signals) is simply that the referent is at least type identifiable, use of this form conversationally implicates by Q1 that the addressee cannot uniquely identify the referent" (296). They also note that since conversational implicature is not an essential inference, a phrase with the indefinite article can be uniquely identifiable, or even familiar in some contexts (296).

Thus, it is possible that while the demonstrative hak conventially encodes the meaning Familiar, it conversationally implicates not activated, or in focus. However, since conversational implicature is not a necessary inference, the demonstrative hak can be used to refer activated or in-focus entities when communicators want to inform their addressees of their attitude for the purpose of imposed salience. In other words, 
communicators use hak to conversationally implicate that the referent is not activated or in focus unless they need to communicate their attitude toward the intended referent and add contextual effects. In order to test these possible explanations, further analysis of narrative and non-narrative texts is needed.

\subsubsection{Further restrictions on the demonstrative haðaka: The role of communicators' previous knowledge of the referent}

Results of the questionnaire and corpus studies conducted in this dissertation indicate that the demonstrative determiner haða signals the status Activated, and that the demonstrative determiner haðaka signals the status Familiar. Consistent with the Givenness Hierarchy predictions, results of the questionnaires as well as the corpus study indicate that both forms were used for the statuses they minimally require, and also for higher statuses. In both studies, tokens of the demonstrative determiner haða were determined to be acceptable in contexts biased toward the statuses Activated and In Focus, and tokens of the demonstrative haðaka were determined to be acceptable to be placed in contexts biased for the statuses Familiar, Activated, and In Focus.

Since both forms can be used for the statuses Activated and In Focus, we expect them to be interchangeable when referring to activated or in-focus entities. Results of the questionnaires conducted in this dissertation, however, suggest that in contexts where both forms satisfy cognitive status criteria (i.e., Activated or In Focus), they are not always interchangeable. In some of those contexts both forms were determined to be acceptable, while in others only the demonstrative haða, but not the demonstrative haðaka was determined to be acceptable. This suggests that there are other factors that further restrict the use of the demonstrative haðaka. For example, in ((115)-(117)) both 
forms are acceptable, while in (118) and (119) only haða as a determiner but not as a pronoun was possible.

(115) The addressee knows the neighbor that the speaker is talking about.

3arti hija lli Sawn-it-ni Sla tanðiif 1- daar neighbor-pos.1s she comp help-past.3fs-me on cleaning the-house "It is my neighbor who helped me clean my house."

1-ћaq nas mlah l-mra haði/ l-mra haðika the truth nice the woman prox2.3fs/the-women nonprox2.3fs "This woman/that woman is really nice."

(116) B knows the apartment that $\mathrm{A}$ is talking about but was not thinking about it before A mentioned it.

A: Salwa naql-it $\quad \begin{array}{rr}\text { min dar-ha } & \text { l-qdima } \\ \text { Salwa move.past-3fs from house-pos.3fs } & \text { the-old } \\ \text { w-Sraa-t } & \text { burtmaan } \\ \text { and-buy-past.3fs } & \text { apartment } \\ \text { "Salwa moved from her old house and bought an apartment." }\end{array}$

B: ih fi-bal-i

yes in-mind-pos.1s

w l-burtmaan haða/l-burtmaan haðaka

and the-apartment prox $2.3 \mathrm{~ms} /$ the apartment nonprox $2.3 \mathrm{~ms}$

$\begin{array}{llccc}\text { huwa } & \text { illi } & \text { habbit } & \text { ni-Sri-h } & \text { ana } \\ \text { he } & \text { comp } & \text { want.past.1s } & 1 \text {-buy-3ms } & \text { I }\end{array}$

"Yes and it is this apartment/that apartment that I wanted to buy" 
(117) The addressee already knows that Leila changes her mind everyday. The speaker knows that the addressee already knows that Leila changes her mind everyday.

A: Leila kul jum t-baddil raj-ha. Leila every day 3f-change mind-pos.3fs

"Leila changes her mind everyday"

B: w inti mqallq-ik l-mawðuuf haða/ l-mawðuuf haðaka and you bothering the-topic prox $1.3 \mathrm{~ms} /$ the-topic nonprox $2.3 \mathrm{~ms}$ "Is this issue/that issue bothering you?"

In examples (118) and (119) on the other hand, only the determiner haða, but not the determiner haðaka was chosen to refer to the noise and the doctor, respectively.

(118) Both speaker and addressee can hear a noise.

qallaq-ni l-his haða/ \# l-his haðaka
bother.past.3ms-1s the-noise prox $2.3 \mathrm{~ms} /$ the-noise nonprox $2.3 \mathrm{~ms}$ "This noise/\# that noise is bothering me"

(119) B doesn't know the doctor that $\mathrm{A}$ is talking about
A: ðahr-i
maiats
ju-3ai-ni.
back-pos.1s neg
3m-hurt-1s
"My back does not hurt anymore."

tbiib-i Sta-ni dwa ðarba ðarba doctor-pos.1s give-past.3ms-1s medication efficient efficient "My doctor gave me very efficient medication."
B: a $-i s m-u$
l-tbiil
haða/
\# l-tbiib
haðaka?
what-name-pos. $3 \mathrm{~ms}$ the-doctor prox $2.3 \mathrm{~ms} /$ the doctor nonprox $2.3 \mathrm{~ms}$ "What is the name of this doctor/ \# that doctor"

The fact that haðaka requires at least Familiar and can therefore be expected to refer to activated or in-focus referents, the restriction on this form in certain contexts where the referent is activated cannot be explained in terms of cognitive status and 
indicates that there are other factors that further restrict its use. The question then arises as to what other factors further restrict the choice among the demonstrative determiners haða and haðaka in contexts where cognitive status criteria for their use are met. One possible explanation for this restriction to be investigated further in future research is that this difference in use may have to do with the speech participants' previous knowledge of the referent prior to its previous mention. The demonstrative haðaka, seems to be restricted if the speech participants do not have shared knowledge of the referent prior to its recent mention, even if the referent is evoked in recent discourse.

In examples ((115)-(117)), where both forms were determined to be acceptable, the referent is known by the speaker and the addressee prior to the current conversation. In example (115) the neighbor can be assumed to be in focus, since it is mentioned in a prominent syntactic position in the previous sentence. Both speaker and addressee also have previous knowledge of the neighbor prior to the current conversation. Similarly, in (116) the apartment can be assumed to be activated, since it is mentioned in one of the two immediately preceding sentences. As mentioned in the context explanation that precedes the example, the apartment is also previously known by the speech participants prior to the current conversation. In (117), the fact that Leila changes her mind everyday can be assumed to be activated, since it is a fact stated in the previous sentence. It is also previously known by both speech participants prior to the current conversation.

In (118) and (119) where only haða, but not haðaka was determined to be acceptable, the intended referent is not known by both speech participants prior to the current conversation. In example (118), the phrase l-his haðaka (that noise) is not acceptable, while the phrase $l$ - $i$ is haða (this noise) is acceptable to refer to the noise. The 
noise is not something that is previously known by the speech participants, since it is taking place at the time of the current conversation. In (119) the doctor is known by speaker A but not by speaker B prior to the current conversation.

Cognitive status does not seem to explain this further restriction on haðaka, since according the Givenness Hierarchy framework, recent previous mention in discourse is a sufficient criterion for a referent to be assumed to be activated or in focus. Examples ((115)-(117)), however, seem to indicate that recent previous mention in the discourse is not a sufficient condition for the appropriate use of haðaka, since it has to be combined with the condition that both the speaker and the addressee already have shared knowledge of the referent prior to its recent mention ${ }^{32}$.

Although the notion of shared knowledge of a referent by the speech participants introduced here seems to be similar to Prince's information status Hearer-Old ${ }^{33}$ (Prince 1988), the information status Hearer-Old does not seem to account for this restriction either. According to Prince, for something to be hearer-old, the speaker either presumes that the hearer already has a mental representation of that entity, or if it is discourse-old by being introduced any time previously in the discourse regardless of whether the hearer has a previous mental representation of it or not (5). For example, according to Prince, the referent of the phrase l-tbiib haðaka which was just mentioned in the conversation in (119) repeated here in (120) is considered hearer-old, because the doctor was just mentioned by speaker A. As mentioned above, however, the phrase l-tbiib haðaka cannot be used here, since the doctor is known prior to the current conversation by speaker A only.

\footnotetext{
${ }^{32}$ It is possible that it is only the speaker who needs to have previous knowledge of the referent.

${ }^{33}$ Upper case is used to refer to the status iself, and lower case is used when the status is used to describe a referent.
} 
(120) B doesn't know the doctor that A is talking about

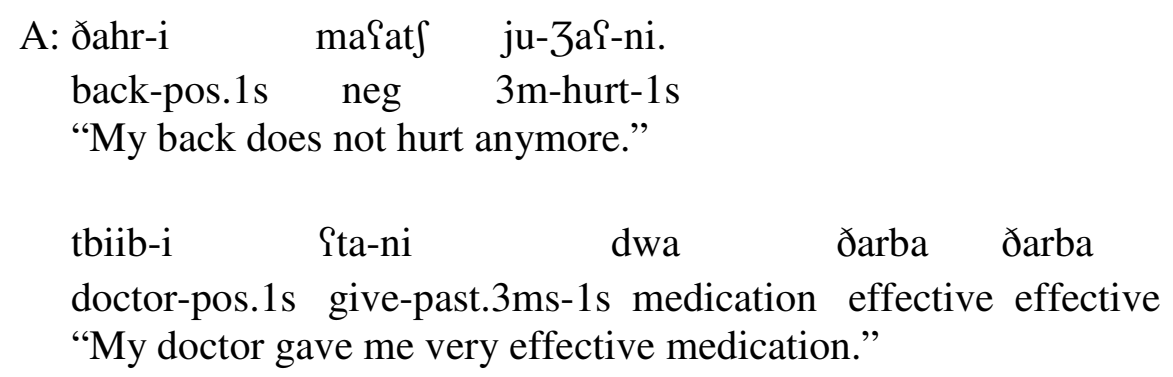
B: af-ism-u l-tbiib haða/ \#l-tbiib haðaka? what-name-pos. $3 \mathrm{~ms}$ the-doctor prox $2.3 \mathrm{~ms} /$ the doctor nonprox $2.3 \mathrm{~ms}$ "What is the name of this doctor/ \# that doctor?"

Prince's Hearer-Old status does not seem to account for the further restriction on haðaka either, because recent previous mention in the discourse is a sufficient condition for an entity to be hearer-old. It is not clear at this point whether a non-recent previous mention in the discourse (e.g., a referent is introduced at the beginning of a story and then reintroduced in the middle of that story) counts as previous knowledge in the sense that seems relevant for the restriction on haðaka, since the questionnaire consists of short pieces of text. Further research is therefore needed to address the following questions: 1) Is the demonstrative haðaka always restricted when speech participants do not have previous knowledge of the referent prior to its recent mention? 2) Is haða less preferred or even sometimes restricted when a referent is previously known by the participants? 3) Does non-immediate previous mention in the discourse (e.g., a referent is introduced at the beginning of a story and then reintroduced in the middle of that story) count as previous knowledge of the referent and restrict the demonstrative haðaka? 4) Is there a possible correlation between previous knowledge and the proximate non-proximate 
distinction (i.e., is the nonproximate haðaka allowed only when the referent is previously known to the interlocutors prior to the current conversation)? 


\section{BIBLIOGRAPHY}

Siid Sfax tayyah qdar 1-syouda. 1997. Al-Sariih, March, 25th, 1997.

Alo, tasma fiya? 1997. Al-Sariih, May, 20th, 1997.

Al-Irwi, Abdelaziz. 1989. Hikayaat Al-Irwi. 2nd ed. Vol. 1. Tunis: Al-Daar Al-Tunisiya Li-1-nachr.

- 1989. Hikayaat Al-Irwi. 2nd ed. Vol. 4. Tunis: Al-Daar Al-Tunisiya Li-l-nachr.

Aoun, Joseph, and Lina Choueiri. 2000. "Epithets". Natual Lanaguage \& Linguistic Theory(18): 1-39.

Ariel, Mira. 1998. Referring and accessibility. Journal of Linguistics(24): 67-87.

Baccar, Jalila. 2001. Junuun. Tunis: Daar Al Janoub li-l-nachr.

Baccar, Taoufik, ed. 2002. Masrah Ali Al Douaji. Tunis: Daar Al Janoub li-1-nachr.

Benmamoun, Elabbas. 2000. The feature structure of functional categories. Oxford/New York: Oxford Unviersity Press.

Boas, Franz. 1911. Introduction. In Handbook of American Indian languages. Vol. 1, 183. Washington: Smothsonian Institution.

Botley, Simon, and Tony McEnery. 2001. Proximal and distal demonstratives: A corpusbased Study. Journal of English Linguistics 29, (3): 214-33.

Brustad, Kristen E. 2000. The syntax of spoken Arabic. A comprehensive study of Moroccan, Egyptian, Syrian, and Kuwaiti dialects. Washington D.C.: Goergetown University Press.

Burenhult, Niclas. 2003. Attention, accessibility, and the addressee: The case of the Jahai demonstrative ton. Pragmatics 13, (3-4): 363-79.

Cowell, Mark W. 1964. A reference grammar of Syrian Arabic. Washington D.C.: Goergetown University Press.

De Saint-Exupéry, Antoine. 1997. Al-amir al-saghir. Trans. Hedi Balegh. Tunisia: Tunis.

Diessel, Holger. 2006. Demonstratives, joint attention, and the emergence of grammar. Cognitive Linguistics(17-4): 463-89. 
- 1999. Demonstratives: Form, function, and gammaticalization. Amesterdam: John Benjamins.

Dixon, R. M. W. 2003. Demonstratives: A cross-linguistic typology. Studies in Language 27, (1): 61-112.

Doss, Madiha. 1979. The position of the demonstrative $d a, d i$ in Egyptian Arabic: A diachronic inquiry. Annales Islamogiques 15.

Enfield, N. J. 2003. Demonstratives in space and interaction: Data from Lao speakers and implications for semantic analysis. Language 79, (1): 82-117.

Gibson, Michael. 1998. Dialect contact in Tunisian Arabic: Sociolinguistic and structural aspects. Ph.D. Dissertation, University of Reading.

Greenbaum, Sidney, and Randolph Quirk. 1990. A student' grammar of the English Language. London: Longman.

Grice, H. P. 1975. Logic and conversation. In Syntax and Semantics: Speech Acts., eds. P. Cole, J. L. Morgan. Vol. 3, 41-58. New York: Academic Press.

Gundel, Jeanette, Bryan Gordon, Bassene Mamadou, Linda Humnick, and Amel Khalfaoui. Testing predictions of the Givenness Hierarchy framework: A crosslinguistic investigation. Paper presented at $10^{\text {th }}$ International Pragmatic Conference, Göteborg, Sweden, July 8-13, 2007.

Gundel, jeanette, Nancy Hedberg, and Ron Zacharski. 1993. Cognitive status and the form of referring expressions in discourse. Journal of Pragmatics 69, (2): 274-307.

Gundel, Jeanette, and Ann E. Mulkern. 1998. Quantity implicatures in reference understanding. Pragmatics and Cognition(6): 21-45.

Haliday, Michael M. K., and Ruqaiya Hasan. 1976. Cohesion in English. London: Edward Arnold.

Himmelman, Nickolaus P. 1996. Demonstratives in narrative discourse: A taxomony of Universal uses. In Studies in Anaphora., ed. Barbara Fox. Amesterdam/Philadelphia: John Benjamins Publishing Company.

Holes, Clive. 2004. Gulf Arabic. London and New York: Routlege.

Kaiser, Elsi Miia Katarina. 2003. The quest of a referent: A crosslinguistics look at reference resolution. PhD. Dissertation, University of Pennsylvania.

Khaidov, S. M. 1966. The dialect divisions of Lak. Studia Caucassica(2): 9-18. 
Khalfaoui, Amel. Demonstratives in Tunisian Arabic: Beyond spatial distance. Paper presented at North American Conference on Afroasiatic Linguistics 36 (NACAL 36), Chicago, Illinois, USA, March 14-16, 2008.

. 2007. A cognitive approach to analyzing demonstratives in Tunisian Arabic. In Perspectives on Arabic Linguistucs XX., ed. Mustafa E. Mughazy, 169-186. Amesterdam/Philadelphia: John Benjamins.

- 2004. Associations between cognitive status and the form of referring expressions in Tunisian Arabic: An application of the Givenness Hierachy Theory. Master's Thesis, University of Minnesota, Twin Cities.

. The choice between the demonstrative $h a ð a$ as a pronoun and as a determiner in Tunisian Arabic: A Relevance Theoretic account. Paper presented at I North Amrican Workshop on Pragmatics (I NAWPRA), Toronto, Canada, October 3-5, 2008.

. A cognitive explanation for communicators' avoidance of ambiguous forms: The case of the Arabic demonstrative haða. Paper presented at the $23^{\text {rd }}$ Arabic Linguistic Symposium. University of Wisconsin, Milwaukee, USA April 3-5, 2009.

Lawson, Sarah, and Itesh Sachdev. 2000. Code Switching in Tunisia: attitudinal and behavioral dimensions. Journal of Pragmatics 32, (9): 1343-61.

Lyons, John. 1977. Semantics. Vol. 2. New York: Cambridge University Press.

Mulkern, Ann E. 2003. Cognitive status, discourse salience and information structure: Evidence from Irish and Oromo. PhD. Dissertation, University of Minnesota, Twin Cities.

Oh, Sun-Young. 2001. A focus-Based study of English demonstrative reference: With special reference to the genre of written avertisements. Journal of English Linguistics 29, (2): 124-48.

Omar, Margaret K. 1976. Levantine and Egyptian Arabic. Washignton D.C.: Foreign Service Institue.

Pope, M. K. 1934. From Latin to modern French. Manchester: Manchester University Press.

Prince, Ellen. 1992. The ZPG letter: Subjects, definiteness, and information status. In Discourse description: diverse analyses of a fund raising text., eds. S. Thompson, W. Mann, 295-325. Philadelphia/Amesterdam: John Benjamins.

Rehg, K. L. 1981. Ponapean reference gammar. Honolulu: University of Hawaii Press. 
Saada, Hachemi M. 1967. The verb in Tunisian Arabic. Master's Thesis. University of Minnesota.

Schiffrin, Deborah. 2006. In other words: Variation in reference and narrative. New York: Cambridge University Press.

Shlonsky, Ur. 2004. The form of semitic noun phrases. Lingua 114, (12): 1465-526.

Sperber, Dan, and Deirdre Wilson. 2006. Relevance Theory. In The Handbook of Pragmatics., eds. Laurence R. Horn, Ward Gregory, 607-632. Oxford: Blackwell. 1986/1995. Relevance: Communication \& cognition. 1st \& 2nd ed. London: Blackwell.

Stanovich, Keith E. 2004. How to think straight about psychology. Boston: Allyn \& Bacon, Inc.

Strauss, Susan. 2002. This, that, and it in Spoken American English: A demonstrative system of gradient focus. Language Sciences 24, (2): 131-52.

Sweet, Henry. 1898. A short historical English grammar. London: Oxford University Press.

Talmudi, Fathi. 1980. The Arabic dialect of Susa (Tunisia). Göteborg: Acta Universitatis Gothoburgensis.

1980. A morphosyntactic study of Romance verbs in the Arabic dialects of Tunis, Susa, and Sfax. Göteborg: Acta Universitatis Gothoburgensis.

Thackston, M. Wheeler. 2000. An introduction to Koranic and calssical Arabic. An elementry grammar of the language. Maryland: IBEX Publishers Bethesda.

Versteegh, Kees. 1997. The Arabic language. Edinburgh: Edinburgh University Press.

Youssi, Abderrahim. 1992. Grammaire et lexique de l'Arabe Marocain moderne. Casablanca: Wallada. 


\section{Appendix I: Coding Protocol for Statuses on the Givenness Hierarchy}

(Gundel, Hedberg and Zacharski 1993) ${ }^{34}$

Last updated July, 2004

\section{USING THE CODING PROTOCOL}

The terms IN FOCUS, ACTIVATED, FAMILIAR, UNIQUELY IDENTIFIABLE, REFERENTIAL, AND TYPE IDENTIFIABLE each describe a cognitive status on the Givenness Hierarchy (Gundel, Hedberg and Zacharski 1993). Cognitive statuses are properties of cognitive entities/mental representations. When determining cognitive status using the protocol, imagine you are the speaker/writer and ask yourself what you can assume about the cognitive status of the intended interpretation/referent for the addressee at the point just before the form is encountered. Check the criteria for each status in the order they are listed below. That is, start with the cognitive status IN FOCUS. If none of the criteria apply, try ACTIVATED. If none of the criteria apply, try FAMILIAR, and so on. Stop when you find a criterion that applies. This is the highest cognitive status for the referent/interpretation you are checking.

\section{A referent is IN FOCUS if it meets at least one of the following criteria:}

1. It is mentioned in main clause subject position in the immediately preceding sentence/clause.

(1) Midge pushed thick, wiry black hair back from her square forehead with a sturdy brown arm. Nothing unsubstantial or fairylike about her. (from Murder after Hourse, Agatha Christie)

(2) John Kerry lost in Ohio. This cost the Senator the election.

2. It is mentioned earlier in the same sentence.

(3) You can wear my scarf if you can find it.

(4) If you stand on this chair, the chair will break.

3. It is mentioned in syntactic focus position of the immediately preceding clause (i.e., postcopular position of a cleft or existential sentence).

(5) There was a mouse on the table. It was very large.

(6) It was the dog that Bill was afraid of. He was very large.

\footnotetext{
${ }^{34}$ Note: These are sufficient, not necessary criteria.
} 
4. It is a higher level topic that is part of the interpretation of the preceding clause (whether it is overtly mentioned there or not).

(7) The kitchen has a new countertops and a beautiful tile floor. There's also a big walkthrough closet. Would you like to take a look at $\underline{\text { it? }}$ Both the kitchen (criterion 4) and the closet (criterion 3) are in focus.

5. It was mentioned in the two immediately preceding clauses.

(8) It was the dog that Bill was afraid of. Small animals didn't usually frighten him. He was very large.

(9) A: She will be nice to Gerda and she will amuse Henry, and she'll keep John in a good temper and I'm sure she'll be most helpful with David -

B: David Angkatell?

A: Yes. He's just down from Oxford. (from Murder after Hours, Agatha Christie)

6. It is the event denoted by the immediately preceding sentence.

(10) John fell off his bike. This happened yesterday.

\section{A referent is ACTIVATED if it meets one of the following criteria.}

1. It is mentioned in one of the immediately preceding two sentences.

(11) Central to the case was a Lewinsky-Tripp conversation that Mrs. Tripp taped on Dec. 22, 1997. This was the last talk between the two women that Mrs. Tripp recorded.

2. It is something in the immediate spatio-temporal context.that is activated by means of a simuaneous gesture or eye gaze)

(12) (looking at the wrench) Please hand me that (wrench (over there)) 
3. It is a proposition, fact, or speech act associated with the eventuality (event or state) denoted by the immediately preceding sentence(s).

(13) A. John fell off his bike.

B. That's not true.

(14) A. John fell off his bike.

B. Can you say that again.

\section{A referent is FAMILIAR if it meets one of the following criteria.}

1. It was mentioned at any time previously in the discourse.

(15) A Phillipine Airlines jet with 290 people aboard was hijacked today by a man who took everyone's money and then parachuted to the ground outside Manila's airport and the passengers were let off safely. The jetliner left Davao City, in the southern Phillipines, for the 90-minute flight to Manila with 278 passengers and 12 crew aboard, PAL said. The hijacker, wearing a blue ski mask and carrying a handgun...

2. It can be assumed to be known by the hearer through cultural/encyclopedic knowledge or shared personal experience with the speaker.

(16) If one takes a step back and looks at the rest of this week's music-group news, the situation looks bad for ugly, unpredictable rock 'n' roll: one of the most popular American rock bands of the 90's

\section{A referent is UNIQUELY IDENTIFIABLE if it meets one of the following criteria:}

1. The referring form contains adequate descriptive/conceptual content to create a unique referent.

(17) s: hello can I help you

$\mathrm{u}$ : yeah I want t- I want to determine the maximum number of boxcars of oranges that I can get to Bath by 7 a.m. tomorrow morning so hm so I guess all the boxcars will have to go through oran- through Corning because that's where the orange juice factory is [Trains Corpus. Heeman \& Allen 1995]

2. A unique referent can be created via a 'bridging inference' by association with an already activated referent.mm(e.g., A house....the front door)

(18) She got into bed,laid her head on the pillow, and in two minutes was sleeping like a child. (from Murder after Hours, Agatha Christie)। 
(19) (Looking at a box) I think the bottom fell out.

A referent exists, is REFERENTIAL, if it meets one of the following criteria.

1. It is mentioned subsequently in the discourse.

(20) When my youngest child was 3 or so, we were at a friend's house visiting and my friend was babysitting her infant nephew.

2. It is evident from the context that the speaker intends to refer to some specific entity.

(21) I want to tell you about this strange guy I saw today.

An interpretation is TYPE IDENTIFIABLE if the sense of the phrase (the descriptive/conceptual content it encodes) is understandable.

(22) I don't have a VCR and neither does my neighbor.

(23) Whenever Mary passes that store, she always picks up a newspaper. 


\section{Appendix II: Consent form}

\section{Reference in Tunisian Arabic}

You are invited to be in a research study of reference in Tunisian Arabic. You were selected as a possible participant, because you are a native speaker of Tunisian Arabic. We ask that you read this form and ask any questions you may have before agreeing to be in the study. This study is being conducted by: Amel khalfaoui, graduate student at the University of Minnesota

Background Information

The purpose of this study is to evaluate claims for reference based on evidence from other languages

\section{Procedures:}

If you agree to be in this study, we would ask you to do the following things:

1) Read the explanation that precedes each sentence or short conversation.

2) Read the short sentence or conversation

3) Read the 11 choices and circle the ones you judge to be appropriate to be placed in the blank space in the preceding sentence or short conversation.

Risks and Benefits of being in the Study

This study has no risks or benefits.

\section{Compensation:}

There is no compensation for this study

\section{Confidentiality:}

The records of this study will be kept private. In any sort of report we might publish, we will not include any information that will make it possible to identify a subject. Research records will be stored securely and only the researcher will have access to the records.

\section{Voluntary Nature of the Study:}

Participation in this study is voluntary. Your decision whether or not to participate will not affect your current or future relations with the University of Minnesota. If you decide to participate, you are free to not answer any question or withdraw at any time without affecting those relationships.

\section{Contacts and Questions:}

The researcher conducting this study is: Amel Khalfaoui. You may ask any questions you have now. If you have questions later, you are encouraged to contact her at 612-331-2340, khal0035@umn.edu. My advisor is Jeanette Gundel, 612-624-7564, Gunde003@umn.edu.

If you have any questions or concerns regarding this study and would like to talk to someone other than the researcher, you are encouraged to contact the Research Subjects' Advocate Line, D528 Mayo, 420

Delaware St. Southeast, Minneapolis, Minnesota 55455; (612) 625-1650.

You will be given a copy of this information to keep for your records.

\section{Statement of Consent:}

I have read the above information. I have asked questions and have received answers. I consent to participate in the study.

Signature:

Date:

Signature of Investigator:

Date: 


\section{Appendix III: Pilot Questionnaire (with English gloss and translation)}

\section{Instructions:}

In this questionnaire there are short texts with balank spaces in them. In every short text speaker (A) says something to speaker (B). Sometimes speaker (B) does not reply. Every short text is preceded by a context explanation and followed by 11 choices.

1) Read the context explanation that precedes each sentence or short conversation.

2) Read the short sentence or conversation

3) Read the 11 choices and circle the ones you judge to be appropriate to be placed in the blank space in the preceding sentence or short conversation.

\section{A knows the neighbor that $B$ is talking about.}
A: 3arti
hija
lli Sawn-it-ni
Sla tanðif 1-daar
neighbor-pos.1s she comp help-past.3fs-1s
"It is my neighbor who helped me clean the house"

l-haq nas mlaah
the truth people nice
"............ is really nice"

B: (no reply)

1. hak l-mra haðika (that woman (literally, that woman that))

2. 3arti (my neighbor)

2. ha- 1-mra (this woman)

4. 1-3ara (the neighbor)

5. 1-mra haði ( this woman)

6. haðika (that)

7. 1-mra haðika (that woman)

8. ha l-mra haði (this woman (literally, this woman this))

9. 1-mra (the woman)

10. haði (this)

11. hak 1-mra (that woman) 


\section{A knows the apartment that $B$ is talking about}
A: Salwa naql-it
min daar-ha
1-qdima
Salwa
move.past.3fs
from house-pos.3fs
the-old
w Sraa- $t \quad$ burtmaan
and-buy.past.3fs apartment
"Salwa moved from her old house and bought an apartment."
B: ih fi-bal-i w........ huwa lli habb-it ni-frii-h ana yes in-mind-pos.1s and....... he comp want.past.1s 1-buy-3ms I "Yes and its ............................ which I wanted to buy."
1. hak 1-burtmaan haðaka (that apartment (literally, that apartment that))
3. nafs 1-burtmaan (the same apartment)
4. ha- 1-burtmaan (this apartment)
4. burtmaan (an apartment)
5. 1-burtmaan haða ( this apartment)
6. haðaka (that)
7. 1-burtmaan haðaka (that apartment)
8. ha 1-burtmaan haða (this apartment (literally, this apartment this))
9. 1-burtmaan (the apartment)
10. haða (this)
11. hak 1-burtmaan (that apartment) 


\section{$\underline{\text { Both } A \text { and } B \text { can hear a noise. }}$}

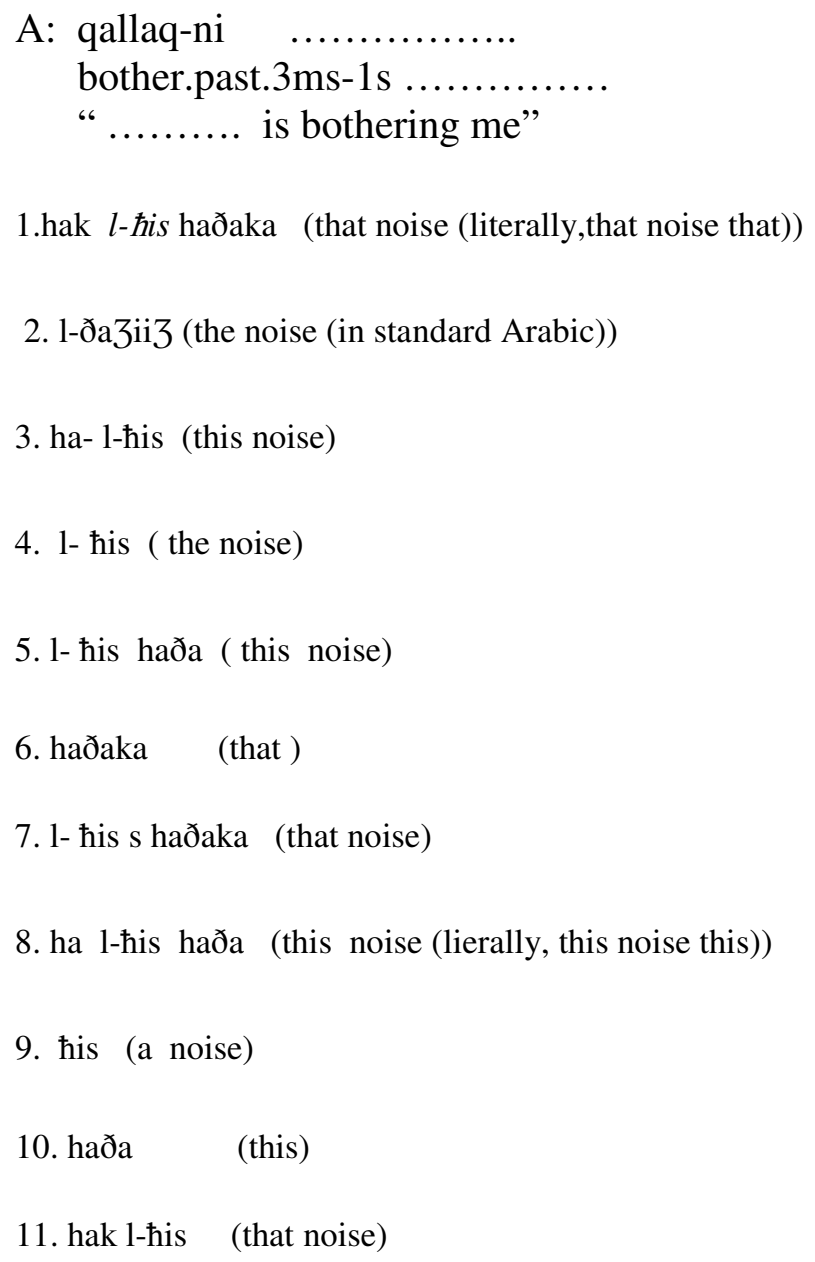


B already knows the fact that Leila changes her mind everyday. A knows that B already knows the the fact that Leila changes her mind everyday.
A: Leila kul jum t-baddil raj-ha.
Leila every day 3f-change mind-pos.3fs
"Leila changes her mind everyday."
w-l- haq $\quad$............. mqallqit-ni
and the- truth .......... bothering-1s
"and ........... is really bothering me."
B: (no reply)
1. hak 1-hkaja haðika (that story (literally, that story that))
2. ha-l-hkaja (this story)
3. ћkajit-na (our story)
4. tbifit-ha (her story)
5. 1-ћkaja haði ( this story)
6. haðika (that)
7. 1-hkaja haðika (that story)
8. ha 1-hkaja haði (this story (literally, this story this))
9. 1-hkaja (the story)
10. haði (this)
11. hak 1-ћkaja (that story) 
B knows that somebody gave Sonia a gift but she was not thinking about it [the gift] before A mentioned it.
A: Sonia
Szib-ha..........
Sonia
please.past.3ms-3fs
"Sonia was pleased by ,"
B: Sraf-t-u
bas ji-\$3ib-ha.
know.past-1s-3ms fut 3ms-please-3fs
"I knew it was going to please her."
1. hak l-kadə haðaka (that gift (literally, that gift that))
2. kaduha (her gift)
3. ha- 1-kadə (this gift)
4.1-kadə mtaSha (her gift)
5. 1-kadə haða ( this gift)
6. haðaka (that)
7. 1-kadə haðaka (that gift)
8. ha 1-kadə haða (this gift (literally, this gift this))
9. 1-kadə (the gift)
10. haða (this)
11. hak 1-kadə (that gift) 


\title{
B knows the accountant, but he was not thinking about him before A mentioned
} him [the accountant]

\author{
A: talb-ik \\ call.past.3ms-2s ............. \\ "............ called you," \\ B: waqtah? \\ when \\ "when?" \\ 1. hak 1-kuntaabli haðaka (that accountant (literally, that accountant that) ) \\ 2. 1-muhasib (the accountant (in standard Arabic)) \\ 3. ha- 1-1-kuntaabli ( this accountant) \\ 4. kuntaabli (an accountant) \\ 5. 1-kuntaabli haða (this accountant) \\ 6. haðaka (that) \\ 7. 1-kuntaabli haðaka (that accountant (literally, this accountant this)) \\ 8. ha 1-kuntaabli haða (this accountant) \\ 9. 1-kuntaabli (the accountant) \\ 10. haða (this) \\ 11. hak 1-kuntaabli (that accountant)
}


(B) bought a house and (A) is asking her about it. (A) has not seen the house yet. (B) knows that (A) has not seen the house yet.

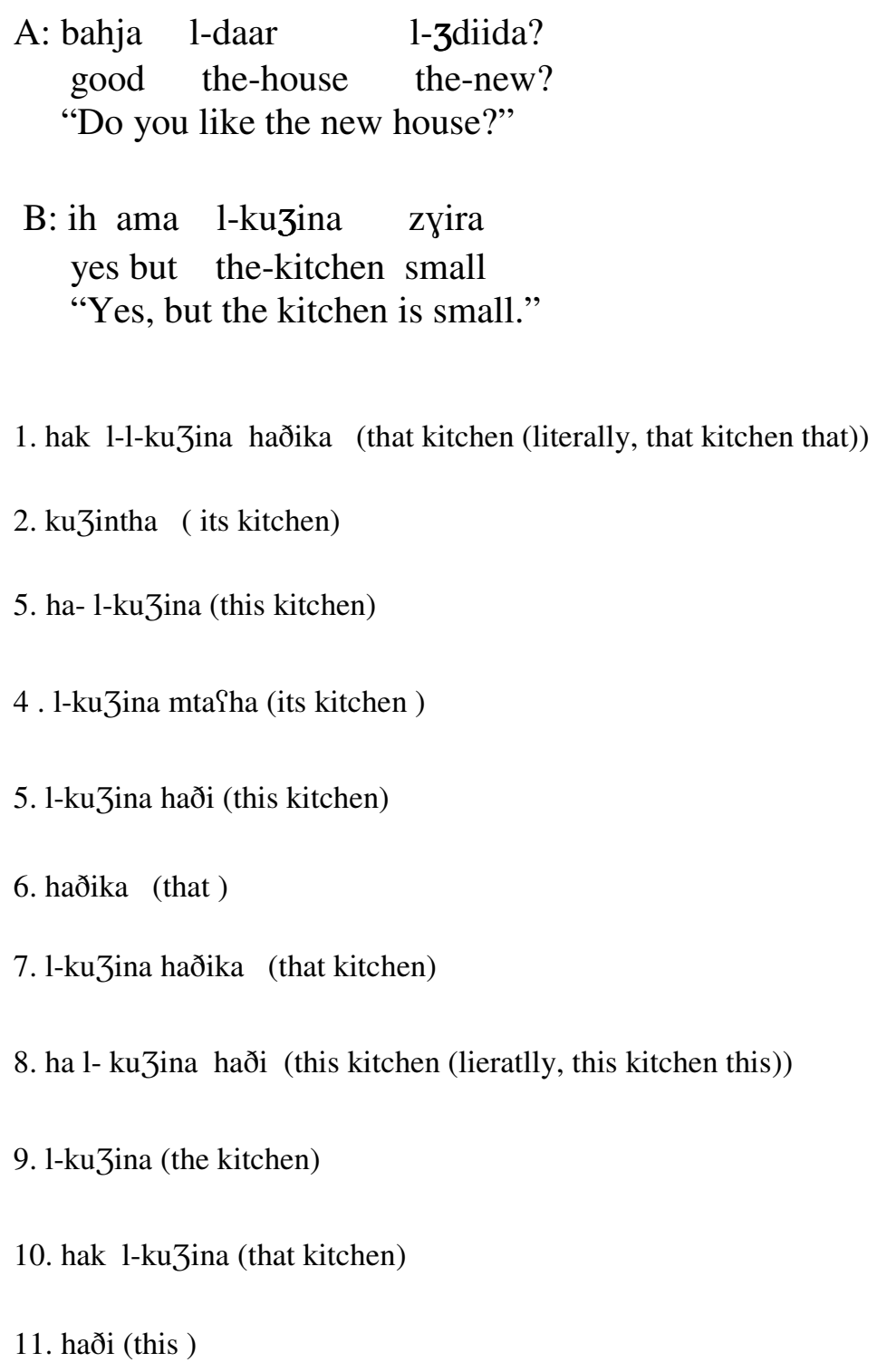




\section{A is not talking about a particular car.}
A: smai-t
illi
Leila t-ћib
ti- $\int \mathrm{ri}$
hear.past-1s comp Leila 3s-want
3fs-buy
"Leila wants to buy.........."
B: (no reply)
1. hak 1-karhba haðika (that car (literally, that car that))
2. karhba (a car)
3. ha- 1-karhba (this car)
4. krihba (a car (diminutive))
5. 1-karhba haði ( this car)
6. haðika (that)
7. 1-karhba haðika (that car)
8. .ha 1-karhba haði (this car (literally, this car this))
9. 1-karhba (the car)
10. hak 1-karhba (that car)
11. haði (this ) 


\section{B doesn't know the grocer that $A$ is talking about. A knows that $B$ doesn't know the} grocer
A: ma nu-ftur- $\int$ l-sbah fi-l-dar.
neg 1-eat-neg the-morning in-the-house.
kul jum ni-ţadda...................... ni-Sri kaskrut
every day 1-pass .................... 1-buy sandwich

"I don't eat at home in the morning. Everyday, I stop by ........ and buy a sandwich."

1. hak 1-9attar lli bi3nabna haðaka (that grocer next door (literally, that grocer next door that))

2. 1-९attar 1-li bi3nab darna (the grocer close to our house)

3. ha 1-Sattar lli bi3nab darna (this grocer next door)

4. 1-\{attar lli bi3nabna aћna (the grocer next door)

5. 1-Yattar lli bi3nab darna haða (this grocer next door )

6. haðaka (that)

7. 1-\{attar 1-li bi3nabna haðaka ( that grocer next door (literally, hat grocer next door that ))

8. ha 1-\{attar 1-li bi3nabna haða (this grocer next door (literally, this grocer next door this))

9. 1-Yattar 1-li bi3nabna (the grocer next door)

10. haða (this)

11. hak 1-Sattar 1li bi3nabna (that grocer next door ) 
$B$ does not know the book that $A$ is talking about. A knows that $B$ does not know it [the book].
A: 1-bariћ Juft
B: (no reply)
1. hak 1-ktaab haðaka (that book (literally, that book that))
2. 1-ktaab (the book)
3. ha- 1-ktaab (this book)
4. ktaab (book)
5. 1-ktaab haða (this book)
6. haðaka (that)
7. 1-ktaab haðaka (that book)
8. ha 1-ktaab haða (this book, (literally, his book this))
9. ktaab tahfun (a nice book)
10. haða (this )
11. hak 1-ktaab (that book) . Sla numuw 1-tifl

the-yesterday see.past.1s.............on development the-child

"Yesterday, I saw a book on child development in the library." 


\section{A doesn't know the doctor that $B$ is talking about}

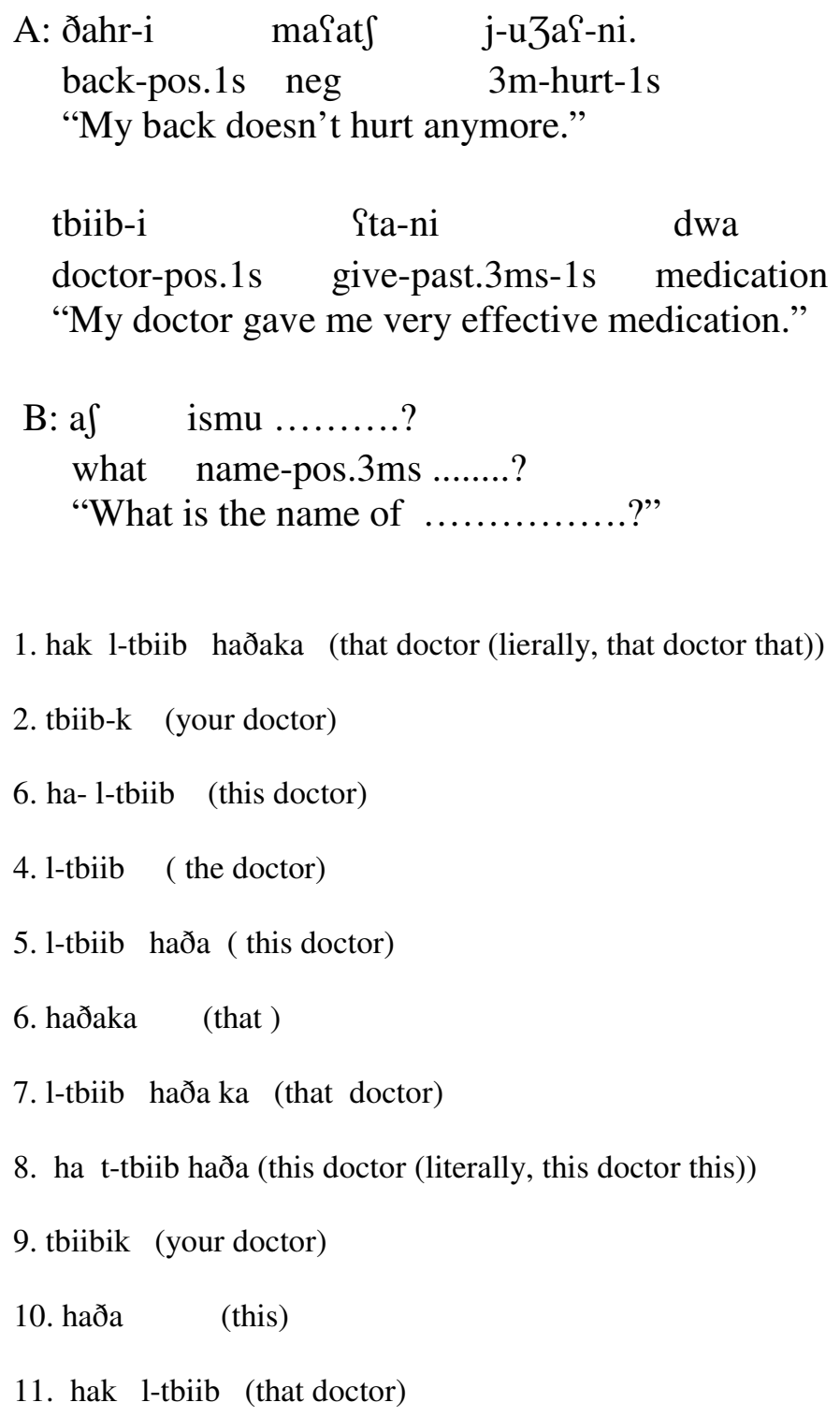




\section{Appendix IV: Revised Questionnaire (with English gloss and translation) $)^{35}$}

\section{Instructions}

In this questionnaire there are 14 questions. In every question, there is a context explanation followed by a short conversation between two people (A) and (B) or a sentence followed by 11 choices.

1) Read the context explanation that precedes each sentence or short conversation.

2) Read the short sentence or conversation

3) Read the 11choices and circle the ones you judge to be appropriate to be placed in the blank space in the preceding sentence or short conversation.

\section{Question 1}

\section{B knows the dog that $A$ is talking about}

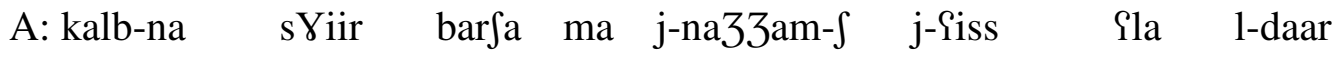 dog-pos.1s small very neg 3ms-can-neg 3ms-watch on the-house "Our dog is very small. He can't watch the house."
B : mniin $\quad$ rit-u inti $\quad \ldots \ldots \ldots \ldots \ldots \ldots \ldots$ ?
where buy-3ms you
"Where did you buy .........................?"
1. hak 1-kalb haðaka (that dog (literally, that dog that)
2. kalbik (your dog)
3. ha- 1-kalb (this dog)
4. 1-kalb 1-s Yiir (the small dog)
5. 1-kalb haða (this dog)
6. haðaka (that)
7. 1-kalb haðaka (that dog)
8. ha l-kalb haða ( this dog (literally, this dog this))
9. 1-kalb (the dog)

\footnotetext{
${ }^{35}$ As mentioned in section 2.3.2.1 in chapter 2, the revised questionnaire consists of the 11 questions given in the pilot after being revised, and three additional questions.
} 

10. haða
(this)
11. hak 1-kalb
(that dog)

\section{Question 2}

\section{Speaker B knows that Samia has been ill.}
A: fi baalik
ill Samia murðit?
in mind-pos.2sm comp Samia got.sick
"Do you know that Samia got sick?"
B: ih taibit-ha barfa
yes make.tired-3fs much
"Yes, .............. was very serious."
1. hak 1-marða haðika (that illness (literally, that illness that))
2. marða (illness)
3. ha- 1-marða (this illness)
4. 1- marða (the illness)
5. 1- marða haði ( this illness)
6. haðika (that)
7. 1-mra haðika (that illness)
8. ha 1-mra haði (this illness (literally, this illness this))
9. marðitha (her illness)
10. hak 1-marða (that illness)
11. haði (this) 


\section{Question 3}

\section{A knows the neighbor that $B$ is talking about.}

\section{A: Skuun Sawnik Sla tanðiif 1-daar? \\ Q help.past.3ms on cleaning the house}

"Who helped you clean the house?"

B: 3arti hija lli Sawnit-ni.

neighbor-pos.1s she comp help-past.3fs-1s

"It is my neighbor who helped me clean the house"

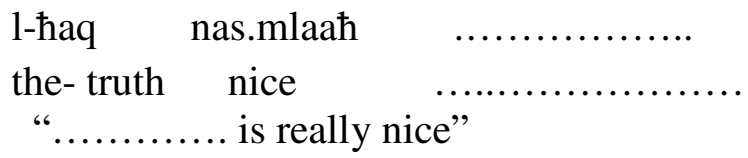

1. hak 1-mra haðika (that woman (literally, that woman that))

2. 3arti (my neighbor)

3. ha- 1-mra (this woman)

4. 1-3ara (the neighbor)

5. 1-mra- haði ( this woman)

6. haðika (that)

7. 1-mra haðika (that woman)

8. ha l-mra haði (this woman (literally, this woman this))

9. 1-mra (the woman)

10. hak 1-mra (that woman)

11. haði. (this) 


\section{Question 4}

\section{B knows the apartment that $A$ is talking about}

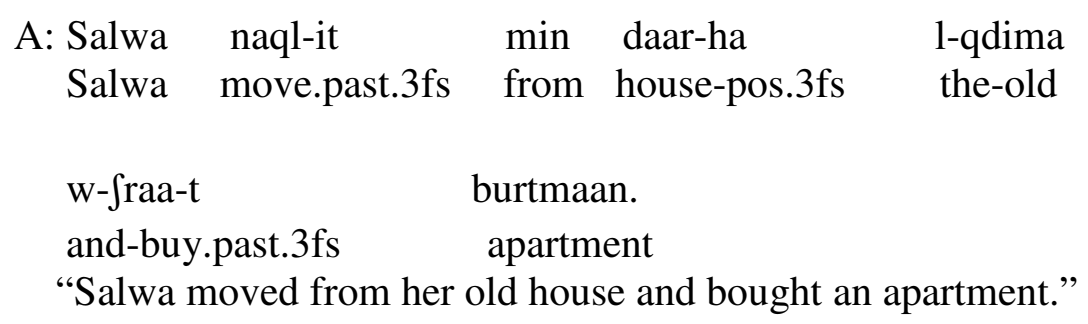

$\begin{array}{llll}\text { ma Paat } & \text { t-hib } & \text { tu-skun fi daar. } \\ \text { neg } & \text { 3fs-want } & \text { 3fs-live in house }\end{array}$

"She no longer wants to live in an apartment."

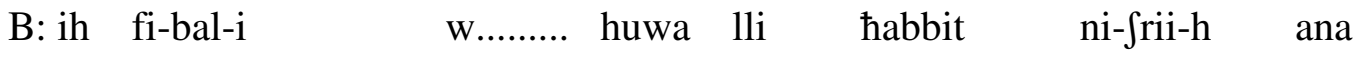
yes in-mind-pos.1s and....... he comp want.past.1s 1-buy-3ms I "Yes and its ........................... which I wanted to buy."

1. hak 1-burtmaan haðaka (that apartment (literally, that apartment that))

2. nafs 1-burtmaan (the same apartment)

3. ha- 1-burtmaan (this apartment)

4. burtmaan ( an apartment)

5. 1-burtmaan haða ( this apartment)

6. haðaka (that)

7. 1-burtmaan haðaka (that apartment)

8. ha 1-burtmaan haða (this apartment (literally, this apartment this))

9. 1-burtmaan (the apartment)

10. haða (this)

11. hak l-burtmaan (that apartment) 


\title{
Question 5
}

\section{Someone and his friend are talking and hearing a noise. One of them said:}

\author{
A: qallaq-ni \\ bother.past. $3 \mathrm{~ms}-1 \mathrm{~s}$.............. \\ "........... is bothering me" \\ 1. hak 1-his haðaka (that noise (literally, that noise that)) \\ 2. 1-ða3ii3 (the noise (in standard Arabic)) \\ 3. ha- 1-his (this noise) \\ 4. 1- his ( the noise) \\ 5. 1-his haða ( this noise) \\ 6. haðaka (that) \\ 7. 1- his s haðaka (that noise) \\ 8. ha 1-his haða (this noise (lierally, this noise this)) \\ 9. his (a noise) \\ 10. haða (this) \\ 11. hak 1-his (that noise)
}




\section{Question 6}

\section{B knows the fact that Leila changes her mind everyday.}

\begin{tabular}{|c|c|c|}
\hline $\begin{array}{l}\text { A: Leila } \\
\text { Leila }\end{array}$ & $\begin{array}{ll}\text { kul } & \text { juum } \\
\text { every } & \text { day }\end{array}$ & $\begin{array}{l}\text { t-baddil } \\
\text { 3f-change }\end{array}$ \\
\hline
\end{tabular}

B: $w$ inti $\ldots \ldots \ldots \ldots \ldots \ldots . \ldots . \ldots . \ldots$ m-qallqik ?

and you 3ms-bothiring

"and is................. bothering you?"

1. hak 1-mawðuuf haðaka (that story (literally, that story that))

2. mawðuuSha (her story)

3. ha-1-mawðuuf (this story)

4. 1-mawðuuf ( the story)

5. 1-mawðuuf haða ( this story)

6. haðaka (that)

7. 1-mawðuu haðaka (that story)

8. ha 1-mawðuuf haða (this story (literally, this story this))

9. mawðuů (the story)

10. haða (this)

11. hak 1-mawðuuf (that story) 


\title{
Question 7
}

\section{speaker A knows that the gift but she was not thinking about it [the gift] before B}

\section{mentioned it.}

\author{
A: mfiit talliit Sla Sonia 1-baarih




\section{Question 8}

Both $A$ and $B$ know the accountant, but B was not thinking about him (i.e... the accountant) before A mentioned him.
A: ma tlab-ni
had?
neg call.past.3ms-1s nobody
"No body called me?"
B: talb-ik ...............
call.past.3ms-2s.............
"............called you."
1. hak 1-kuntabli haðaka (that accountant (literally, that accountant that))
2. 1-muhaasib (the accountant (in standard Arabic))
3. ha- 1-kuntabli ( this accountant)
4. kuntabli (an accountant)
5. 1-kuntabli haða (this accountant)
6. haðaka (that)
7. 1-kuntabli haðaka (that accountant)
8. ha 1-kuntabli haða (this accountant (literally, this accountant this) )
9. 1-kuntabli (the accountant)
10. haða (this)
11. hak 1-kuntabli (that accountant ) 


\title{
Question 9
}

\section{(B) bought a house and (A) is asking her about it because she has not seen it yet.}

\author{
A: bahija 1-daar 1-3dida? \\ good the-house the-new? \\ "Do you like your new house?" \\ B: ih ama...................... 3Yiira

yes but small \\ "Yes, but ............. small." \\ 1. hak 1-kußina haðika (that kitchen (literally that kitchen that)) \\ 2. ku3initha (its kitchen) \\ 3. ha- 1-ku3ina (this kitchen) \\ 4. 1-ku3ina mtaiha (its kitchen) \\ 5. 1-ku3ina haði (this kitchen) \\ 6. haðika (that) \\ 7. 1-ku3ina haðika (that kitchen) \\ 8. ha l- kußina haði (this kitchen (literally, this kitchen this)) \\ 9. 1-ku3ina (the kitchen) \\ 10. hak 1-ku3ina (that kitchen) \\ 11. haði (this )
}




\section{Question 10}

\section{$\underline{A}$ is not talking about a particular car.}

\begin{tabular}{|c|c|c|c|c|}
\hline $\begin{array}{ll}A: & \text { smai-t } \\
\text { hear past-1s }\end{array}$ & $\begin{array}{l}\text { illi } \\
\text { comp }\end{array}$ & $\begin{array}{l}\text { Leila } \\
\text { Leila }\end{array}$ & $\begin{array}{l}\text { t-hib } \\
\text { 3s-want }\end{array}$ & $\begin{array}{l}\text { ti-Sri .............. } \\
\text { 3fs-buv }\end{array}$ \\
\hline
\end{tabular}

1. hak 1-karhba haðika (that car (literally, that car that))

2. karhba (a car)

3. ha- 1-karhba (this car)

4. krihba (a car (diminutive))

5. 1-karhba haði (this car)

6. haðika (that)

7. 1-karhba haðika (that car)

8. ha l-karhba haði (this car (literally, this car this))

9. 1-karhba (the car)

10. hak 1-karhba (that car)

11. haði (this ) 


\title{
Question 11
}

\section{(A) and (B) are sitting in their office at work talking. (A) doesn't know the grocer that $(B)$ is talking about.}

\author{
A: tu-ftur fi 1-daar 1-sbaah? \\ 2-eat in the-house the-morning? \\ "Do you eat at home in the morning?" \\ B: ma nu-ftur- $\int$ 1-sbaah fi-l-daar. \\ neg 1-eat-neg the-morning in-the-house. \\ kul jum ni-tiadda...................... ni-fri kaskruut \\ every day 1-pass .................... 1-buy sandwich \\ "I don't eat at home in the morning. Everyday, I stop by .......... and buy a sandwich." \\ 1. hak 1-Sattar l-li bi3nabna haðaka (that grocer next door (literally, that grocer next door that)) \\ 2. 1-9attar 1-li bi3nab darna (the grocer close to our house) \\ 3. ha liattarl-li bi3nabna (this grocer next door) \\ 4. 1-Sattar 1-li bi3nabna ahna (the grocer next door) \\ 5. 1-Sattar lli bi3nabna haða( this grocer next door) \\ 6. haðaka (that) \\ 7. 1-9attar lli bi3nabna haðaka ( that grocer next door ) \\ 8. ha 1-Yattarl-li bißnabna haða (this grocer next door (literally, this grocer next door this) ) \\ 9. 1-Yattar lli bi3nabna (the grocer next door) \\ 10. haða (this ) \\ 11. hak liattar l-li bi3nabna (that grocer next door)
}


Question 12

A woman is talking to her friend about a book. Her friend has never heard of it (i.e.,. the book).
A: 1-barih
fi 1-maktba suft
Sla numuw
1-tifl
the-yesterday in the library see.past.1s ...... on development the-child
"Yesterday, I saw a book on child development in the library."
ama ma na33amt $\quad$-xarr3u
but neg can.past.1s-neg 1s-check out
"but I couldn't check it out."
1. hak 1-ktab haðaka (that book (literally, that book that))
2. 1-ktab (the book)
3. ha- 1-ktab (this book)
4. ktab (book)
5. 1-ktab haða (this book)
6. haðaka (that)
7. 1-ktab haðaka (that book)
8. ha 1-ktab haða (this book (literally,this book this))
9. ktab tahfuun (a nice book)
10. haða (this )
11. hak 1-ktab (that book) 


\section{Question 13}

\section{(B) doesn't know the doctor that (A) is talking about}

\begin{tabular}{|c|c|c|c|c|}
\hline $\begin{array}{l}\text { A: ðahr-i } \\
\text { back-pos.1s } \\
\text { "'My back does }\end{array}$ & $\begin{array}{cc}\text { maiaats } & \text { j-uZai } \\
\text { neg } & 3 \mathrm{~m}-\text { hur } \\
\text { n't hurt anymore." }\end{array}$ & & & \\
\hline $\begin{array}{l}\text { tbiib-i } \\
\text { doctor-pos.1s }\end{array}$ & $\begin{array}{l}\text { Sta-ni } \\
\text { give-past.3sm-1s }\end{array}$ & $\begin{array}{l}\text { dwa } \\
\text { medication }\end{array}$ & $\begin{array}{l}\text { ðarba } \\
\text { effective }\end{array}$ & $\begin{array}{l}\text { ðarba } \\
\text { effective }\end{array}$ \\
\hline
\end{tabular}

B: as ismu ........?

what name-pos. $3 \mathrm{~ms}$

"What is the name of ............?"

1. hak 1-tbiib haðaka (that doctor (literally, that doctor that))

2. tbiib-k (your doctor)

3. ha- 1-tbiib (this doctor)

4. 1-tbiib (the doctor)

5. 1-tbiib haða( this doctor)

6. haðaka (that)

7. 1-tbiib haðka (that doctor)

8. ha 1-tbiib haða(this doctor (literally, this doctor this))

9. tbiibik (your doctor)

10. haða (this)

11. hak 1-tbiib (that doctor) 


\section{Question 14}

The speaker is standing in front a watermelon merchant. He pointed to one watermelon and said:
A: brabbi
u3in-1-i
please weigh-to-me
"Can you please weigh. for me."
1. hak 1-dilla9a haði ka (that watermelon (literally,that watermelon that))
2. 1-dillaia (the watermelon)
3. ha-1-dillaia (this watermelon)
4. dillaiti (my watermelon)
5. 1-dillaia haði ( this watermelon)
6. haðika (that)
7. 1-dillaia haðika (that watermelon)
8. ha 1-dillaia haði (this watermelon (literally, this watermelon this))
9. dillaia (watermelon)
10. hak -dillaia (that watermelon)
11. haði (this ) 


\section{Appendix V: Sample of coded text}

Title: The devil and the blacksmith

Language: Tunisian Arabic

Primary coder: Amel khalfaoui

This text is a folk story written down from memroy by a male native speaker of Tunisian Arabic in 2004. He wrote it in Tunisian Arabic using Arabic script.

\#The devil and the blacksmith 001

Oamma 3maia shaab

there group friends

"There is a group of friends,"

kul jum fi-l-lil ji-t-qaabl-u

every day in-the-evening 3-refl-meet-p

fi garage sahib-hum 1-haddad ja-hki-w w j-nakt-u.

in garage friend-pos.3p the-blacksmith 3-talk-p and 3-telljokes-p

Every evening, they meet in the the garage of their blacksmith friend to talk and tell jokes."

\#The devil and the blacksmith 002

fi nhar mi-l-nharat

in day of - the-days

"One day,"

t-hal mawðuৎ Sla $1-\int$ itan

refl-open.past.3sm subject on the-devil

"a topic about the devil came up."

1-3maSa 1-kul bda-w j-sibb-u fi- 1- $\int$ itan

the-group the-all start.past-p 3-curse-p in- the-devil

"The whole group started cursing the devil" 
\#The devil and the blacksmith 003

$\begin{array}{lll}\text { tlaffit } & \text { sahib-hum } & \text { 1-haddad } \\ \text { turn.past.3ms } & \text { friend-pos.3p } & \text { the-blacksmith }\end{array}$

$\begin{array}{lcccc}\text { w } & \text { qal-il-hum } & \text { 'bi-l-lah } & \text { ja } & \text { 3maia } \\ \text { and } & \text { say.past.3ms-to-3p } & \text { "with-the-god } & \text { voc } & \text { group }\end{array}$

jizzi-w kul fay t-wahl-u-h fi-l- $\int i t a n$

stop-p every thing 2-blame-p-3ms in-the-devil

w huwa xati-h'

and he not-3ms

"Their friend the blacksmith and told them: "please people, stop it, you blame everything on the devil, and he is innocent'."

\#The devil and the blacksmith004

$\begin{array}{rlccccc}\text { ajja } & \text { zad-u } & \text { 1- 3maia } & \text { Swaya } & \text { w } & \text { min } & \text { baid } \\ \text { so } & \text { stay.past-3p } & \text { the-group } & \text { little } & \text { and } & \text { from } & \text { after }\end{array}$

kul wahid haz ruh-u w mfa

every one take.past. $3 \mathrm{~ms}$ self-pos. $3 \mathrm{~ms}$ and go.past. $3 \mathrm{~ms}$

'tu-sbah Sla xir tu-sbah Sla xir'

2-have morning on good 2-have morning on good

"The group stayed a little longer and then everyone left 'good night, good night'."

\#The devil and the blacksmith 005

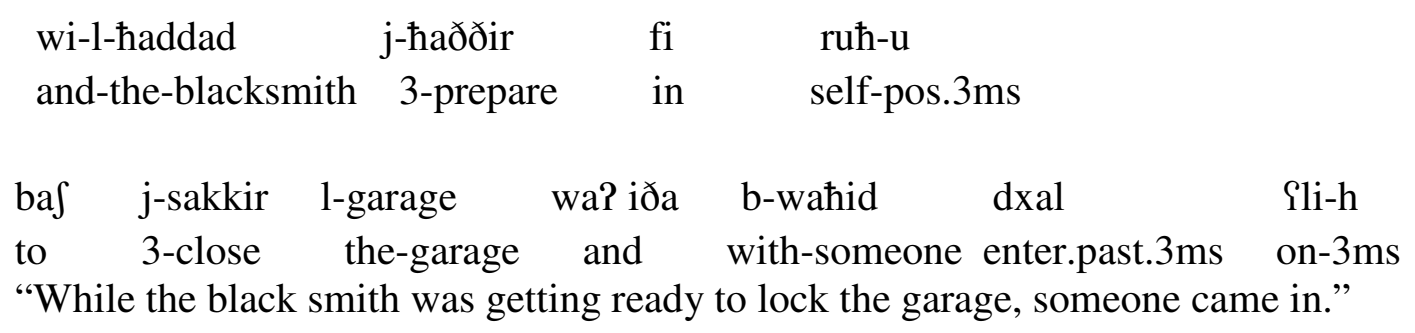


\#The devil and the blacksmith006

[dialogue]

Hello, come in. Who are you?"

B: ana 1-jitan w rani min bikri qaSid

I the-devil and emph from early staying. $3 \mathrm{~ms}$

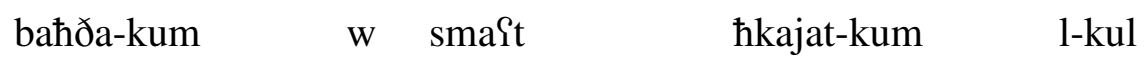

near-2p and hear.past.1s story-pos.2p the-all

"I am the devil and I have been sitting close to you and the group and heard all your stories."

w ha-ni xall-it hatta 1-3maaia rawhu

and here-1s let.past-1s till the-group gohome.past.p

w ðhart-l-ik baf nu- krr-ik xatir-hum 1-kul

and appear.past.1s- to-2s to 1-thank-2s because-3p the-all

sabb-u-ni illa inti l-wahiid illi dafis-t Sli-ja

curse.past.3p-1s except you the-only one comp defend.past-1s on-1s

"Here I am, I waited till the group left home, and appeared to you to thank you, because they all cursed me except you. You are the only one who defended me."

\#The devil and the blacksmith00 7

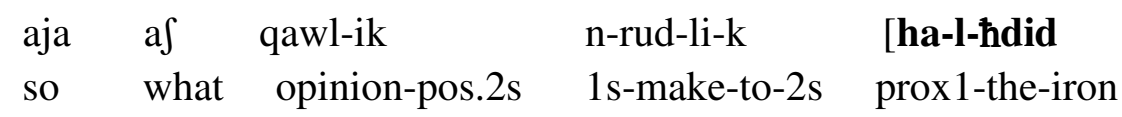

illi fi-l-garage l-kul $]^{36} \quad$ ðhab

comp in-the-garage the-all gold

"What if I turn all this iron in the garage into gold."

${ }^{36}$ ha-1-hdid illi fi-lgarage; RF1; ACT; $2 ;$ = The iron that is in the blacksmith's garage 
\#The devil and the blacksmith 008

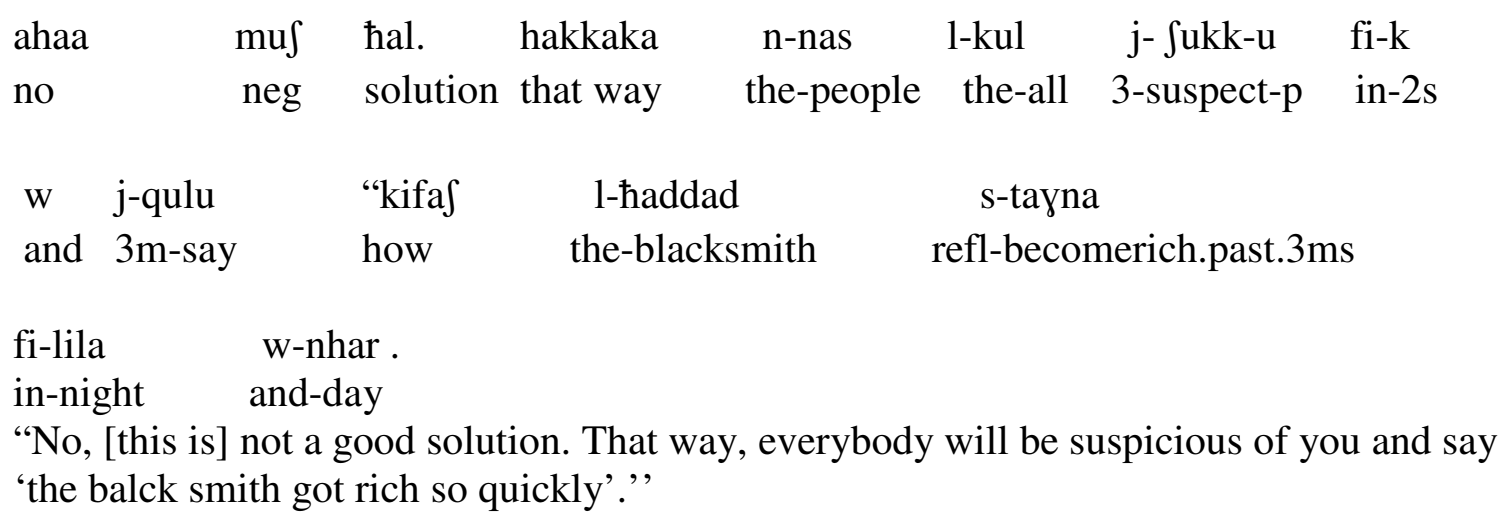

\#The devil and the blacksmith009

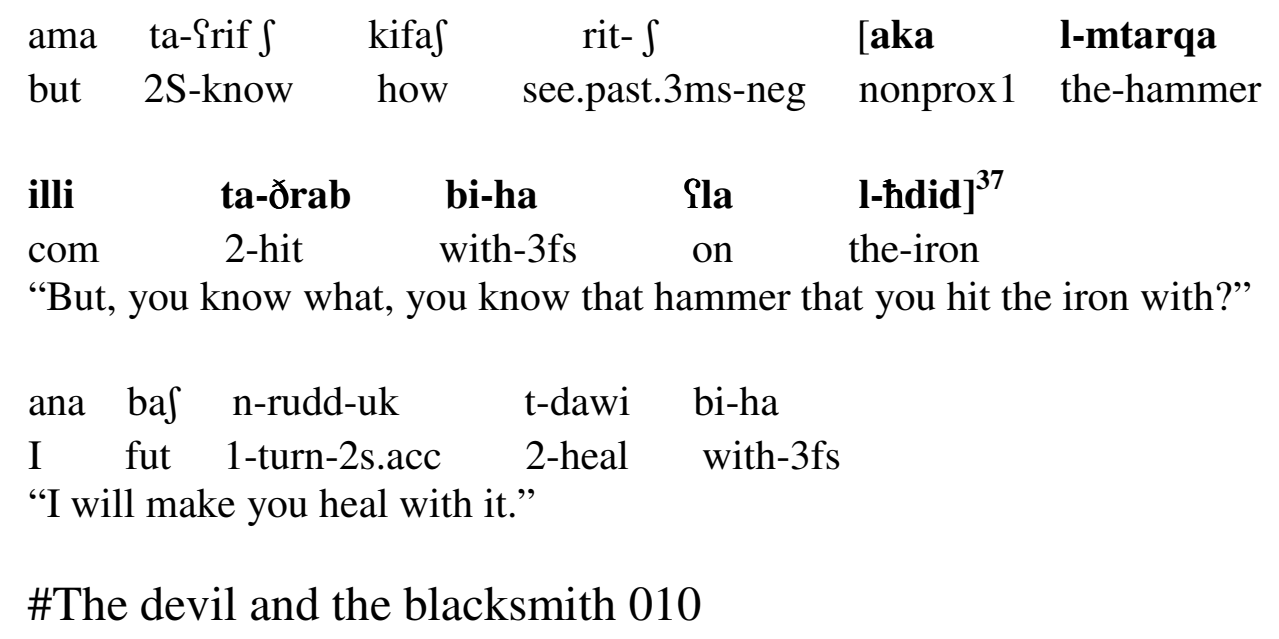

$\begin{array}{cccccc}\text { ahawka } & \text { illi } & \text { tu-3i-u } & \text { blasa } & \text { ta-ðrb-u } & \text { inti } \\ \text { so } & \text { com } & \text { 2-hurt-3ms } & \text { place } & 2-h i t-3 m s & \text { you }\end{array}$

b-[hak l-mtarqa $]^{38}$ Sli-ha ja-rtah

with-nonprox1 the-hammer on-3fs 3ms-heal

\footnotetext{
${ }^{37}$ Aka 1-mtarqa illi ta-ðrab bi-ha Sla 1-ћdid; RF2; ACT; 2; = the hammer that the blacksmith uses in his work.

${ }^{38}$ hak 1-mtarqa; RF2; FOC; 5
} 
w-akkaka ti-s-tayna w ma-j-suk fi-k had

and-like.that 2-refl-get.rich and neg-3ms-suspect in-2s someone

"So whoever hurts somewhere, you tap him/her with that hammer on that place, and this way nobody gets suspicious about you."

\#The devil and the blacksmith 0011

min yudwa sbah [aka l-haddad] ${ }^{\mathbf{3 9}}$ tbiib

from tomorrow bcome.past.3ms nonprox1 the-blacksmith doctor.

The following day that blacksmith became a doctor."

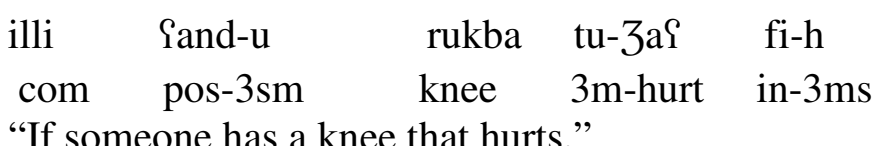

ja-ðrbu [hak l-haddad] ${ }^{\mathbf{4 0}}$ bi-l-mtarqa 9li-ha ja-rtah

3ms-tap-3ms nonprox1 the-blacksmith with-the-hammer on-3fs.acc 3ms-heal

"The blacksmith hits it with the hammer, and he heals."

wi lli Sand-u bard fi ðahr-u willa miSt-u tu-3ai

and comp pos-3ms cold in back-pos. $3 \mathrm{~ms}$ or stomach-pos.3ms 3f-hurt ....

"if a person has arthritis in his back, that balcksmith hit him on it with the hammer, and s/he heals; and if someone has a stomach pain ...."

\#The devil and the blacksmith 012

w bda [aka l-haddad] ${ }^{41}$ ji-t $-\int$ har fi-l-blaad]

and start.past nonprox1 the-blacksmith 3m-rfl-bcome.famous in-the-country

'ismai jalli ma ti-smai- $\int$ 1-haddad mtarqt-u

listen voc neg 2-hear-neg the-blacksmith hammer-pos. 3ms

t-3ammid 1-ma'

3fs-freeze the-water

"That blacksmith started becoming famous in the country. Everybody is telling everybody else 'Did you hear about the blacksmith's hammer which has magical powers?'."

39 aka 1-haddad; RF3; Act; 1 ; = the main character in the story

40 hak 1-haddad; RF3;FOC; 1

${ }^{41}$ aka 1-haddad; RF3; FOC; 3 
\#The devil and the blacksmith 013

aw l-sultan mtai [aka l-blad aðika ${ }^{\mathbf{4 2}}$ Sand-u bint-u

so the-sultan pos nonprox 2 the-country nonprox $2.3 \mathrm{fs}$ pos-3ms daughter-pos. $3 \mathrm{~ms}$

t-Sani min w3i९a fi ras-ha har-u fi-ha l-tubba

$3 \mathrm{f}$-suffer from pain in head-pos.3fs worry-past.3p in-3fs the-doctors

"The Sultan of that country has a daughter who suffers from migraine that the doctors couldn't treat."

\#The devil and the blacksmith0 14

$\begin{array}{llc}\text { nash-u-h } & 1-\hbar \text { ajja } & \text { mtå-u } \\ \text { advise-past.3ms-3ms } & \text { the-advisors } & \text { pos-3ms }\end{array}$

qalu-1-u 'bint-ik ma-j-dawi-ha kan 1-haddad'

tell-past.3p-to-3ms "daughter-your neg-3m-treat-her only the-blacksmith."

'They told him "the only one who can treat your daughter is the blacksmith".'

\#The devil and the blacksmith 015

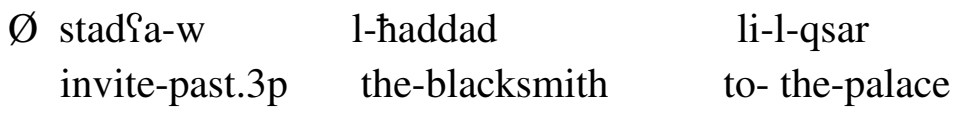

"They invited the blacksmith to the palace."

$\varnothing$ dxal li-l-qsar $\quad \varnothing$ farh-u bi-h

enter.past.3ms to-the-palace welcome-past.3p with-3ms

"He entered the palace and they welcomed him."

\#The devil and the blacksmith 016

$$
\begin{aligned}
& \varnothing \text { hazz-u-h li-l-bnaja } \\
& \text { take-past.3p-3ms to-the-girl } \\
& \text { "They took him to the girl." }
\end{aligned}
$$

$\begin{aligned} & \text { 3bid } \varnothing \quad \text { [aka } \\ & \text { take out-past }\end{aligned}$ nonprox1
"He took out his hammer."

42 aka l-blad aðika, RF4; FAM; $1 ;=$ the country where the story is taking place.

${ }^{43}$ aka 1-mtarqa mtå-u; RF2; FAM; 1 
$\begin{array}{llll}\text { waxxir } & \text { w-qaddim } & \text { w } & \text { nzil } \\ \text { move back.past.3ms } & \text { and- move.forward.past.3ms } & \text { and } & \text { push.past.3ms }\end{array}$

Sla [aka l-bnaja $]^{44}$ fi ras-ha

on nonprox.1 the-girl in head-pos.3fs

"He moved back and forth and hit that girl on the head."

3ab-ha jabsa

turn.past-3fs hard

"He killed her."

\#The devil and the blacksmith 017

$\begin{array}{lllll}\text { dar-u } & \text { bi-h } & \text { l-hurras } & \text { mtaf } & \text { l-qsar } \\ \text { turn-past.3P } & \text { with-3fs } & \text { the-guards } & \text { pos } & \text { the-palace }\end{array}$

w hazzu-h li-l-habs

and take-past.3p-3ms to-the-jail

"The palace guards surrounded him and took him to jail."

\#The devil and the blacksmith 018

w huwa akaka fi-l-habs w tal Sli-h 1 - -itan and he like that in-the-jail and appear-past on-3ms the-devil "While he was in jail the devil appeared to him."

$\begin{array}{llcc}\text { dar-l-u } & \text { 1-haddad } & \text { w } & \text { qal-1-u } \\ \text { turn-to-him } & \text { the-blacksmith } & \text { d } & \text { say-past-to-3ms }\end{array}$

"tawwa [haði] ${ }^{\mathbf{4 5}} \quad$ Samla ta-Smil-ha fi-ja?"

now prox2.3fs deed 2-do-3fs in-me

"The balcksmith turned to him and said "why have you done this to me ?"”

\footnotetext{
44 aka 1-banaya; RF5; ACT; 1; = the daughter of the Sultan

${ }^{45}$ haði; RF6; ACT; 2 = the blacksmith being in jail
} 
\#The devil and the blacksmith 019

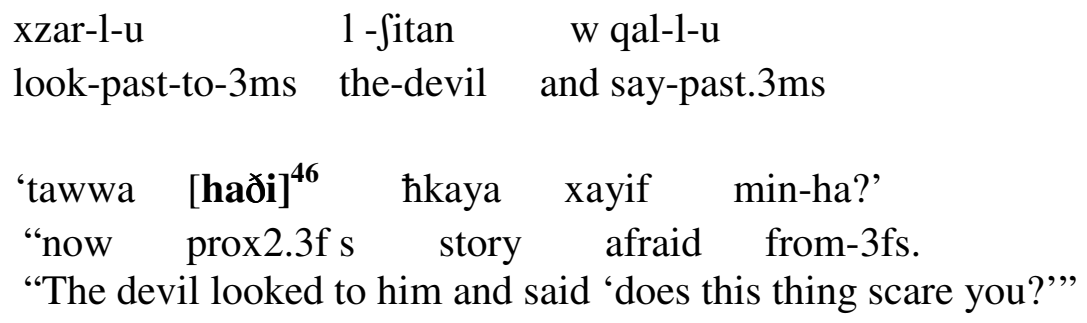

maw huma yudwa bas j-hizzu-k li-l-ma $\int$ nqa

emph hey tomorrow fut $3 p$-take-2s to- the execution room, "So tomorrow, they will take you to the execution room,"

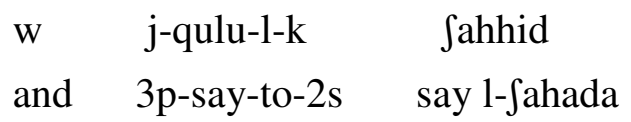

"and ask you to say 1-Sahada"

inti qul-1-hum ma n-Sahid- $\int$ "fi Sahhid minna..."

you tell-to-3p neg 1s-say.l- -ahada-neg "in say.l- Sahada from.here."

"and you tell them that you won't say l- Sahada, they will say "say Sahada.",

tawwa $\quad \varnothing \quad$ j-ra3iu-k li-l-habs

so $\quad 3 p-r e t u r n-3 s$ to-the-jail

"so, they will put you back in jail."

w inti aimil 1-hum kul yum nafs l-hkaya

and you make to-them every day same the-story

"and you do to them the same thing everyday."

\#The devil and the blacksmith 020

aya frah [aka l-haddad $]^{47}$ bi-l-fikra

so bcome-past happy nonprox 1 the-blacksmith with-the-idea "The blacksmith was happy with the idea."

46 hað; RF6; ACT; 2

${ }^{47}$ aka l- haddad; RF3; FAM; 1 


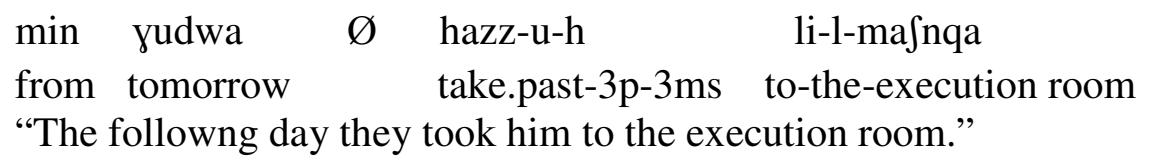
$\varnothing$ qal-u-l-u 'ja fulan Jahhid' say.past-3p-to-3ms voc person say $1-\int$ ahada

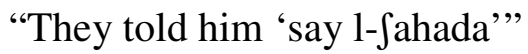

\section{\#The devil and the blacksmith021}
$\varnothing$ qal-1-hum 'ma n- $\int$ ahhid- $\int$ '
say.past-to-3p "neg 1- say 1- $\int$ ahada-neg
"He told them 'I won't say 1 - $\int$ ahada'."

\begin{tabular}{|c|c|c|c|}
\hline marra & $\theta$ nin & walla-w & nizl-u \\
\hline once & to & become.past-3p & puf.past-3p \\
\hline
\end{tabular}

"They tried once and twice and then executed him"

$\begin{array}{lll}\mathrm{w} & \text { maat } & \mathrm{ki}-1-3 \mathrm{ifa} \\ \text { and } & \text { die.past.3ms } & \text { like-the-corpse }\end{array}$

"and he died like a corpse."

w [aðika $^{\mathbf{4 8}}$ nhayat illi j-tabbas 1-jitan ja-linn[u w-yaxzi-h and prox2.3fs end comp 3-follow he-devil 3m-damn-him "And that is the end of that who follows the devil, may God damn him"

48 aðika; RF 7; ACT; 2; = the event of the black smith being executed 